MICHELE JOANA ALVES

\title{
CAQUEXIA ASSOCIADA AO CÂNCER: A CONTRIBUIÇÃO DA VIA DE SINALIZAÇÃO DO TGF $\beta$ NA FIBROSE DO TECIDO ADIPOSO
}

Tese apresentada ao Programa de PósGraduação em Biologia Celular e Tecidual do Instituto de Ciências Biomédicas da Universidade de São Paulo, para obtenção do Título de Doutor em Ciências.

São Paulo

2016 
MICHELE JOANA ALVES

CAQUEXIA ASSOCIADA AO CÂNCER: A CONTRIBUIÇÃO DA VIA DE SINALIZAÇÃO DO TGFß NA FIBROSE DO TECIDO ADIPOSO

Tese apresentada ao Departamento de Biologia Celular e do Desenvolvimento do Instituto de Ciências Biomédicas da Universidade de São Paulo, para obtenção do Título de Doutor em Ciências.

Área de concentração: Biologia Celular e Tecidual

Orientadora: Prof ${ }^{-a}$ Dr $^{a}$ Marília Cerqueira Leite Seelaender

Versão corrigida. A versão original eletrônica encontra-se disponível, tanto na Biblioteca do ICB, quanto na Biblioteca Digital de Dissertações e Teses da USP (BDTD). 
DADOS DE CATALOGAÇÃO NA PUBLICAÇÃO (CIP)

Serviço de Biblioteca e Informação Biomédica do Instituto de Ciências Biomédicas da Universidade de São Paulo

(c) reprodução parcial

Alves, Michele Joana.

Caquexia associada ao câncer: a contribuição da via de sinalização do TGF $\beta$ na fibrose do tecido adiposo / Michele Joana Alves. -- São Paulo, 2016.

Orientador: Marília Cerqueira Leite Seelaender.

Tese (Doutorado) - Universidade de São Paulo. Instituto de Ciências Biomédicas. Departamento de Biologia Celular e do Desenvolvimento. Área de concentração: Biologia Celular e Tecidual. Linha de pesquisa: Bases moleculares e metabólicas da caquexia associada ao câncer.

Versão do título para o inglês: Cancer cachexia:TGF $\beta$ pathway contribution in adipose tissue fibrosis.

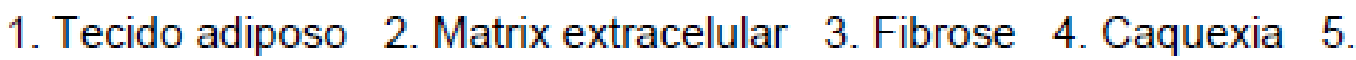
Câncer 6. TGF beta I. Seelaender, Marilia Cerqueira Leite II. Universidade de São Paulo. Instituto de Ciências Biomédicas. Programa de Pós-Graduação em Biologia Celular e Tecidual III. Título. 


\begin{abstract}
Candidato(a): $\quad$ Michele Joana Alves.
Título da Tese: $\quad$ Caquexia associada ao câncer: a contribuição da via de sinalização do TGF $\beta$ na fibrose do tecido adiposo.
\end{abstract}

Orientador(a): $\quad$ Marília Cerqueira Leite Seelaender.

A Comissão Julgadora dos trabalhos de Defesa da Tese de Doutorado, em sessão pública realizada a considerou

( ) Aprovado(a) ..$/ \ldots$ considerou

( ) Reprovado(a)

\begin{tabular}{|c|c|}
\hline \multirow{3}{*}{ Examinador(a): } & Assinatura: \\
\hline & Nome: ........... \\
\hline & Instituição: ...... \\
\hline \multirow[t]{3}{*}{ Examinador(a): } & Assinatura: ..... \\
\hline & Nome: .............. \\
\hline & Instituição: ....... \\
\hline \multirow[t]{3}{*}{ Examinador(a): } & Assinatura: . \\
\hline & Nome: ............... \\
\hline & 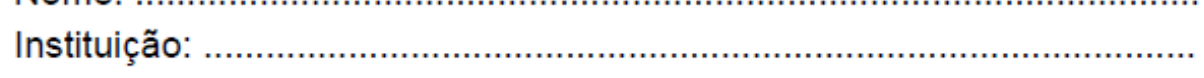 \\
\hline \multirow[t]{3}{*}{ Examinador(a): } & Assinatura: ........ \\
\hline & Nome: ................. \\
\hline & Instituição: ........ \\
\hline \multirow[t]{3}{*}{ Presidente: } & Assinatura: . \\
\hline & 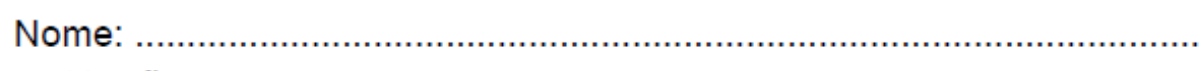 \\
\hline & Instituição: .......... \\
\hline
\end{tabular}


São Paulo, 28 de julho de 2014.

$I^{\text {mo(a) }} \cdot S^{\text {(a) }}$

Profa. Dra. Marilia Cerqueira Leite Seelaender

Departamento de Biologia Celular e do Desenvolvimento

Instituto de Ciências Biomédicos I

UNIVERSIDADE DE SÃO PAULO

REFERENTE: Projeto de Pesquisa "Caquexia associada ao câncer: a via de sinalização do TGF-ß e sua contribuição no remodelamento do tecido adiposo"

Pesquisador(a) responsável: Profa. Dra. Marilia Cerqueira Leite Seelaender

Equipe de Pesquisa: Michele Joana Alves, Paulo Sergio Martins de Alcântara

CAAE: 05186912.7.0000.5467

Registro CEP-HU/USP: $1391 / 14$

Prezado(a) Senhor(a)

O Comitê de Ética em Pesquisa do Hospital Universitário da Universidade de São Paulo, em reunião ordinária realizada no dia 25 de julho de 2014 , analisou o Projeto de Pesquisa acima citado, considerando-o como APROVADO, bem como o seu Termo de Consentimento Livre e Esclarecido.

Lembramos que cabe ao pesquisador elaborar e apresentar a este Comitê, relatórios parciais e final, de acordo com a Resolução $n^{\circ} 466 / 2012$ do Conselho Nacional de Saúde, inciso XI.2, letra "d".

O primeiro relatório está previsto para 26 de janeiro de 2015.

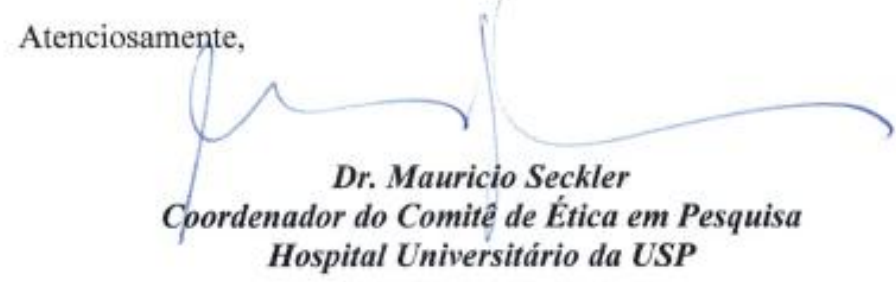

COMITÉ DE ÉTICA EM PESOUSA DO HOSPITAL UNIVERSITÁRIO DA USP Avenida Professor Lineu Prestes, 2565 - Cidade Universitaria - 05508-000 Søo Paulo - SP Tel.: (11) 3091-9457 - E-mail: scpiaholusp.br 


\section{PARECER 1082/CEP}

A Comissão de Ética em Pesquisas em Seres Humanos do ICB, nesta data APROVOU o projeto intitulado: "Caquexia associada ao câncer: a via de sinalização do $\operatorname{tgf-\beta }$ e sua contribuição no remodelamento do tecido adiposo" dos autores Profa. MARILIA C.L.SEELEANDER $e$ a aluna MICHELE JOANA ALVES.

Cabe os Pesquisadores executantes elaborarem e apresentar a este Comitê, relatórios anuais (parciais ou final ). de acordo com a resolução 196/06 do Conselho Nacional da Saúde, item IX. 2 letra c.

O primeiro relatório deverá ser encaminhado à Secretaria deste CEP em 11.10.2013.

Atenciosamente,

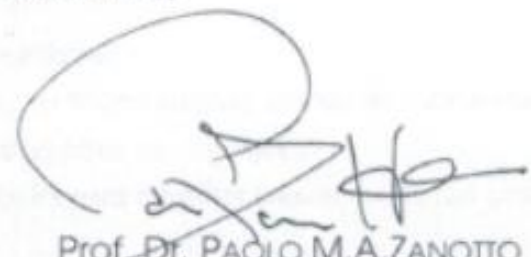

Prof DI. PAdLOM.A.ZANOTOO

Coordenador da Comissão de Ética em

Pesquisas com Seres Humanos - ICB/USP

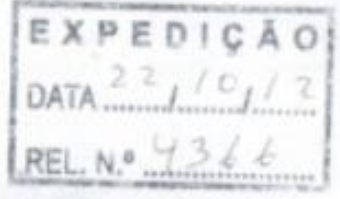

Comissão de Ética em Pesquisa com Seres Humanos do Instituto de Ciências Biomédicas / USP Aprovada pela Comissåo Nacional de Ética em Pesquisa - CONEP, em 10 de fevereiro de 1998. 
Dedico a meu filho amado, Matheus: Um presente de Deus na minha vida.

A quem é meu grande companheiro

$\mathrm{E}$ que me ama incondicionalmente.

Minha razão de ser.

Com muito amor... 


\section{AGRADECIMENTOS}

Agradeço a Deus primeiramente, minha fé é plenamente em Ti. Onipresente em minha vida, transbordando-me de ânimo quando estava desanimada, me dando coragem para suportar todos os desafios, enxugando minhas lágrimas e me enchendo do teu amor.

À minha querida Orientadora Dra. Marília Cerqueira Leite Seelaender, muito obrigada por ter acreditado no meu trabalho, por contribuir no meu crescimento, e amadurecimento profissional. Muito obrigada, por sempre me encorajar a voar mais alto. Agradeço também, pela amizade e companhia por todos esses anos.

À minha família. Ao meu filho, a quem dedico meu trabalho. Agradeço à ele por fazer com que tudo se tornasse mais prazeroso, por me acompanhar inúmeras vezes no laboratório, nas reuniões, nos passeios e viagens alegrando os pequenos, e grandes momentos com muita curiosidade e cumplicidade.

Ao meu Pai e minha Mãe agradeço imensamente. É de total conhecimento meu que minhas singelas palavras, não são suficientes para expressar todo meu amor, e gratidão por vocês. Devo tudo que aprendi na vida à vocês. Devo minha vontade de lutar e completar essa fase da minha vida profissional à vocês, pois sempre me incentivaram em todos os momentos. Aos meus irmãos; Alex e Adriana, e aos meus sobrinhos; Bruna, Gabriel, e Luiz Felipe, sou grata por todo apoio e carinho.

À minha madrinha Cícera e meu padrinho Gino, agradeço por alegrarem minha vida com o amor de vocês, e por todo apoio durante essa fase na minha vida.

Ao Prof. Gerd e sua família; Telma e Ana, por me receberem durante minha estadia na Alemanha, por todo o carinho e cuidado comigo, e especialmente com o Matheus.

Ao laboratório de Bioquímica da Nutrição da Universidade de Potsdam: Frank Neuschäfer-Rube, Andrea Neuschäfer-Rube, Anne Schraplau, Stephie, Katia, Janin Henkel-Oberländere, e ao Prof. Gerhard Paul Püschel; obrigada a todos por todo o suporte técnico e científico, e pelos momentos alegres e confortantes no lab. Em especial à Manuela Kunae Ines Kahnt, sou muito grata por todo o aprendizado que tive a oportunidade de ganhar com vocês duas que muito me ensinaram, e me acolheram com muita paciência, sou mais grata ainda, pelo carinho e as longas 
conversas que preencheram os dias frios no laboratório. Agradeço à Heidi Mahler pela enorme ajuda na minha chegada, por todo esforço entre as diferentes formas de comunicação.

À Emília Ribeiro por todo o carinho e suporte técnico, por compartilhar comigo parte do seu conhecimento, e cuidar de mim de maneira especial. Minha eterna gratidão.

Aos amigos do antigo Laboratório de Lípides, em especial: Renata Silvério, Fábio Lira, Alex Shimura e José César Rosa Neto. Agradeço por toda ajuda no meu início na pós, e pela amizade.

Aos colegas e amigos atuais do Laboratório de Lípides: Emidio Matos, Rodolfo Camargo, Rodrigo Xavier, Diego Cavallaro, Daniela Riccardi, Daniela Caetano, Silvio Gomes, Ana Flávia, Katrin Radloff, Joanna, Paula Leme, Nelson (agregado), Marcelo Semiatz, Marcelo (Cebola), Reinaldo Bassit (Tubarão), e ao Marco Aurélio por todo auxílio e pelo suporte técnico.

Agradeço em especial à Raquel e a Bruna Fernanda por iluminarem os dias mais nebulosos, agradeço à Deus pela amizade de vocês, que possa permanecer a nossa amizade para vida toda.

A Profa Marinilce Fangundes dos Santos, eu agradeço pela amizade, e todo aconselhamento que me propiciou durante todo meu período na pós-graduação. Ao Laboratório de Migração: Gabriela, Mariana Marin, Maíra, Ana Flávia por todo apoio em todos os momentos.

À Mariana Marin, em especial, por sua amizade e amor, minha imensa gratidão.

A Prof ${ }^{a}$ Alison Colquhoun pelas inúmeras dicas e conselhos técnicos que muito contribuíram no meu aprendizado, e o pessoal do laboratório: Renata, Felipe, Tati e Matthew, e ao querido Prof. Bauer.

Agradeço a Prof ${ }^{a}$ Patricia Gama por todos os momentos e discussões científicas, e à todos do laboratório por todo auxílio.

À Flavia Azevedo que me propiciou grande amizade e conforto em um momento especial, e pela parceria imensa na bancada e nas imunos.

Ao meu grande amigo, Luiz Fernando Domingos por sempre estar presente, por me incentivar, por acreditar em mim quando nem eu acreditava mais. Sou grata de todo coração. 
Aos amigos que não mencionei nomes, mas que moram no meu coração, e auxiliaram de alguma maneira, muito obrigada por tudo.

Aos técnicos Junior Cruz e Fernanda Barrence do Departamento de Biologia Celular, por todo apoio técnico e muito mais. À técnica Marta do Departamento de Anatomia por todo auxílio animado e musical com as colorações.

Agradeço aos professores que fizeram parte do meu exame de qualificação, por todo apoio técnico, científico e acadêmico.

Agradeço à equipe do Hospital Universitário, em especial da Clínica Médica Cirúrgica. Agradeço à equipe de enfermagem por todo suporte e auxílio durante os procedimentos cirúrgicos. Ao Dr. Paulo Alcântara e o Dr. Pinhatta, os médicos responsáveis por disponibilizarem a parceria formada entre o laboratório de lípides e o Hospital Universitário. Aos pacientes que participaram da pesquisa. Muito obrigada à todos por viabilizarem a realização do trabalho.

Agradeço à todos da biblioteca do ICB pelo apoio durante todos esses anos, sempre com muita paciência.

À secretária de pós-graduação, em especial; Regina Valbom, muitíssimo obrigada por toda ajuda, pela eficiência e também pelo carinho.

Agradeço à Comissão de pós-graduação por todo auxílio e suporte.

A todos os professores e funcionários do Departamento de Biologia Celular e do Desenvolvimento. 


\section{RESUMO}

ALVES, M. J. CAQUEXIA ASSOCIADA AO CÂNCER: A CONTRIBUIÇÃO DA VIA DE SINALIZAÇÃO DO TGF $\beta$ NA FIBROSE DO TECIDO ADIPOSO. 2016. $123 \mathrm{f}$. Tese (Doutorado em Biologia Celular e Tecidual) - Instituto de Ciências Biomédicas, Universidade de São Paulo, São Paulo, 2016.

A caquexia associada ao câncer é uma síndrome multifatorial e irreversível. Considerada um marcador, a profunda perda do tecido adiposo reflete alterações morfológicas e moleculares da matriz extracelular (MEC). A composição da MEC é crucial para a biologia do microambiente tecidual; no entanto, a caquexia pode induzir o descontrolado rearranjo tecidual e resultar em fibrose. O TGF $\beta$ é uma citocina chave envolvida nesse processo. $O$ objetivo do estudo foi investigar $O$ remodelamento tecidual e fatores modulados pela via do TGF $\beta$ no tecido adiposo subcutâneo na vigência da caquexia associada ao câncer gastrointestinal. $O$ estudo incluiu 59 pacientes divididos em três grupos: Controle, Câncer com peso estável (WSC), e Câncer e Caquexia (CC). Foram observadas alterações morfológicas exclusivas ao tecido adiposo do grupo CC (HE) que incluiram a diminuição das células adiposas (área, diâmetro e perímetro). Houve o aumento na deposição de colágeno, glicoproteínas associadas e fibras do sistema elástico, detectados por colorações específicas. Já a imunohistoquímica revelou alterações no conteúdo dos colágenos do tipo I, III e VI, e da fibronectina, no grupo CC em relação ao grupo Controle e WSC. A presença de miofibroblastos no grupo CC foi confirmada pela imunomarcação para aSMA, e o aumento de 20 vezes da expressão gênica da FSP1 no tecido adiposo, em associação com expressiva marcação de vimentina em fibroblastos isolados do mesmo grupo. A concentração de TGF $\beta 3$ foi superior no tecido adiposo no grupo $\mathrm{CC}$, enquanto que nos adipócitos, a expressão de TGF $\beta 1 \mathrm{e}$ TGFß3 foi maior nos pacientes caquéticos, em relação ao grupo Controle. Evidenciou-se forte marcação do TGF $\beta 1$ por imunohistoquímica somente no grupo CC. Os níveis de RNAm das SMADs 2, 3 não foram modulados pela caquexia, apenas o RNAm da SMAD4 foi maior no grupo CC. Contudo, a imunolocalização revelou maior intensidade para SMAD3 e SMAD4 no grupo CC. Adicionalmente, no grupo CC, a expressão dos genes foi 30 vezes maior para o c-Myc, e 4 vezes para ciclina D1, ambos em relação ao grupo Controle. Em conclusão, na caquexia associada ao câncer, a via do TGF $\beta$ contribui para o comprometimento da biologia do tecido adiposo e o desenvolvimento da fibrose. 
Palavras-chave: Caquexia associada ao câncer. Tecido adiposo. Matriz extracelular. Fibrose. TGF $\beta$. 


\begin{abstract}
ALVES, M. J. CANCER CACHEXIA: TGF $\beta$ PATHWAY CONTRIBUTION IN ADIPOSE TISSUE FIBROSIS. 2016. 123 p. Ph.D Thesis (Cellular and Tissue Biology) - Instituto de Ciências Biomédicas, Universidade de São Paulo, São Paulo, 2016.

Cancer cachexia is an irreversible multifactorial syndrome, in which there is a marked loss of adipose tissue wich is mirrored by morphological, and molecular extracellular matrix (ECM) alterations. ECM composition is crucial for tissue biology however, cancer cachexia may induce uncontrolled tissue remodelling and result in fibrosis. TGF $\beta$ is a key cytokine in this process. The aim of the study was to investigate tissue remodelling and factors modulated by the TGF $\beta$ pathway in the subcutaneous adipose tissue of cachectic gastrointestinal cancer patients. The study included 59 patients enrolled into three groups: Control, Weight-stable Cancer (WSC) and Cancer Cachexia (CC). Morphological alterations (HE) were observed in the adipose tissue of CC solely, with reduction in the content of fat cells (area, diameter and circumference). There was an increase in the depositing collagen, glycoproteins, and fibers of the elastic system, detected by specific staining in CC. Markedly stain to collagens type I, III, IV and fibronectin by immunohistochemistry revealed changes in the CC group as compared to the control and WSC. Presence of myofibroblasts in CC was observed by immunostaining for aSMA, and a 20-fold increase of the FSP1 gene expression in the adipose tissue. Along with enhanced immunolabelling for vimentin in isolated fibroblasts. TGF $\beta 3$ concentration was higher in the adipose tissue of CC, while in the adipocytes higher TGF $\beta 1$ and TGF $\beta 3$ levels were found in the cachectic patients in relation to control group. Moreover, evidence of stronger labelling for TGF $\beta 1$ was observed for CC. mRNA levels of SMADs 2, 3 no showed modulation by cancer cachexia, only in regard to SMAD4 expression. However, immunolocalization revealed greater intensity for SMAD3 and SMAD4 in CC. Additionally, gene expression was higher 30-fold in c-Myc, and 4-fold cyclin D1, for $\mathrm{C}$, in relation to the control group. Thus, during cancer cachexia the TGF $\beta$ pathway contributes to disruption of adipose tissue biology and fibrosis development.
\end{abstract}

Keywords: Cancer cachexia. Adipose tissue. Extracellular matrix.Fibrosis. TGF $\beta$. 


\section{LISTA DE ILUSTRAÇÕES}

Figura 1 - Estágios Clínicos da Caquexia.

Figura 2 - Manifestações Clínicas causadas pela Caquexia.

Figura 3 - Componentes do Tecido Adiposo.

Figura 4 - Visão geral dos Mecanismos envolvidos no reparo Tecidual e na Fibrose.

Figura 5 - Estrutura da Forma Latente do TGFß.

Figura 6 - Desenho Experimental.

Figura 7 - Parâmetros Clínicos e da Caracterização dos grupos

Figura 8 - Qualidade de Vida dos Pacientes.

Figura 9 - Aspectos Morfológicos e Morfométricos do Tecido Adiposo Subcutâneo na Caquexia Associada ao Câncer.

Figura 10 - Conteúdo total de colágeno por Picro Sirius Red.

Figura 11 - Detecção do Conteúdo de Fibras Reticulares.

Figura 12 - Detecção do Sistema Elástico no Tecido Adiposo.

Figura 13 - Detecção por imunohistoquímica de marcadores de fibrose tecidual.

Figura 14 - Expressão gênica e proteica de marcadores de ativação de miofibroblastos e proliferação celular.

Figura 15 - Deteç̧ão de por imunohistoquímica para vimentina, migração e proliferação de fibroblastos isolados do tecido adiposo.

Figura 16 - Expressão Gênica e Proteica da Via de Sinalização do TGFß.

Figura 17 - Detecção do TGFR2 e TGFß1 por Western Blotting no tecido adiposo.

Figura 18 - Imunofluorescência para detecção de SMAD2 no tecido adiposo.

Figura 19 - Imunofluorescência para detecção de SMAD3 no tecido adiposo.

Figura 20 - Imunolocalização e Expressão Gênica de fatores de transcrição relacionados ao TGF $\beta$.

Figura 21 - Correlação entre TGF $\beta 1$ e Citocinas no Tecido Adiposo do grupo Controle.

Figura 22 - Correlação entre TGFß2 e Citocinas no Tecido Adiposo do grupo Controle.

Figura 23 - Correlação entre TGF $\beta 1$ e Citocinas no Tecido Adiposo do grupo Controle.

Figura 24 - Correlação entre TGF $\beta 1$ e Citocinas no Tecido Adiposo do grupo WSC. 
Figura 25 - Correlação entre TGF $\beta 2$ e Citocinas no Tecido Adiposo do grupo WSC. Figura 26 - Correlação entre TGF $\beta 3$ e Citocinas no Tecido Adiposo do grupo WSC. Figura 27 - Correlação entre TGF $\beta 1$ e Citocinas no Tecido Adiposo do grupo CC. Figura 28 - Correlação entre TGF $\beta 2$ e Citocinas no Tecido Adiposo do grupo CC. Figura 29 - Correlação entre TGFß3 e Citocinas no Tecido Adiposo do grupo CC. 


\section{LISTA DE TABELAS}

Tabela 1 - Seqüência de Primers.

Tabela 2 - Caracterização dos grupos de estudo.

Tabela 3 - Parâmetros Clínicos: Perfil Lipídico e Enzimas Hepáticas

Tabela 4 - Concentração Plasmática de citocinas inflamatórias e anti-inflamatórias.

Tabela 5 - Concentração de citocinas inflamatórias e anti-inflamatórias no tecido adiposo subcutâneo.

Tabela 6 - Concentração de citocinas inflamatórias e anti-inflamatórias em adipócitos isolados do tecido adiposo subcutâneo. 


\section{LISTA DE ABREVIATURAS}

aSMA Alfa- actina de músculo liso

ALT Aspartato aminotransferase

AST Alanina aminotransferase

ATGL Lipase de triacilglicerol

CEP Comitê de Ética

CCN Ciclina

c-Myc Homólogo do oncogene viral "v-myc avian myelocytomatosis"

$\mathrm{COL} \quad$ Colágeno

CC

Câncer e caquexia

DMEM Meio de cultura Dubecco Modified Eagle Medium

EDTA Ácido etileno-diamino tetra-acético

EGF Fator de crescimento epidermal

FGF Fator de crescimento de fibroblastos

HE Hematoxilina e eosina

HDL Lipoproteínas de alta densidade

HIF1 Fator induzido por hipóxia

HSL Lipase hormônio sensível

IFNy Interferon gamma

IL Interleucina

IMC Índice de Massa Corporal

LAP Pró-peptídeo latente

LPL L Lipase de lipoproteína

LTPB Proteína latente ligante de TGF

MCP1 Proteína quimioatrativa de monócitos

MEC Matriz extracelular

MMP Metaloproteinase

NEFA Ácidos graxos não essenciais

NFkB Fator nuclear kappa B

SMAD Proteínas transdutoras de sinal

sILR Receptor solúvel de interleucina

SIRT1 Sirtuin1

sTNFR Receptor solúvel do fator de necrose tumoral 
TAG Triacilglicerol/triglicerídeos

TIMP Inibidor tecido específico de metaloproteinase

TCLE Termo de consentimento livre e esclarecido

TGF $\beta \quad$ Fator transformante de crescimento beta

TGFR Receptor do fator transformante de crescimento

TNF Fator de necrose tumoral

WSC Câncer de peso estável

4EBP1 Fator de iniciação de transcrição eucariótica 4E-ligante 
1 INTRODUÇÃO

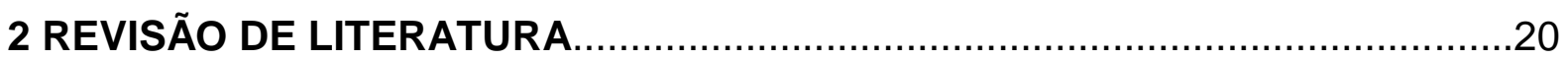

2.1 A Caquexia Associada ao Câncer: Importância, Perspectiva Histórica e

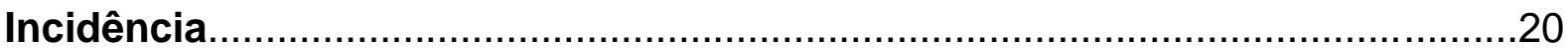

2.2 Caquexia Associada ao Câncer: Síndrome Multifatorial e Inflamatória........24

2.3 Tecido Adiposo Branco: Regulação na Caquexia associada ao Câncer e suas funções

2.4 A MEC do Tecido Adiposo e o Remodelamento na Caquexia associada ao Câncer

2.5 Mecanismos Do Remodelamento Tecidual No Reparo De Lesões à

Fibrose. .30

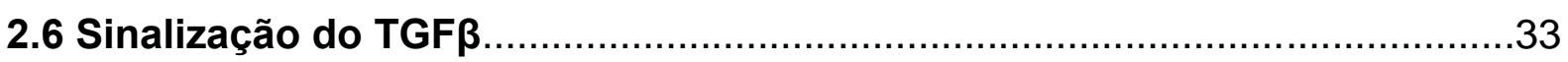

2.7 TGF $\beta$ na Fibrose

3 JUSTIFICATIVA

4 OBJETIVOS

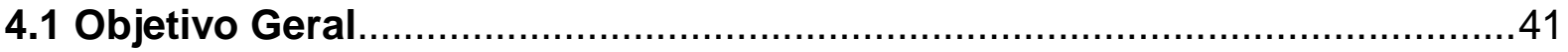

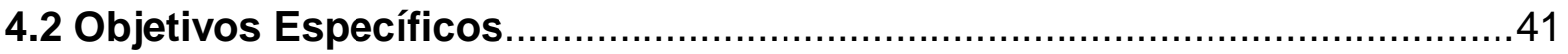

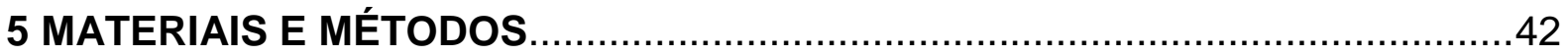

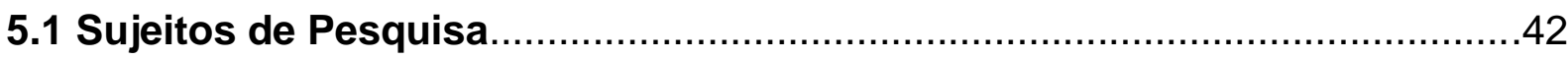

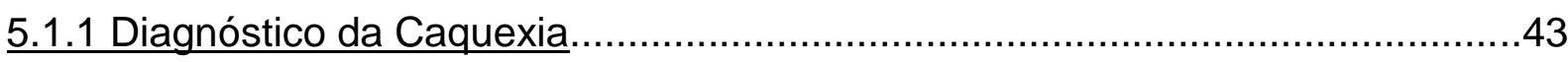

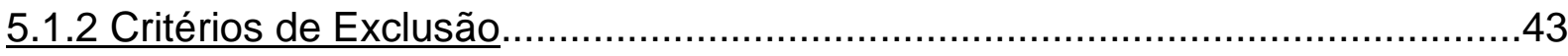

5.2 Procedimentos Cirúrgicos e Obtenção das Amostras................................4

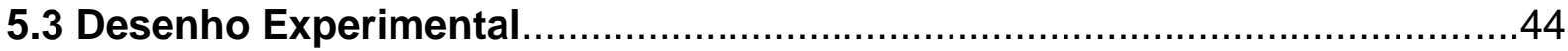

5.4 Coleta Sanguínea

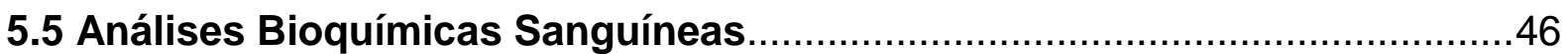

5.6 Microscopia de Luz e Análises Histológicas............................................

5.6.1 Obtenção e Processamento dos Tecidos...................................................46

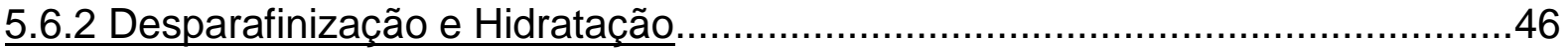

5.6.3 Coloração por Hematoxilinade Harris e Eosina (HE)...................................47

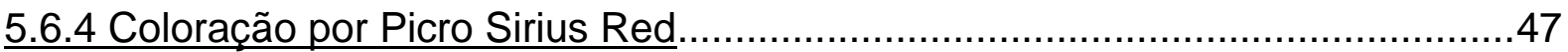

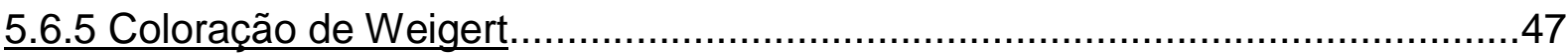

5.6.6 Coloração de Verhoeff's Van-Gieson ............................................................ 48 


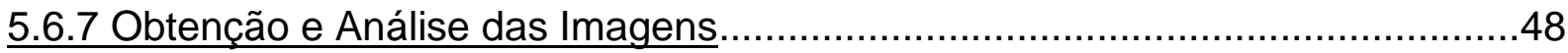

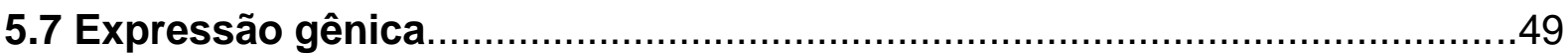

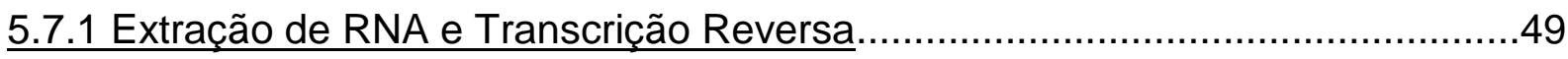

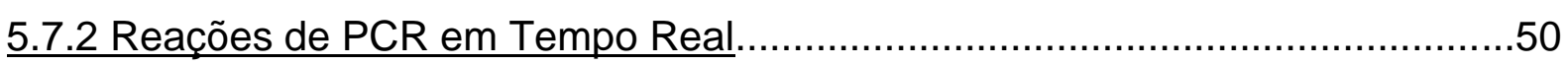

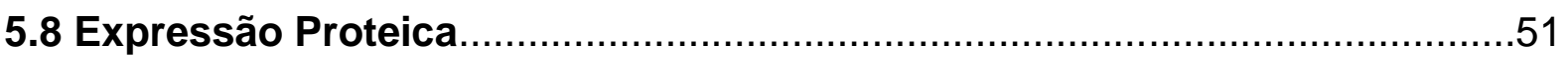

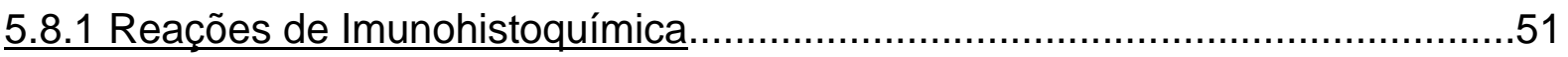

5.8.2 Reações de Imunofluorescência em cortes parafinizados...............................52

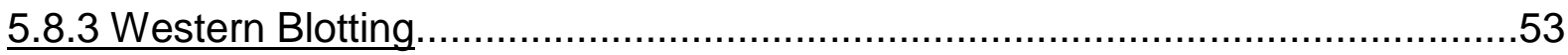

5.8.4 Expressão das citocinas do tecido adiposo, adipócitos e plasma utilizando a

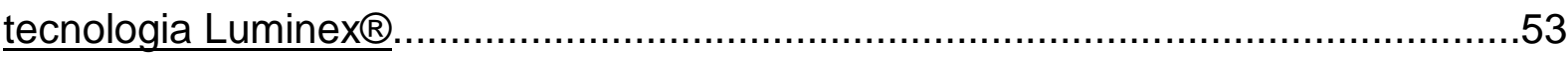

5.9 Processamento e Isolamento de Células no Tecido Adiposo.......................54

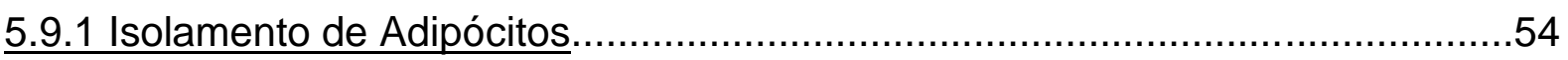

5.9.2 Explantes ex-vivo e Cultura de Fibroblastos do Tecido Adiposo.......................55

5.9.3 Imunofluorescência em Células.....................................................................5

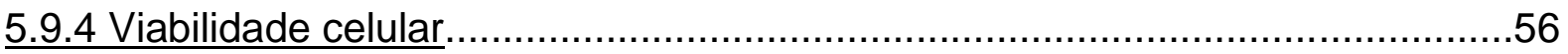

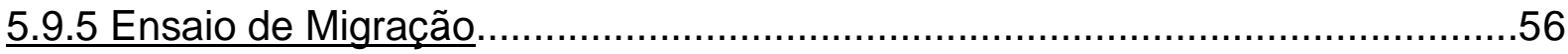

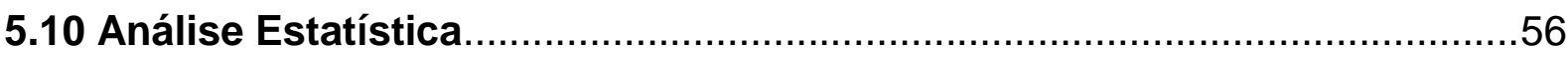

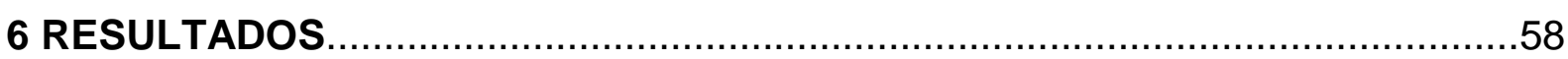

6.1 Características Gerais dos Grupos de Estudo e Parâmetros Clínicos.........58

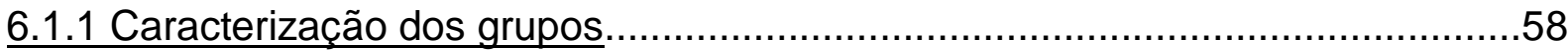

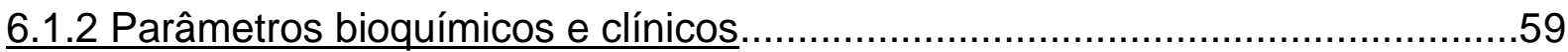

6.2 Características do Tecido Adiposo na Caquexia Associada ao Câncer.......61

6.2.1 Análises Morfológicas e Morfométricas do Tecido Adiposo..............................61

6.3 Remodelamento da MEC do Tecido Adiposo na Caquexia............................64

6.3.1 Análise do Conteúdo Total de Colágeno no tecido Adiposo..............................64

6.3.2 Detecção de Fibras Reticulares no Tecido Adiposo ...........................................64

6.3.3 Análise do Sistema Elástico no Tecido Adiposo.............................................64

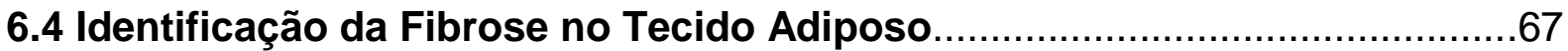

6.4.1 Imunomarcação de componentes da MEC envolvidos na fibrose tecidual.......67

6.4.2 Conteúdo das Citocinas Inflamatórias relacionadas à fibrose..........................69

6.4.3 Detecção de Miofibroblastos e da proliferação celular no Tecido Adiposo.......71

6.5. TGF $\beta$ Como Contribuinte Na Fibrose do Tecido Adiposo ...........................74

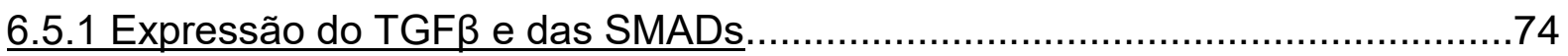

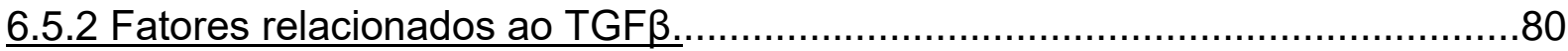




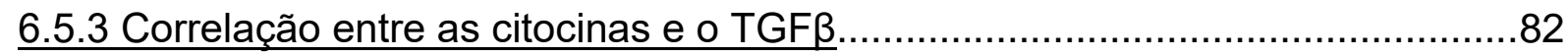

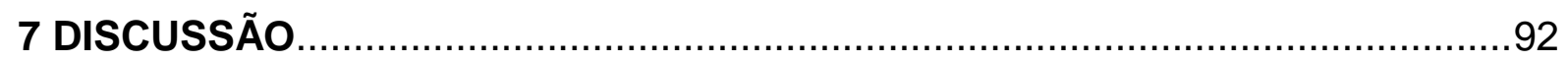

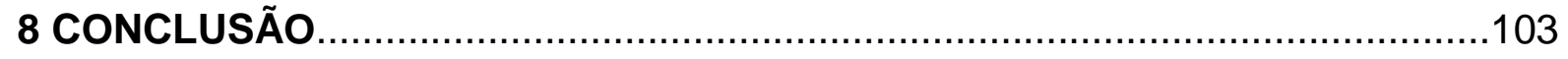

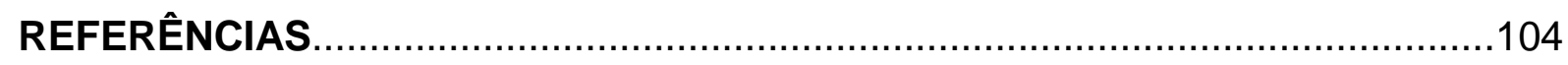

ANEXOS

A - Termo de Consentimento Livre e Esclarecido.......................................115

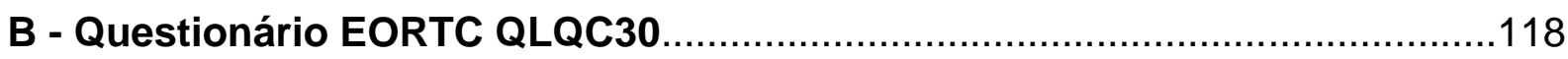

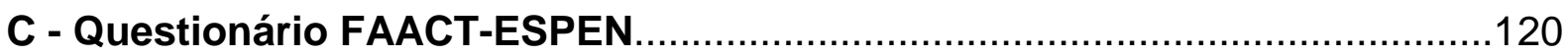




\section{INTRODUÇÃO}

A origem da palavra caquexia deriva do termo grego "kakoshexis", o qual significa literalmente má condição (Argilés et al., 2003). A imagem de indivíduo caquético ou em má condição é muito característica e facilmente distinguida por ser a confirmação visual dos piores medos do próprio indivíduo, de que a doença está piorando e provavelmente não haverá melhoras (Lok, 2015).

A caquexia é uma manifestação comum presente no avanço de diversas doenças crônicas, especialmente em pacientes em fase terminal (Argilés et al., 2014). É uma desordem metabólica que afeta cerca de 09 milhões de pessoas no mundo inteiro, e aproximadamente $80 \%$ da população com câncer avançado, não existindo um tratamento efetivo até o momento que reverta completamente à síndrome (Lok, 2015).

A profunda modificação na biologia do tecido adiposo tem sido considerada um importante marcador para síndrome (Bing et al., 2006). O tecido adiposo é considerado um importante órgão endócrino e pleiotrópico por ser capaz de sintetizar mais de cem fatores conhecidos, além de atuar na modulação de importantes processos, tais como: proliferação, inflamação, metabolismo, entre outros (Kwok et al., 2016).

Nosso grupo de pesquisas demonstrou recentemente que o tecido adiposo possui alterações morfológicas na caquexia associada ao câncer, com maior recrutamento de células inflamatórias (Batista et al., 2016). No entanto, alterações morfológicas levam ao remodelamento, e a deposição de matriz extracelular, são principalmente mediadas pelos fibroblastos, e em especial o TGF $\beta$. A via de sinalização desencadeada pela ativação do TGF $\beta$ está associada ao desenvolvimento da fibrose tecidual.

O presente trabalho aborda sobre as características do remodelamento do tecido adiposo na caquexia associada ao câncer, bem como, a presença de fibrose, e a contribuição da via de sinalização do TGF $\beta$ através das SMADs. 


\section{REVISÃO DE LITERATURA}

\subsection{A Caquexia Associada ao Câncer: Importância, Perspectiva Histórica e Incidência}

A caquexia associada ao câncer é uma condição irreversível que leva à contínua perda de peso corporal, sendo de impacto devastador na qualidade de vida, e na sobrevivência do paciente. Nos últimos anos, tem havido um enorme esforço da comunidade científica em apresentar uma definição efetiva para síndrome. Entre todas as abordagens, podemos encontrar dois fatores comuns; a perda de peso, oriunda da perda de massa muscular esquelética e de massa gorda, e a inflamação sistêmica (Argilés et al., 2014). No entanto, em um consenso formal e internacional, a caquexia associada ao câncer foi definida como "síndrome multifatorial, na qual há perda contínua de massa muscular (com perda ou ausência da perda de massa gorda) que não pode ser totalmente revertida pela terapia nutricional convencional, conduzindo ao comprometimento funcional progressivo do organismo" (Fearon et al., 2011). A definição como síndrome multifatorial é um dos conceitos mais claros, uma vez que a caquexia compromete a função de muitos tecidos e órgãos (Argilés et al., 2014).

Relatos a cerca da caquexia são anteriores à Cristo, segundo Hipócrates (c. 460-377 A.C) apud Katz e Katz (1962) "A carne é consumida e se torna água... o abdômen se enche de água, os pés e as pernas incham, a ombros, clavículas, peito e coxas derreter... Esta doença é fatal". A caquexia é uma manifestação comum a muitas patologias tais como: síndrome da imunodeficiência adquirida (AIDS), artrite reumatóide, moléstias digestivas, doença crônica obstrutiva pulmonar, doenças cardíacas crônicas, fibrose cística, doença de Crohn's e estágios terminais de falência renal (Tisdale, 2002; Bennani-Baiti e Walsh, 2009; Argilés et al., 2010).

A questão é que, historicamente, e por muito tempo, a caquexia foi apenas vista como uma complicação séria e inevitável, somente devido à perda de peso, por aparecer em associação às mais diversas doenças crônicas. No século 19, relatouse uma forma de caquexia africana, essa ocorria somente nas populações de escravos, os quais desenvolviam dificuldade de respirar, dores de estômago, diarréia, náusea, sendo o óbito decorrente em menos de três meses. Em 1912, Hebert French relatou que o termo caquexia era usado para incluir qualquer 
condição do corpo em que o suporte nutricional estivesse desequilibrado. Portanto, era continuamente observada em pacientes que apresentassem ao mesmo tempo, perda progressiva de peso, palidez ou anemia, e, podendo a palavra ser precedida do adjetivo que qualifica a doença que acompanha. Essa elegante revisão relata que em 1915, Howard Canning Taylor, fundador da Sociedade Americana para o Controle do Câncer, aborda que nada é mais distintivo que a caquexia associada ao câncer, e essa reflete diretamente na figura clínica do paciente, o paciente apresenta uma palidez de palha. Os sintomas são graduais e progressivos. Em geral, a presença da caquexia pode variar de acordo com a localização e o tipo de tumor. Por fim, sua causa não pode estar associada a apenas um simples fator (BennaniBaiti e Walsh, 2009).

Já em 1997, Roubenoff, et al., padronizam e diferenciam o uso da nomenclatura caquexia do termo perda por se (wasting), em que, a perda reflete qualquer perda, podendo significar a atrofia de uma parte do corpo, por exemplo, após uma intervenção cirúrgica, enquanto que caquexia deve ser usado somente para referir a perda involuntária de peso acompanhada de perda de massa magra. Ainda, devendo ser diferenciada da perda de peso voluntária, jejum prolongado, perda de apetite e anemia, entre as quais podem ser revertidas por tratamentos (Roubenoff et al., 1997). No jejum prolongado, a perda de peso é em maior proporção, de massa gorda, com pequena contribuição da massa esquelética, enquanto que na caquexia a perda ocorre em ambos os compartimentos, de massa esquelética e de massa gorda (Tisdale, 1997).

A perda de peso decorrente da caquexia em pacientes com câncer surge ainda em estágios iniciais da doença, apesar de estar erroneamente, em visões mais obsoletas, associada aos estágios finais do câncer. Estudos com pacientes de câncer pancreático demonstraram que esses pacientes já haviam perdido 14\% do peso corporal, no momento do diagnóstico, comparado com o momento prédiagnóstico, no qual eram considerados de peso estável (Tisdale, 2002). Além disso, a porcentagem da perda de peso associada à caquexia está diretamente relacionada com o tempo de sobrevivência do paciente. A perda de importantes funções vitais ocorre com $15 \%$ de perda de peso corporal, ao atingir $30 \%$ a perda de peso se torna quase sempre fatal, sendo que poucos pacientes conseguem sobreviver até $50 \%$ de perda do peso corporal (Dewys et al., 1980; Tisdale, 2002). 
A incidência da caquexia acomete cerca de $50 \%$ de todos os pacientes diagnosticados com câncer, alcançando a $80 \%$ dos pacientes em estágios terminais (Laviano et al., 2005). Após o diagnóstico, a perda de peso decorrente da caquexia pode variar de acordo com a localização do tumor. É relatada maior incidência, acima de $80 \%$, de perda de peso em pacientes com câncer pancreático, gastrointestinal e esôfago, ocorrendo com frequência de 50 a $60 \%$ em câncer do pescoço e cabeça, cólon-reto e pulmonar, enquanto que tumores menos agressivos, tais como: linfomas Hodgkin's, leucemias não-linfocitárias e câncer de mama, a caquexia acomete somente 10-30\% dessa população (Tisdale, 2002; Laviano et al., 2005).

Apesar de acometer diferentemente os pacientes de câncer, de acordo com a localização do tumor, a caquexia é responsável direta pelo óbito de 20-40\% desses pacientes (Tisdale, 2002; 2010; Argilés et al., 2014). Sua presença, também, está associada ao pior prognóstico e diminuição da resposta ao tratamento. Os pacientes que apresentam perda de peso durante o tratamento de câncer possuem diminuída expectativa de vida, em relação aos pacientes de peso estável, bem como, pacientes que estão em tratamento de quimioterapia ou radioterapia para câncer de cabeça e pescoço, que conseguem reverter parcialmente a perda de peso, respondem positivamente ao tratamento influenciando na qualidade de vida e na sobrevivência do mesmo (Gullett et al., 2009; Muscaritoli et al., 2011).

A conduta clínica conferida à caquexia atualmente é limitada, uma vez que é raramente reconhecida em decorrência do aspecto variável em termos de sintomatologia. Em pacientes com câncer gastrointestinal superior, o tumor pode levar a obstrução mecânica reduzindo a ingestão alimentar e causando a perda de peso indiretamente (Fearon et al., 2012). Com a devida importância atribuída à complexidade da síndrome, essa deve ser reconhecida prontamente na clínica, diagnosticada, e por fim tratada, ainda que seja de forma paliativa.

Para garantir que a síndrome seja mais facilmente detectada, a caquexia foi classificada em três estágios de relevância clínica a fim de facilitar sua identificação e intervenção; pré-caquexia, a caquexia e caquexia refratária, mas nem todos os pacientes apresentarão todos os estágios bem definidos (Figura 1). 
Figura 1 - Estágios Clínicos da Caquexia.

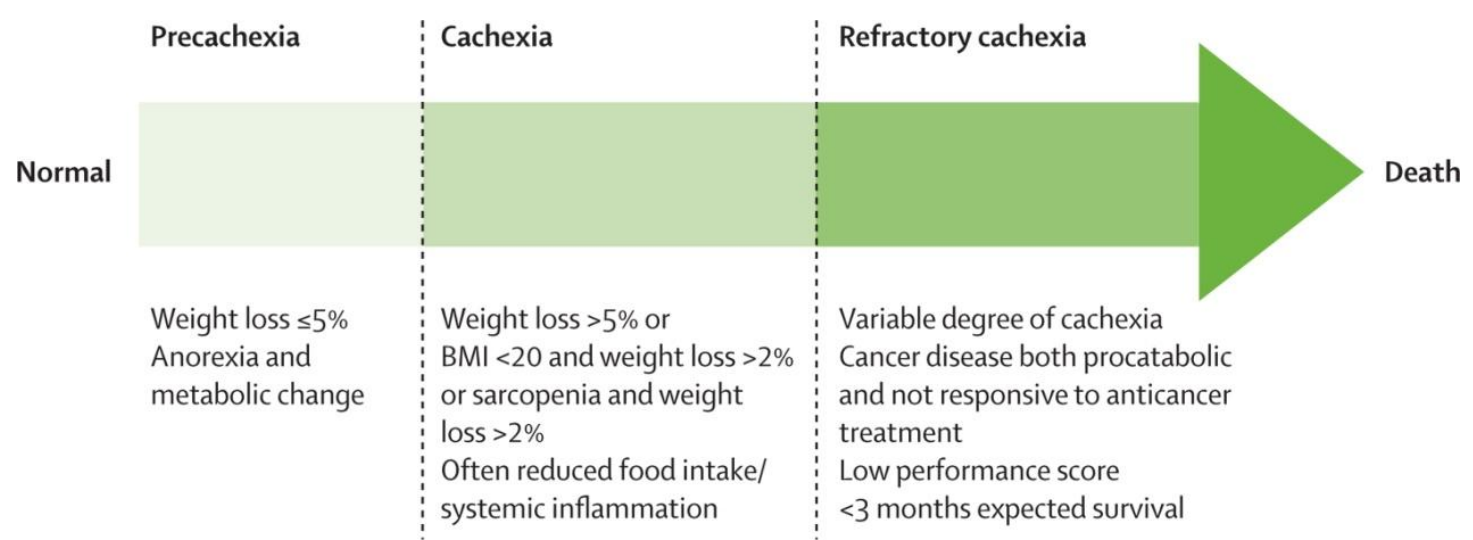

FONTE: Adaptado de (Fearon et al., 2011)

Na pré-caquexia ocorrem algumas mudanças metabólicas tais como: anorexia e tolerância a glicose que podem preceder da perda de peso $(\leq 5 \%)$. Na caquexia propriamente dita, o paciente já apresenta perda de peso $\geq 5 \%$ nos últimos seis meses, ou o Índice de Massa Corporal menor que $20 \mathrm{~kg} / \mathrm{m}^{2}$, sarcopenia, inflamação sistêmica. No último estágio, o paciente já não responde a terapia anticâncer, sendo o câncer de rápido progresso, a perda de peso se torna mais acentuada, com catabolismo altamente ativo, e a expectativa de vida é de apenas 03 meses (Fearon et al., 2011).

As manifestações clínicas da caquexia em geral, incluem a perda de peso em adultos maior que 5\% nos últimos 12 meses ou menos, ou diminuição do crescimento em crianças, juntamente com mais três de cinco sintomas: anorexia, inflamação sistêmica com parâmetros bioquímicos alterados [(parâmetros inflamatórios IL6 sérica ou plasmática e proteína C-reativa; anemia (hemoglobina $\geq$ $12 \mathrm{~g} / \mathrm{dL})$; baixa albumina $(3,2 \mathrm{~g} / \mathrm{dL})]$, fadiga, diminuição da força muscular e diminuição do índice livre de massa magra (Figura 2). Além disso, o paciente também pode apresentar resistência à insulina e aumento da quebra proteica muscular (Evans et al., 2008). 
Figura 2- Manifestações Clínicas causadas pela Caquexia.

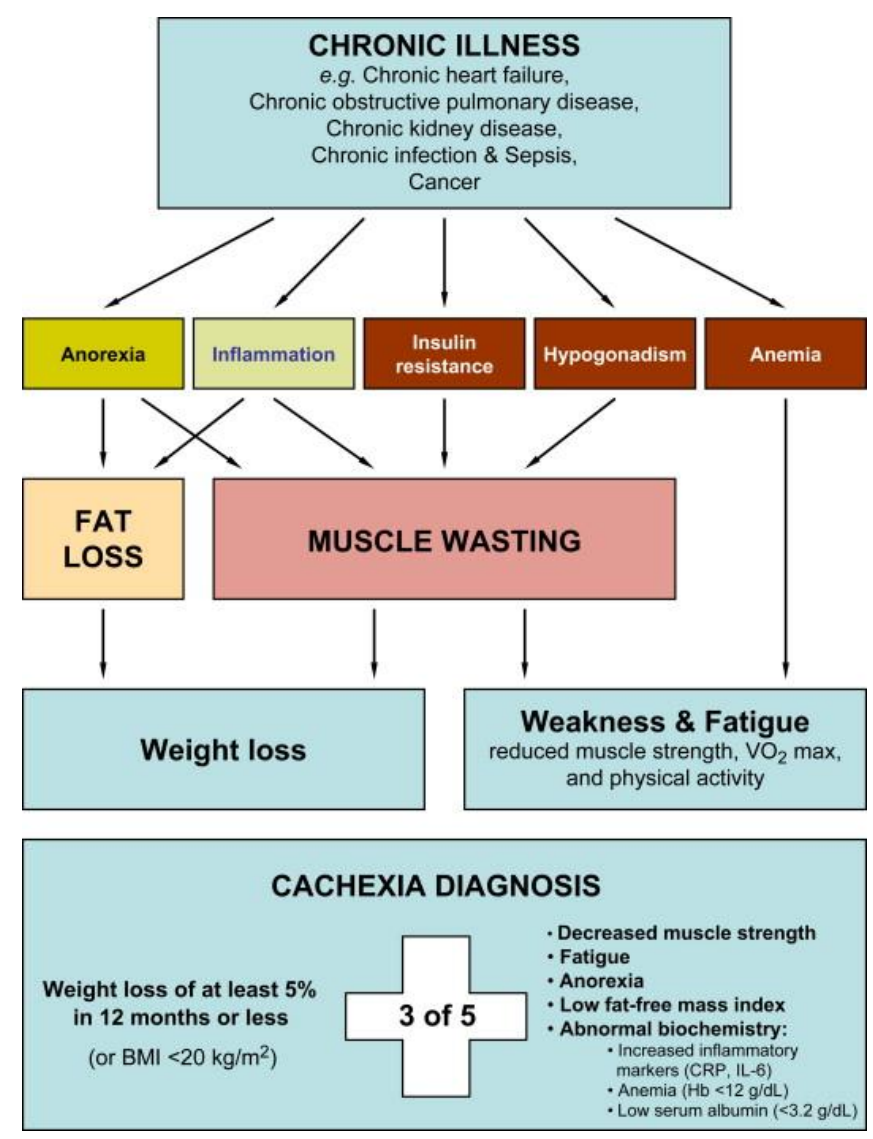

FONTE: Adaptado de (Evans et al., 2008).

\subsection{Caquexia Associada ao Câncer: Síndrome Multifatorial e Inflamatória.}

Como uma síndrome que envolve múltiplos órgãos, sabemos que a inflamação crônica presente na caquexia é decorrente da interação entre organismo e a presença do tumor. A produção de citocinas e fatores pró-inflamatórios são provenientes tanto do tumor quanto de diversos tecidos e órgãos (Argilés e LópezSoriano, 1999; Argilés et al., 2003; Argilés et al., 2009; Batista, Peres, et al., 2012; Argilés et al., 2014). Entre todas as citocinas estudadas na caquexia, de acordo com Argilés et al.(2003; 2009),o fator de necrose tumoral alfa (TNFa) é uma das citocinas mais citadas como indutora da caquexia por estar diretamente envolvido na desregulação metabólica imposta pela síndrome, mas, os autores sugerem também, que o estado caquético é determinado pelo balanço entre citocinas pró-caquéticas: TNFa, interleucina-6 (IL-6), interleucina-1 beta (IL-1 $\beta$ ), interferon-gamma (IFN- $\gamma$ ), Fator inibitório de leucemia (LIF), Fator transformante crescimento beta (TGF $\beta$ ), Fator neurotrófico ciliar (CNTF), e citocinas anti-caquéticas: interleucina-4 (IL-4), 
interleucina-10 (IL-10), interleucina-13 (IL-13), receptor solúvel do Fator de necrose tumoral (sTNFR) e receptor solúvel de interleucina-6 (sIL-6R), respectivamente consideradas, pró - e anti-inflamatórias (Argilés et al., 2003; Argilés et al., 2009).

Nesse contexto, a contribuição de diversos órgãos e tecidos é dada, por exemplo, de alterações no cérebro, que são promovidas pela falta de balanço de mediadores anorexigenos e orexígenos, esses são profundamente alterados, e estão associados com o controle de ingestão alimentar (apetite, saciedade, tato e olfato em relação ao sabor e cheiro da comida). Esse desbalanço dos mediadores diminui a produção do neuropeptídio Y (NPY) que resulta na anorexia observada nos pacientes, e consequentemente, na desregulação do balanço energético (Argilés et al., 2014). No trato gastrointestinal é observado uma disfunção da barreira intestinal, contribuindo para síntese de mediadores inflamatórios. No fígado, as alterações impostas pela síndrome resultam em concentrações aumentadas de proteína CReativa, bem como, na produção ineficiente de energia devido a diminuição na capacidade oxidativa das mitocôndrias observadas em modelos animais (Argilés et al., 2014). A fibrose cardíaca, a ultraestrutura do miocárdio prejudicada, e diminuição de proteínas contráteis (miosina de cadeia pesada e troponina I) são modificações relatadas que induzem a atrofia cardíaca através da via de sinalização do TGFß/ALK5, miostatina e activina, em modelos experimentais para caquexia (Zhou et al., 2010; Argilés et al., 2014). No músculo esquelético, as alterações na síntese e degradação de proteínas, diminuição no metabolismo de amino ácidos, aumentada razão de células em apoptose e prejudicada capacidade de regeneração contribuem para perda de massa muscular na caquexia. Além disso, muitas vias de sinalização estão envolvidas no processo de perda muscular, as citocinas inflamatórias, como por exemplo, TNFa e IL1 ativam as vias do fator de transcrição nuclear-kappa B (NF$\mathrm{KB}$ ), quinase MAP (MAPK), e proteína quinase ativadora de mitógeno-38 (p38) que resultam na ativação de E3 ligases (MURF1) e atrogina 1, entre outras, as quais promovem a quebra proteica e inibe a síntese de proteínas (Glass, 2010; Argilés et al., 2014). A inflamação sistêmica imposta pela síndrome produz todas essas alterações nos diversos órgãos e tecidos, que resultam em respostas inflamatórias, em cada um deles, exacerbando e contribuindo ainda mais para o agravamento da inflamação sistêmica presente na síndrome. Nosso grupo de pesquisa tem demonstrado as mais diversas alterações acometidas no fígado, hipotálamo, músculo e no tecido adiposo na vigência da caquexia associada ao câncer, tanto em 
animais, quanto em humanos (Bertevello e Seelaender, 2001; Machado et al., 2004; Lira et al., 2008; Batista, Neves, et al., 2012; Batista et al., 2013; Camargo et al., 2015; Seelaender et al., 2015).

\subsection{Tecido Adiposo Branco: Regulação na Caquexia associada ao Câncer e suas funções.}

Adicionalmente à progressiva perda de peso corporal, e à perda de músculo esquelético, a caquexia induz uma profunda perda do tecido adiposo (Bruera e Sweeney, 2000; Tisdale, 2002; Argilés et al., 2010). Essa perda de massa gorda pode anteceder aquela de massa magra, e de acordo com Dahlman et al., (2010), ocorre primeiramente a redução no conteúdo lipídico dos adipócitos, relacionado com a mudança na expressão de genes que regulam o turnover energético, citoesqueleto e matriz extracelular, refletindo posteriormente na diminuição do tecido adiposo (Dahlman et al., 2010).

No entanto, (Argilés et al., 2005) atribuem a perda de tecido adiposo a três diferentes processos. O aumento da atividade lipolítica é o primeiro deles, decorrente da ativação da enzima lipase hormônio sensível (HSL) no tecido adiposo, responsável por realizar a quebra de triacilglicerol (TAG) em glicerol e ácidos graxos não essenciais (NEFA). Em segundo, ocorre a diminuição da atividade da lipase de lipoproteína (LPL), a qual catalisa a hidrólise de TAG presente em lipoproteínas, em glicerol e ácidos graxos, promovendo a diminuição na captação de lípides para os tecidos. E por último, o processo de lipogênese que é prejudicado na caquexia, por haver uma diminuição na disponibilidade de ácidos graxos para captação e depósito no tecido adiposo (Argilés et al., 2005; Frühbeck et al., 2014)

O tecido adiposo branco é amplamente encontrado em humanos, um dos maiores depósitos é encontrado na região subcutânea (superior: embaixo da pele na superfície abdominal, e inferior: gluteofemoral), e na região visceral (incluindo os depósitos omental, mesentérico, mediastinal e epicardial) (Kwok et al., 2016). tecido adiposo subcutâneo é visto primariamente como barreira contra infecções dérmicas, isolante térmico e realizando proteção (como uma almofada) contra estresses mecânicos externos (Ouchi et al., 2011; Kwok et al., 2016). Uma das principais características do tecido adiposo é sua heterogeneidade morfofuncional: de acordo com a localização anatômica de cada depósito, o tecido exibe 
propriedades diferentes, tanto em relação às células quanto à própria fisiologia (Kwok et al., 2016). Por outro lado, o tecido adiposo, considerado como importante órgão endócrino, possui uma ação central atuando na modulação de processos tais como: proliferação, adipogênese, metabolismo, inflamação, termogênese e angiogênese (Rodríguez et al., 2015). A funcionalidade do tecido adiposo se torna pleiotrópica, devido suas células ser capazes de sintetizar uma ampla gama de adipocinas, incluindo fatores de crescimento, citocinas, hormônios, proteínas da matriz extracelular e fatores vasoativos (Rodríguez et al., 2015; Kwok et al., 2016). Cabe esclarecermos, que o tecido adiposo não é somente composto por suas células adiposas, os adipócitos e pré adipócitos, possuindo ainda células endoteliais, fibroblastos, células do sistema imune, sendo todos envoltos em uma rica matriz extracelular, como demonstrado na Figura 3 (Ouchi et al., 2011).

Figura 3 - Componentes do Tecido Adiposo.

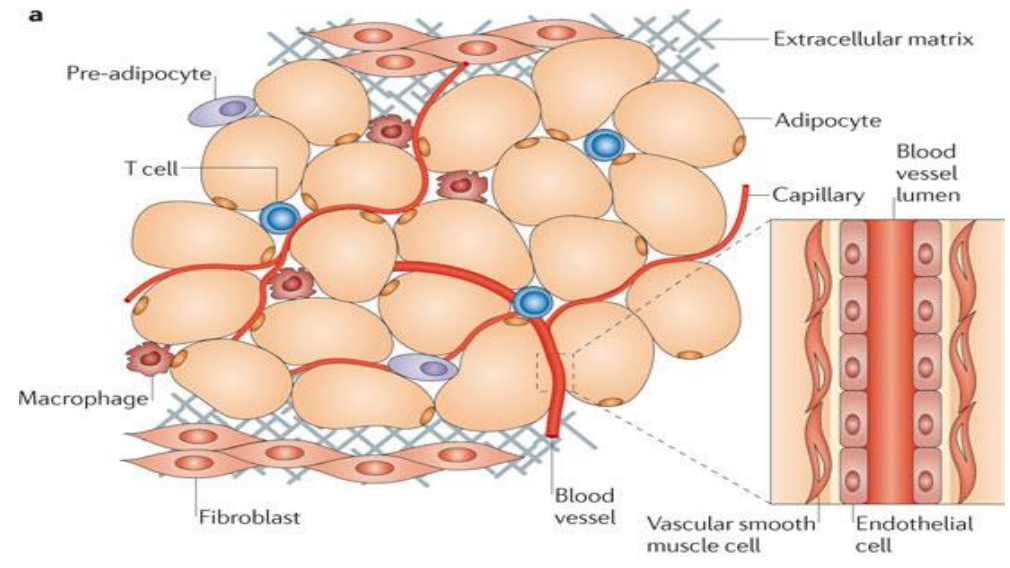

FONTE: Adaptado de (Ouchi et al., 2011).

$\mathrm{Na}$ caquexia associada ao câncer, o tecido adiposo parece ser um importante contribuinte para inflamação presente na síndrome, uma vez que apresenta a síntese aumentada de diversos fatores inflamatórios (Batista, Peres, et al., 2012). Em modelos animais de caquexia, inoculados com células tumorais de carcinosarcoma de Walker 256, a síntese de TNFa foi encontrada significantemente aumentada em macrófagos infiltrados dos diferentes depósitos de tecido adiposo, enquanto que, a síntese de leptina estava reduzida nos depósitos de tecido adiposo (Machado et al., 2004). Em pacientes caquéticos, a expressão gênica do TNFa, IL6, leptina e adiponectina foi positivamente regulada no tecido adiposo subcutâneo, enquanto, não houve mudanças significativas no depósito visceral, em comparação 
com pacientes considerados controle (Batista et al., 2013). Em outro estudo de nosso grupo de pesquisa, houve o aumento do NFKB, um importante modulador "downstream" da via do TNFa. A expressão proteica desse fator estava significantemente alterada, bem como, a expressão de genes relacionados à inflamação: IL6, interleucina-1 beta (IL1 $\beta$ ), inibidor alpha do fator de transcrição nuclear kappa-B (IKBa) e do próprio TNFa, no grupo de pacientes caquéticos e com câncer gastrointestinal em relação aos grupos controle e câncer (Camargo et al., 2015). Esses achados evidenciam a modulação do TNFa na inflamação do tecido adiposo.

Animais caquéticos, portadores de adenocarcinoma de cólon C26, também exibem importantes modificações no tecido adiposo, associadas com níveis elevados de outra citocina inflamatória, a IL6, através da fosforilação das proteínas: proteína tradutora de sinal e ativadora de transcrição-3 (STAT3) e proteína supressora da sinalização de citocinas-3 (SOCS3), bem como o aumento nos níveis de RNAm dos genes das mesmas. A presença de inflamação no tecido adiposo desses animais é encontrada regulando alterações no metabolismo lipídico, uma vez que os níveis proteicos da lípase de triacilglicerol do adipócito (ATGL) e do fator de iniciação de transcrição eucariótica 4E-ligante de proteína1 (4EBP1) foram relatados duas vezes maiores que no grupo de animais controles (Tsoli et al., 2014).

Em adição a esses achados, adipócitos diferenciados cultivados por 24 horas com TNFa mostram o aumento rápido, de mais de setenta vezes, da expressão de proteína quimioatrativa de monócitos (MCP1) e IL6, com o pico de aumento após 2 horas de incubação, sendo que os níveis aumentados de MCP1 foram mantidos após as 24 horas de incubação (Wang e Trayhurn, 2006). Na caquexia associada ao câncer, a expressão elevada de MCP1 em adipócitos diferenciados, e em préadipócitos, é associada com os níveis altos de TNFa. Além, de induzir o recrutamento de monócitos para o sítio, o macrófago infiltrado auxilia na produção dessas e outras citocinas inflamatórias, as quais irão exacerbar o quadro inflamatório (Machado et al., 2004).

\subsection{MEC do Tecido Adiposo e o Remodelamento na Caquexia Associada ao Câncer}


A matriz extracelular (MEC) é uma estrutura não celular, tridimensional, presente em todos os tecidos, e essencial à vida (Bonnans et al., 2014). A composição da MEC é única em cada tecido, bem como o seu dinamismo, que se tornam essenciais para estrutura e funcionamento celular. $O$ tecido adiposo é caracterizado como tecido conjuntivo frouxo de propriedades especiais, em que cada adipócito é encoberto por uma delicada MEC promovendo integridade física e elasticidade ao tecido. Os componentes da MEC, no tecido adiposo, são produzidos pelos próprios adipócitos, e também, por outras células presentes na fração vascular estromal (Mariman e Wang, 2010). Aproximadamente mais de 300 proteínas são conhecidas como constituintes da MEC em mamíferos, no tecido adiposo as proteínas que compõe a MEC incluem uma variedade de colágenos dos tipos I, III, VI, proteínas de adesão tais como; a fibronectina, laminina, proteoglicanos (perlecan, decorin) e elastinas (Divoux e Clément, 2011; Bonnans et al., 2014). Além disso, as integrinas, presentes na membrana basal das células, atuam na comunicação intracelular, sendo capazes de ativar os microtúbulos do citoesqueleto e os filamentos de actina, ou disparando vias de sinalização. Portanto, quaisquer mudanças da MEC são rapidamente percebidas intracelularmente, e podem regular a proliferação celular, diferenciação, migração e apoptose (Divoux e Clément, 2011). Nesse contexto, a MEC pode seqüestrar e sintetizar fatores de crescimento; o fator de crescimento de fibroblastos (FGF), o fator de crescimento epidermal (EGF), além de outras moléculas de sinalização como o TGF $\beta$, que podem modificar completamente o microambiente tecidual, regulando a arquitetura da MEC e o ambiente celular (Bonnans et al., 2014).

No tecido adiposo, a MEC também é altamente dinâmica. Na obesidade, em que é observada a expansão dos adipócitos, a MEC é rapidamente remodelada para acomodar o crescimento dessas células (Mariman e Wang, 2010). A expressão aumentada de diversas isoformas de colágenos é observada nos diversos depósitos de tecido adiposo em animais $d b / d b$, em paralelo com o aumento de marcadores inflamatórios, no entanto, o aumento mais expressivo entre os componentes da MEC está associado com o colágeno tipo $\mathrm{VI}(\mathrm{COL} 6)$, as cadeias $\alpha 1$, a2 e $\alpha 3$, concomitantemente com a deposição dos mesmos, e o remodelamento do tecido. Por outro lado, animais nocaute do colágeno tipo VI, demonstram a expansão desenfreada dos adipócitos, sugerindo que esse tipo de colágeno possui um papel essencial em fornecer um "scaffold" (formato) para o tecido adiposo (Khan et al., 
2009). Em concordância com esses achados, em humanos, também é demonstrado o mesmo perfil de alterações; foi observado em indivíduos obesos resistentes à insulina, o aumento da expressão do COL 6 no tecido adiposo subcutâneo, em comparação com indivíduos magros (Spencer et al., 2010). Já em estudos in vitro, utilizando cultura de adipócitos imortalizados, e incubados sob alta concentração de glicose e insulina, houve alteração na composição da MEC resultando no aumento de laminina $\beta 1$, fibulina 1 e espondina 1, bem como a diminuição na MMP2 e TIMP2, indicando a relevância da MEC na modulação metabólica imposta ao tecido durante a diabetes associada à obesidade (Mariman e Wang, 2010).

Diferentemente da obesidade, na caquexia associada ao câncer, em que ocorre a diminuição do tecido adiposo em diversos depósitos, ao mesmo tempo à diminuição no tamanho dos adipócitos, e essas mudanças refletem na sua morfologia, e leva o adipócito a perder seu formato classicamente esférico, bem como há um acúmulo de fibrilas colágenas na MEC do tecido (Bing et al., 2006). A questão da importância da MEC para o tecido adiposo na vigência da caquexia ainda tem sido pouco estudada, e a fim de explorar mais essa questão nosso grupo de pesquisa recentemente publicou um estudo abordando o rearranjo do tecido adiposo na caquexia (Batista et al., 2016). Em acordo, nossos achados em pacientes com câncer gastrointestinal com caquexia demonstram maior intensidade em coloração específica para colágenos, em conjunto com maior recrutamento de macrófagos e linfócitos do tecido adiposo (Batista et al., 2016).

\subsection{Mecanismos do Remodelamento Tecidual no reparo de lesões à Fibrose Tecidual}

O remodelamento tecidual é um processo contínuo da MEC e essencial para o desenvolvimento embrionário e morfogênese dos tecidos, assim como no reparo tecidual na cicatrização de feridas. A desregulação na composição, estrutura e contratilidade da MEC pode contribuir para diversas doenças, como a fibrose (Gurtner et al., 2008).

A fibrose tecidual é o resultado de uma inflamação crônica contínua, que leva à persistente ativação dos mecanismos envolvidos na resposta de reparo tecidual, e portanto, induzindo o acúmulo excessivo de componentes da MEC, principalmente de colágeno e da fibronectina (Wynn e Ramalingam, 2012). 
Em um tecido epitelial saudável, ao sofrer uma lesão, as células epiteliais e/ou endoteliais iniciam uma cascata de sinalização através de mediadores inflamatórios a fim de formar uma barreira com coágulos de fibrina, e também a formação de uma MEC provisória (Wynn, 2007; Gurtner et al., 2008). A ativação de plaquetas e sua agregação promovem rapidamente um tampão na lesão e a hemostasia primária. A desgranulação das plaquetas auxilia a vasodilatação e a permeabilidade dos vasos sanguíneos, possibilitando maior recrutamento de células inflamatórias para o sítio da lesão, bem como dos miofibroblastos, das células endoteliais e de epiteliais, que promovem a secreção de metaloproteinases (MMPs), para facilitar esse processo (Wynn, 2007). Além disso, a síntese de fatores de crescimento, citocinas e quimiocinas estimula a proliferação e o recrutamento dessas células inflamatórias para a lesão, os macrófagos e neutrófilos, que respondem previamente fazem a eliminação dos debris teciduais, das células mortas e de organismos estranhos, além de contribuir para maior produção de fatores inflamatórios (Wynn, 2008). Essa produção aumentada dos fatores, em retorno, age como fatores mitogênicos para as células endoteliais, que proliferam e migram para o centro da lesão participando na formação de novos vasos sanguíneos. Em conjunto, ocorre a produção de fatores pró-fibróticos e fatores de crescimento, tais como: TGF $\beta$, IL13 e PDGF por linfócitos ativados, entre outras células, causando maior ativação de macrófagos e fibroblastos (Wynn, 2008). Os fibroblastos recrutados, também podem se diferenciar em miofibroblastos expressando $\alpha$ Smooth Actin ( $\alpha$-SMA, alfa actina de músculo liso), sendo estas células especializadas em sintetizar potencialmente componentes da MEC, com destaque para o colágeno tipo I (Ueha et al., 2012; Wynn e Ramalingam, 2012). Ambas as células migram sobre as fibras de fibrina para o centro da lesão promovendo sua contração, já os fibroblastos e miofibroblastos atuam em conjunto para produzir MEC, principalmente sob a forma de colágeno, formando a base da cicatriz. A deposição de colágeno é regulada por MMPs, e essas por seus inibidores, TIMPs, para que não ocorra uma deposição em excesso (Gurtner et al., 2008; Wynn, 2008). Após 2-3 semanas da lesão, todos os mecanismos ativados são diminuídos e cessam, e as células recrutadas, macrófagos e miofibroblastos sofrem apoptose, ou então migram para outro sítio, e a MEC se torna mais consistente e com ampla variedade de componentes (Gurtner et al., 2008; Wynn, 2008; Ueha et al., 2012; Wynn e Ramalingam, 2012). 
O equilíbrio na razão entre a síntese de MEC e sua degradação é o que resulta no remodelamento, entretanto, quando a nova síntese de colágeno por miofibroblastos excede a razão de degradação, o total de colágeno aumenta e resulta em deposição excessiva e na fibrose (Wynn, 2008). A ativação, proliferação e sobrevivência de miofibroblastos são controladas por uma gama de fatores solúveis tais como citocinas (IL1, TNFa, TGF $\beta$, IL13), fatores de crescimento (CTGF, PDGF) e fatores físicos presentes na MEC, tais como: fragmentos de ácido hialurônico, estresse mecânico e rigidez da matriz. Como mencionado acima, após um processo de reparo tecidual, os miofibroblastos são programados a sofrerem apoptose, todavia, a falha no mecanismo de resposta pode ocasionar em uma persistente ativação da mesma, bem como na resistência dessas células em sofrer apoptose em um sítio fibrótico (Wynn e Ramalingam, 2012). A figura 4 representa a visão geral dos mecanismos envolvidos no reparo tecidual e na fibrose já descritos acima.

Figura 4 - Visão geral dos Mecanismos envolvidos no reparo Tecidual e na Fibrose.

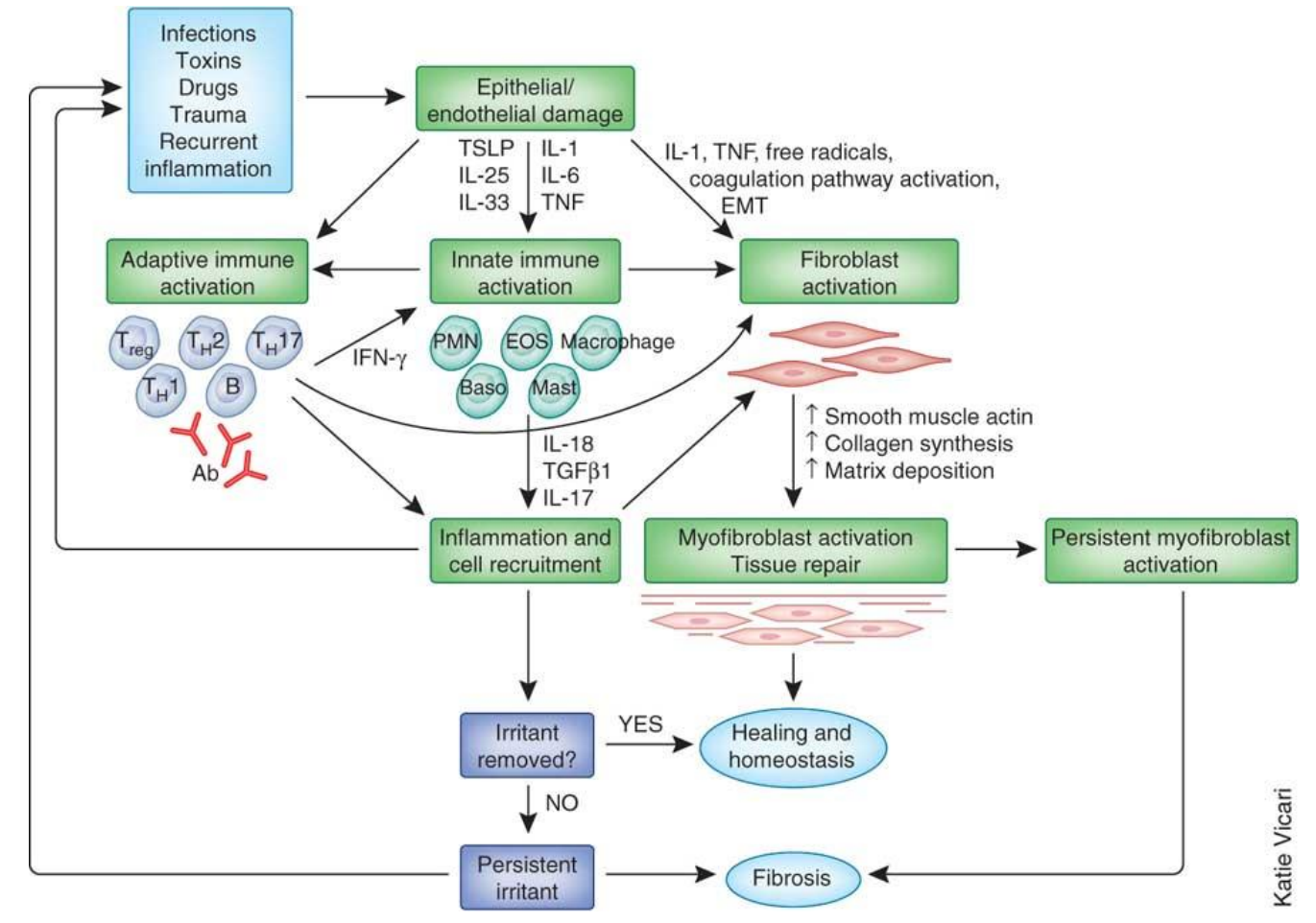

FONTE: ADAPTADO de (Wynn e Ramalingam, 2012).

A fibrose tecidual é um processo que pode ocorrer ao longo do tempo, mas resulta na disfunção do tecido afetado no processo, e consequentemente leva à falência do órgão, e por final, ao óbito do indivíduo (Wynn e Ramalingam, 2012). 
Entre as doenças fibróticas descritas estão: nefropatia diabética, cirrose hepática, fibrose pulmonar idiopática, artrite reumatóide, fribrosarcomas, arteriosclerose e esclerodermia. Até o presente momento, também não existe terapias efetivas no tratamento da fibrose tecidual (Leask e Abraham, 2004).

\subsection{Sinalização do Fator Transformante de Crescimento Beta TGF $\beta$}

O fator transformante de crescimento (TGF- $\beta$ ) é uma das citocinas chave envolvida no processo de fibrose; contudo para entendermos sua atuação na base molecular da fibrose, é necessário primeiramente compreendermos como ele regula diferentes processos fisiológicos, bem como sua sinalização desencadeia a expressão de genes que atuam em diferentes contextos celulares.

O TGF $\beta$ é uma citocina pleiotrópica, multifuncional e altamente conservada, que está envolvida no controle de importantes processos celulares tais como: embriogênese, diferenciação, crescimento celular, migração, apoptose e produção de matriz extracelular (Massagué e Chen, 2000). O TGF $\beta$ faz parte de uma superfamília que inclui mais de 30 proteínas em humanos, e seus ortólogos são encontrados nos organismos mais primitivos (Schmierer e Hill, 2007). Podemos encontrar duas subfamílias distintas, a subfamília do TGF $\beta$, activina e proteína NODAL, e a subfamília das proteínas ósseas morfogenéticas (BMPs); incluindo 03 isoformas do TGF $\beta, 04$ activinas de cadeia $\beta$, proteína nodal, 10 BMPs e 11 fatores de crescimento e diferenciação (GDFs). Todos esses ligantes são sintetizados com dois dímeros ligados por pontes dissulfídicas contendo pró-domínios, e a dimerização é necessária para ativação (Massagué e Chen, 2000; Schmierer e Hill, 2007; Huminiecki et al., 2009).

O TGF $\beta$ é encontrado na matriz extracelular em sua forma inativa, ligado ao complexo latente formado por uma proteína latente ligante de TGF $\beta$ (LTBP), e o propeptídeo de latência (LAP). O TGF $\beta$ é secretado como homodímero $(25 \mathrm{kDa}$ em cada monômero) associado ao LAP, e mesmo após sua clivagem no complexo de Golgi, esse peptídeo continua associado à molécula de TGF $\beta$ por ligação não convalente formando uma "jaqueta de força" em volta do TGF $\beta$, e prevenindo sua ligação aos receptores (Shi et al., 2011; Macias et al., 2015). Em adição, na maior parte das células, esse peptídeo é ainda, ligado convalentemente à LTBP. A ativação do TGF $\beta$ requer a ligação da seqüência RGD presente no pró-domínio com uma integrina $\alpha_{v}$, 
que irá exercer força mecânica graças à interação com o citoesqueleto de actina/miosina, e promover uma mudança conformacional no pró-domínio, liberando a "jaqueta de força" que envolve os monômeros (Shi e Massagué, 2003; Shi et al., 2011; Hinz, 2015; Macias et al., 2015). A figura 5 representa a estrutura latente do TGF $\beta$, a associação com o pró-peptídeo de latência, e sua ativação.

Figura 5 -Estrutura da Forma Latente do TGF $\beta$.

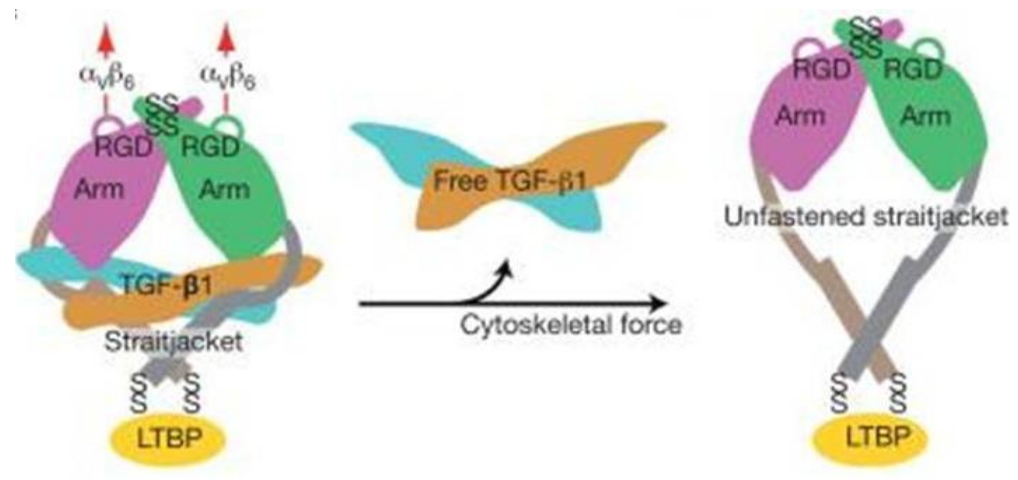

FONTE: ADAPTADO DE (Shi et al., 2011)

O TGF $\beta$ também pode ser ativado ou regulado, através da interação com outras moléculas da matriz. Por exemplo, no sistema plasminogênio/plasmina, a plasmina interage com o domínio serina do LAP, clivando o mesmo do complexo de latência, e ativando o TGF $\beta$. A glicoproteína trombospondina 1 (TSP1), também ativa o TGF $\beta$, a interação com a sequência RFK da sua molécula provoca uma mudança conformacional no LAP expondo o fator de crescimento (Khalil, 1999; Theocharis et al., 2016). Por outro lado, a atividade biológica do TGF $\beta$ é regulada também, por sua associação com proteoglicanos, como por exemplo, o decorin, que é capaz de sequestrar o TGF $\beta$ da matriz resultando na inativação da sua sinalização (Markmann et al., 2000).

A família do TGF $\beta$ é composta por 07 receptores tipo I, e 05 tipo II codificados no genoma humano, sendo que o próprio TGF $\beta$ exclusivamente se liga ao TGFBR1 (ALK5 ou TGFßRI) e ao TGFBR2 (TGF $\beta R I I)$ (Massagué, 2012). Podemos também, caracterizar os receptores tipo I, como receptores ativadores, enquanto que os receptores tipo II, como receptores propagadores de sinal (Massagué, 2012). A estrutura de ambos receptores é formada por um domínio extracelular rico em cisteína, um domínio transmembrana, e o domínio intracelular altamente conservado 
com atividade quinase serina/treonina sobre a superfície celular (Schmierer e Hill, 2007; Massagué, 2012).

O nome das proteínas mediadoras efetoras intracelularmente da via do TGF $\beta$, as SMADs deriva de uma contração dos nomes da Drosophilamelanogaster (Mad) e Caenorhabdits elegans (Sma), pois foram primeiramente identificadas nessas espécies (Massagué e Chen, 2000). As SMADs são constituídas estruturalmente de dois domínios globulares (MH1 e MH2) unidos por uma região ligante (Macias et al., 2015). A família de proteínas Smads é constituída por oito diferentes tipos de proteínas em mamíferos, que são agrupados em três sub-famílias: cinco tipos de SMADs ativadas por receptores (R-SMAD), SMAD mediadora comum (Co-Smad) e dois tipos de SMAD inibitórias (I-Smad) (Schmierer e Hill, 2007; Massagué, 2012). Entre as R-SMADs, as SMADs 2 e 3 são ativadas pelo TGF- $\beta$, enquanto as SMADs 1,5 e 8 são ativadas por ligantes de BMPs, membros da família TGF- $\beta$. A CoSmad (SMAD4) é aquela que medeia a formação de complexos com R-Smads, permitindo a translocação desses para o núcleo, onde podem interagir com fatores de transcrição. As I-Smads são compostas pela SMAD6 (via de sinalização ativada por BMPs) e a SMAD 7 (na via de sinalização ativadas do TGF- $\beta$ ), as quais ao se ligarem com o receptor TGF $\beta R I$ impedem o recrutamento ou a fosforilação das $R$ Smads (Schmierer e Hill, 2007; Massagué, 2012). Além disso, as I-SMADs também induzem a ligação do TGF $\beta R I$ com ubiquitina ligases E3, e consequentemente, sua ubiquitinação e a degradação do receptor no proteassoma (Horbelt et al., 2012). No estado basal as SMADs são retidas no citoplasma, no caso da SMAD2, isso é mediado por uma proteína ancoradora denominada SARA (Massagué, 2012). A SMAD2 interage com SARA ocorre na região que medeia a importação nuclear limitando seus movimentos. Contudo, a fosforilação no receptor, aumenta a afinidade de SMAD2 por SMAD4 e, também diminui a afinidade por SARA levando ao rápido acúmulo de SMAD2 no núcleo (Massagué, 2012). Além disso, as RSMADs e a SMAD4 possuem domínios em comum, denominados de domínios homólogos MAD, MH1 no N-terminal que é a região ligante ao DNA, e MH2 no Cterminal que possui interação com proteínas (Massagué, 2000; Schmierer e Hill, 2007; Horbelt et al., 2012; Macias et al., 2015).

A sinalização desencadeada pela via canônica do TGF- $\beta$ possui um papel importante na regulação transcricional de uma vasta gama de genes, que por sua vez estão envolvidos em diversos processos celulares. Como revisto por (Massagué, 
2012), o TGF $\beta$ inicia sua sinalização ao se ligar aos seus receptores de membrana do tipo I e II, e sua, ou de outros ligantes, promove a oligomerização entre os dímeros dos receptores tipo II com dímeros dos receptores do tipo I formando um complexo heterotetramérico. O receptor TGF $\beta R$ Il fosforila o domínio quinase do receptor TGFßRI ou ALK5 (Shi e Massagué, 2003; Massagué, 2012). Com o TGFBRI ativado, ocorre o recrutamento das SMADs reguladas pelo receptor ( $R$ SMADs): SMAD2 e SMAD3, que são fosforiladas em seus resíduos serina na região carboxi-terminal, o que aumenta a afinidade e o recrutamento de uma co-SMAD (SMAD4) mediadora (Shi e Massagué, 2003; Massagué, 2012). A oligomerização dessas SMADs leva à formação de um novo complexo homomérico, o qual é rapidamente translocado para núcleo (Shi e Massagué, 2003; Massagué, 2012). No núcleo, os complexos interagem com fatores transcricionais que agem como cofatores. Esses complexos R-SMAD/SMAD4 se ligam ao DNA através do domínio $\mathrm{MH1}$, e juntamente aos co-fatores (CBP, p300, ARC105 e Smif), estão diretamente envolvidos na regulação positiva ou negativa da transcrição de genes alvos (Shi e Massagué, 2003; Schmierer e Hill, 2007; Massagué, 2012). No entanto, quais genes alvos serão ativados pela sinalização das SMADs depende do microambiente em que a célula-alvo se encontra, e essa que decidirá especificamente o que necessita (Massagué, 2000). A figura 5 apresenta o esquema da sinalização da via canônica do TGF $\beta$ desencadeada por SMADs. 
Figura 5 - Sinalização da via do TGFß-SMADs em mamíferos.

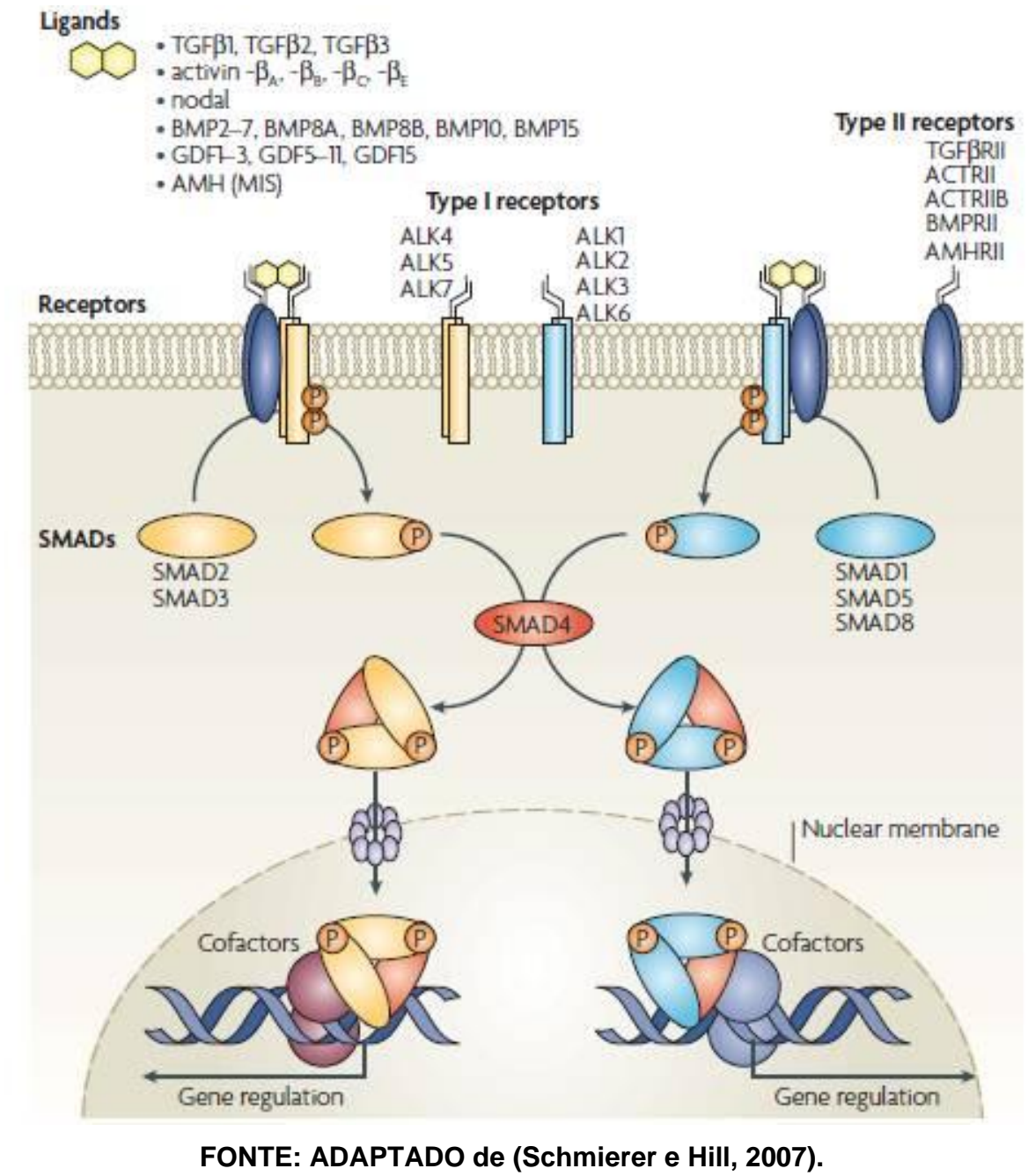

\subsection{TGF $\beta$ na Fibrose}

O TGF $\beta$ é uma das principais citocinas envolvida no mecanismo da fibrose. A produção aumentada de TGF $\beta$ é encontrada em muitas doenças fibróticas, tais como: cirrose hepática, hepatite crônica, glomerulonefrite, escledodermia, fibrose cárdica e pulmonar (Leask e Abraham, 2004).

Os níveis aumentados de TGF $\beta$ são encontrados em estágios iniciais da resposta na cicatrização de feridas derivados da secreção por macrófagos recrutados para o sítio da lesão, e agindo como citocina pró-fibrótica, mas podendo atuar como citocina antiinflamatória quando secretada por linfócitos CD4+ T reguladores (Wynn e Ramalingam, 2012). Concomitantemente, há a ativação do TGF $\beta$ nos fibroblastos, resultando no aumento da expressão de colágeno e fibronectina, e com isso, a diferenciação desses para miofibroblastos (Ueha et al., 2012). 
No entanto, foi observado em estudos in vitro com células epiteliais, que o estresse mecânico pode causar a desregulação na síntese de proteínas da MEC via TGF $\beta$. Enquanto que em fibroblastos, esses podem se tornar ativados expressando aSMA, ao utilizar um substrato mais rígido combinado com o estímulo por TGF $\beta$, e que essas células continuam expressando o fenótipo ativo mesmo após ser transferidas para um substrato mimetizando um tecido saudável (Flanders, 2004). Nesse contexto, foi observado em amostras de pulmão de pacientes com doença pulmonar cística, o aumento da expressão de TGF $\beta$ e SMAD2 fosforilada, em conjunto com o aumento de colágeno e a expressão de aSMA (Harris et al., 2013). Em modelos experimentais, tanto de irradiação resultando em fibrose dérmica, quanto na obstrução unilateral da uretra induzindo à fibrose renal intersticial, há redução na fibrose em camundongos deficientes para SMAD3, demonstrando a importância da via de sinalização do TGF $\beta$ durante o processo (Wynn, 2008). A diminuição da função do TGF $\beta$ através da deleção de SMAD3 em camundongos nocaute tem se demonstrado eficiente, uma vez que esses animais se tornam mais resistentes à fibrose. Na fibrose cardíaca causada pelo infarto do miocárdio, também é observado o aumento da expressão de TGF $\beta$, colágeno do tipo I, e de SMADs 2, 3 e 4, além da diminuição de SMAD 7 no centro do sítio da lesão, sendo que a contínua expressão dessas proteínas conduz a progressiva perda da função cardíaca em modelos animais (Flanders, 2004).

No tecido adiposo, o aumento da secreção de TGF $\beta$ é correlacionado com o aumento do conteúdo de gordura resultante da obesidade em humanos (Fain et al., 2005). A obesidade está associada com o remodelamento do tecido adiposo e fibrose. Em animais geneticamente modificados $o b / o b$ exibindo obesidade são encontrados o aumento da expressão gênica e proteica do TGF $\beta$ e da SMAD3 fosforilada. A fim de entender o papel da sinalização do TGF $\beta$ nesse tecido, o estudo ainda realizou a deleção de SMAD3, em animais submetidos à dieta hiperlipídica, resultando na prevenção da resistência à insulina e da expansão dos adipócitos, que estavam significantemente menores em relação aos animais controle (Tsurutani et al., 2011).

Em relação ao papel fibrótico do TGF $\beta$ na caquexia associada ao câncer, os estudos referem um membro da família do TGF, a activina, e seu papel no músculo (Mathew, 2011). Em um desses elegantes estudos, relata-se que o aumento da activina $A$, e de seu receptor ActRIIB induzem respostas deletérias, levando à atrofia 
muscular associada à elevada presença de ubiquitina ligases, diminuição da síntese proteica através da via de sinalização da Akt/mTOR, e resulta na fibrose do músculo (Chen et al., 2014). 


\section{JUSTIFICATIVA}

Com base no exposto, foi de nosso interesse compreender como a inflamação crônica causada pela caquexia associada ao câncer afeta 0 tecido adiposo, e como conseqüentemente, pode conduzir à fibrose. Em face da inexistência de tratamentos clínicos efetivos para a fibrose ou para caquexia, fica clara a relevância do tema. $O$ remodelamento tecidual pode levar a alterações na composição da MEC, sendo, no entanto, um processo passível de reversão; contudo, leva à falha funcional e progressiva do tecido, e conseqüentemente, à falência do órgão. O tecido adiposo é considerado um importante órgão endócrino, capaz de sintetizar uma ampla gama de fatores solúveis e citocinas. O fato é que a inflamação sistêmica afeta o tecido adiposo, e esse responde com sinalização humoral que exacerba o comprometimento estrutural e funcional do próprio tecido. A maior parte das evidências acerca do papel da MEC no tecido adiposo é pertinente à obesidade, sendo poucos os estudos relacionando alterações da MEC no quadro de caquexia. Sabendo da importância do tecido adiposo no controle dos diversos processos biológicos, e da sua importância na caquexia, pareceu-nos oportuno investigar profundamente o remodelamento tecidual, bem como o papel da via do TGF $\beta$ modulando o processo fibrótico nos pacientes caquéticos. 


\section{OBJETIVOS}

\subsection{Objetivo Geral}

O objetivo do presente trabalho foi investigar a expressão de genes e proteínas relacionadas à via de sinalização canônica do TGF $\beta$ no remodelamento do tecido adiposo branco subcutâneo na vigência da caquexia associada ao câncer em pacientes portadores de tumores no trato gastrointestinal.

\subsection{Objetivos Específicos}

Os objetivos específicos foram:

a) Avaliar os aspectos morfológicos e caracterizar o remodelamento do tecido adiposo subcutâneo.

b) Verificar se o remodelamento do tecido adiposo na caquexia associada ao câncer é modulado pela via de sinalização do TGFß, analisando a expressão das isoformas TGF $\beta 1$, TGF $\beta 2$, TGF $\beta 3$ no tecido, e nos adipócitos isolados.

c) Avaliar os efetores da via de sinalização canônica do TGFß e os receptores no tecido adiposo subcutâneo.

d) Avaliar a expressão de genes diretamente modulados pelo TGF $\beta$ no tecido adiposo.

e) Investigar a possível modulação dos fibroblastos do tecido adiposo durante o processo de remodelamento, analisando a expressão de genes e marcadores específicos a essas células. 


\section{MATERIAIS E MÉTODOS}

\subsection{Sujeitos da Pesquisa}

Todos os indivíduos participantes da pesquisa foram selecionados entre 2012-2015 no ambulatório de Clínica Médica Cirúrgica do Hospital Universitário (HU) da Universidade de São Paulo (USP).

Todos os procedimentos foram aprovados pelo Comitê de Ética em Pesquisa Envolvendo Seres Humanos do Instituto de Ciências Biomédicas da USP (1082 / CEP) e pelo Comitê de Ética em Seres Humanos do Hospital Universitário da USP (CEP 752/07).

A aceitação para participação no estudo foi obtida através da assinatura do termo de consentimento livre e esclarecido (TCLE) (ANEXO A), após a explicação detalhada por integrantes do grupo de pesquisa no momento da consulta, no ambulatório dos médicos participantes da pesquisa.

Foram previamente selecionados 212 indivíduos, homens e mulheres, com idade entre 18 e 80 anos, não havendo distinção de etnia, ou classe social pelos pesquisadores. Foram selecionados inicialmente, dois grupos de pacientes. $O$ primeiro, composto por pacientes com indicação cirúrgica para retirada de hérnia inguinal, epigástrica, umbilical ou incisional (controles). No segundo grupo, todos os pacientes foram diagnosticados previamente com câncer no sistema gastrointestinal. A proposta clínica para tratamento de tumores gastrointestinal inclui a remoção cirúrgica do tumor e o pós-tratamento de quimioterapia e radioterapia, ou o tratamento paliativo. Todos os diagnósticos foram obtidos através de exames clínicos, laboratoriais e/ ou de imagens (tomografia computadorizada). A confirmação do diagnóstico de câncer sucedeu o procedimento cirúrgico, através da análise patológica do tecido retirado, pelo Setor de Anatomia Patológica do HU.

Os tecidos foram coletados durante o procedimento cirúrgico, conforme detalhado na seção 5.3. Contudo, cabe salientarmos que todas as amostras experimentais foram obtidas exclusivamente para o uso da pesquisa e que a própria retirada das amostras não representou nenhum risco adicional ao paciente, ou causou maior dor física além do que o próprio já estava sendo submetido, bem como, não modificou a rotina médica, ou o tratamento pós-cirúrgico do paciente. 


\section{$\underline{\text { 5.1.1 Diagnóstico da Caquexia }}$}

Os critérios utilizados para o diagnóstico da caquexia estavam de acordo com (Evans et al., 2008). Para ser considerado caquético o indivíduo deveria ter apresentado perda de peso superior a $5 \%$ do seu peso corporal nos últimos 12 meses ou menos, ou o índice de massa corporal (IMC) IMC $<20,0 \mathrm{~kg} / \mathrm{m}^{2}$, adicionalmente a mais três dos seguintes critérios descritos por (Evans et al., 2008):

-Fadiga; definida como cansaço físico ou mental (aferida pelo questionário descrito abaixo);

-Anorexia; Ingestão alimentar limitada ou ainda a falta de apetite (aferida pelo questionário descrito abaixo);

-Alterações em parâmetros bioquímicos: a) níveis aumentados de marcadores inflamatórios: proteína C-reativa $>5,0 \mathrm{mg} / \mathrm{l}$, e IL6 $>4,0 \mathrm{pg} / \mathrm{ml}$; b) anemia ( $<12 \mathrm{~g} / \mathrm{dl})$; c) baixa albumina sérica $(3,2 \mathrm{~g} / \mathrm{dl})$.

Os dados obtidos através da aplicação de questionários de qualidade de vida EORTC QLC30 (ANEXO B) e anorexia FAACT/ESPEN (ANEXO C) foram utilizados para indicar a presença de fadiga e anorexia nos pacientes e avaliar a qualidade de vida dos mesmos.

\subsubsection{Critérios de Exclusão}

Os critérios de exclusão adotados previamente à seleção dos indivíduos foram: insuficiência hepática ou renal, AIDS, processos inflamatórios crônicos não relacionados à caquexia e, terapia anti-inflamatória crônica, e ainda, realização de tratamento de quimioterapia ou radioterapia, prévios à remoção cirúrgica do tumor.

Critérios de exclusão adicionais foram utilizados para garantir a consistência dos dados obtidos e a reprodutibilidade do estudo. Esses foram: inconsistência de dados obtidos nos questionários aplicados, amostras de tecido insuficientes para as análises ou a falta de amostra sanguínea do tecido correspondente que impedisse análises para confirmação dos grupos a qual o paciente pertencesse na pesquisa, pacientes obesos com IMC superior a $29,9 \mathrm{~kg} / \mathrm{m}^{2}$, pacientes do grupo controle (detalhados na seção 5.3) com evidência de inflamação ( $P C R>5 \mathrm{mg} / \mathrm{L}$ ) e pacientes com análises patológicas inconsistentes (por exemplo; pacientes com diagnóstico 
prévio de câncer, porém com análise patológica evidenciando um tecido não tumoral).

\subsection{Procedimentos Cirúrgicos e Obtenção de amostras}

Os procedimentos cirúrgicos no geral incluíam: herniorrafia abdominal, herniorrafia inguinal, colescistectomia, gastrectomia, vídeolaparoscopia e laparotomia exploratória.

Todos os procedimentos cirúrgicos ocorreram no centro cirúrgico do hospital, o qual era plenamente estruturado para a realização dos mesmos.

Após os pacientes receberem anestesia geral pelo médico anestesista, o médico cirurgião responsável iniciava o procedimento realizando a incisão na pele com lâmina de bisturi estéril na região abdominal, e a retirada do tecido adiposo subcutâneo com o auxílio de pinças e outras lâminas estéreis. O tecido adiposo subcutâneo foi retirado da região abdominal superior ao umbigo em todos os grupos, e não adjacente ao tecido tumoral, nos grupos câncer.

Aproximadamente 01 grama de tecido adiposo subcutâneo foi retirado pelo cirurgião responsável e imediatamente dividido com o bisturi e o auxílio de uma pinça cirúrgica sob uma bandeja. O material foi distribuído em criovials (cerca de 300- 400mg), e congelado em gelo seco e mantidos no freezer $-80^{\circ} \mathrm{C}$ para análises posteriores. O restante do material, (cerca de $400 \mathrm{mg}$ ), coletado foi dividido, e acondicionado em tubo cônico $(15 \mathrm{ml})$ contendo meio de cultura de células (descrito na secção 5.9), e também, em tubo contendo paraformaldeído 4\% (200 mg), para as análises histológicas.

\subsection{Desenho Experimental}

Seguindo os critérios de inclusão e exclusão, os participantes do estudo foram divididos em três grupos. O grupo CONTROLE; incluiu pacientes submetidos à remoção cirúrgica de hérnias umbilicais, inguinais, epigástricas e incisionais, ou pacientes submetidos à colescistectomia sem evidências de inflamação, como já descrito anteriormente, e de peso estável.

Os pacientes diagnosticados com câncer gastrointestinal foram divididos em dois grupos: grupo CÂNCER PESO ESTÁVEL (WSC) e o grupo CÂNCER com 
CAQUEXIA (CC). No primeiro grupo (WSC) foram inclusos pacientes com câncer gastrointestinal, porém sem perda de peso significativa $(<5 \%)$ nos últimos 06 meses. O grupo CC incluiu pacientes com câncer gastrointestinal e portadores da síndrome da caquexia. A figura 6 representa a distribuição dos grupos. No total, foram inclusos 59 pacientes no estudo.

Figura 6 - Desenho Experimental e distribuição dos sujeitos na seleção, inclusão e exclusão na pesquisa.

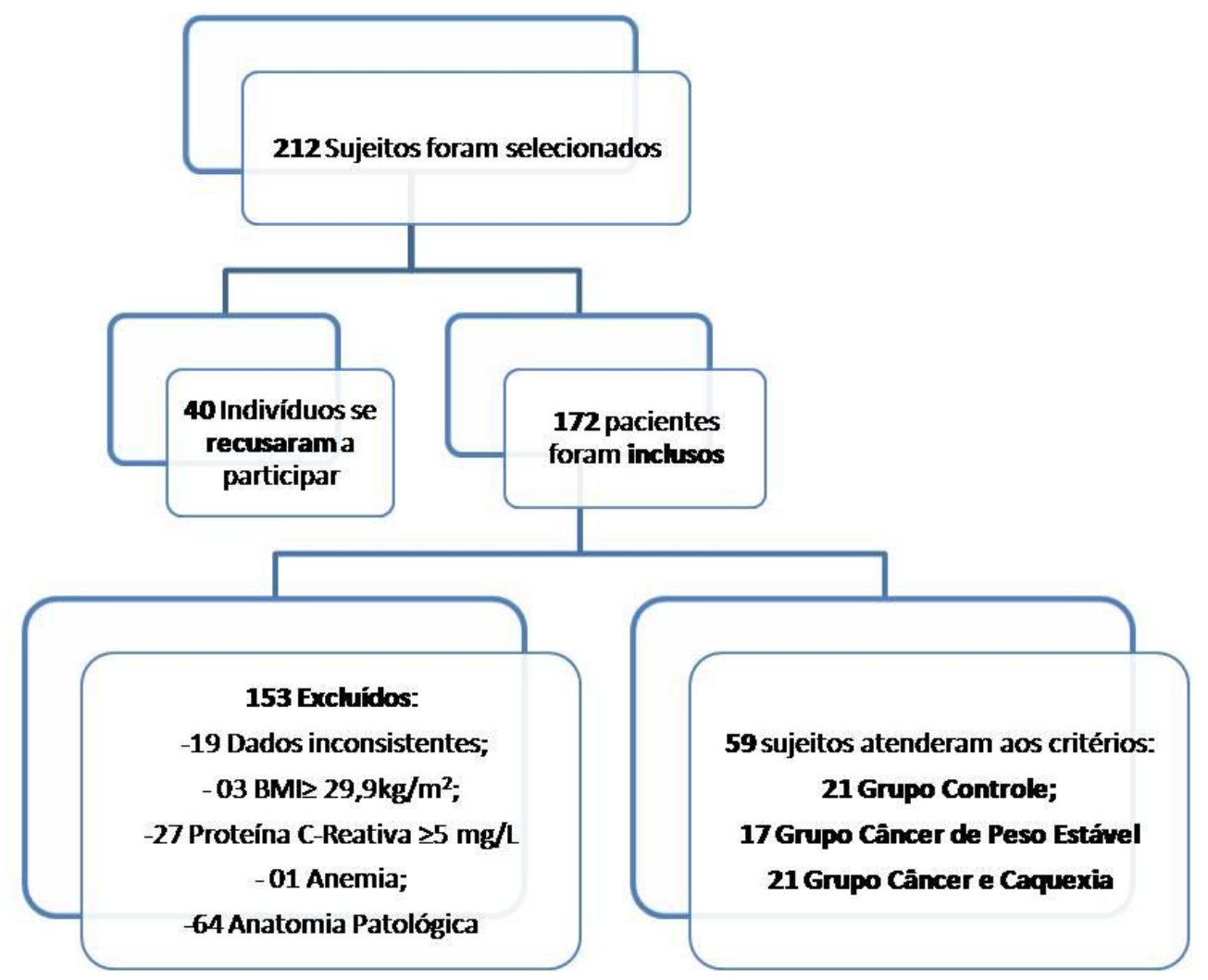

\subsection{Coleta Sanguínea}

As coletas sanguíneas foram realizadas previamente ao procedimento cirúrgico, no momento da internação do indivíduo no hospital. Foram coletados aproximadamente $20 \mathrm{ml}$ de sangue por um profissional da saúde autorizado, que foram colocados em tubos apropriados Vacuntainer contendo ou não ácido etilenodiamino tetra-acético (EDTA). As amostras foram centrifugadas a 3000 rotações por minuto durante 15 minutos, a $4{ }^{\circ} \mathrm{C}$, em centrífuga refrigerada (Hettich Zentrifugen, Alemanha). Após o período, o soro e o plasma foram aliquotados em tubos eppendorfs de $1,5 \mathrm{ml}$, e armazenados no freezer $-80^{\circ} \mathrm{C}$, para análises posteriores. 


\subsection{Análises Bioquímicas Sanguíneas}

Todas as análises foram realizadas em equipamento LABMAX@ 240 (Labtest Diagnóstica $S / A$ ), com sistema completamente automatizado pertencente ao Departamento de Alimentos e Nutrição Experimental da Faculdade de Ciências Farmacêuticas USP. Foram utilizados cerca de $1 \mathrm{ml}$ de soro, no total, para as seguintes análises: proteína C-reativa, albumina, hemoglobina, colesterol, triglicerídeos e HDL (Labtest Diagnóstica S/A).

\subsection{Microscopia de Luz e Análises Histológicas}

\subsubsection{Obtenção e Processamento dos Tecidos}

Os fragmentos cúbicos $\left(1 \mathrm{~cm}^{3}\right)$ de tecido adiposo subcutâneo obtidos durante o procedimento cirúrgico foram submersos em solução fixadora, contendo paraformaldeído $4 \%(\mathrm{p} / \mathrm{v})$ em tampão fosfato $(\mathrm{pH} 7.4)$ durante 24 horas, e então colocados em álcool etílico $70 \%$ por tempo indeterminado (não superior a 4 semanas). Os fragmentos dos tecidos foram processados, em que primeiramente foram desidratados em soluções de álcool etílico crescentes, seguidos da diafanização em xilol e inclusão em Paraplast (Paraplast X-TRA, SIGMA-ALDRICH), em estufa a $37^{\circ} \mathrm{C}$. Os fragmentos incluídos em Paraplast foram colocados em "Tissue Cassetes" (FISCHER SCIENTIFIC). Os cortes de 5-6 $\mu \mathrm{M}$ foram obtidos em micrótomo rotatório ( $R$ Jung-Heidelberg, LEICA MICROSYSTEMS HOLDING, Alemanha) e estendidos em lâminas silanizadas StarFrost ${ }^{\circledR}$ (Knittel Glass, WALDEMAR KNITTEL, Alemanha).

\subsubsection{Desparafinização e Hidratação}

Os cortes de tecido adiposo subcutâneo foram desparafinizados com banhos sucessivos de xilol, sendo 03 banhos de 5 a 6 minutos para colorações ou 03 banhos de 15 minutos cada para imunohistoquímica. Em seguida, foram hidratados com álcool etílico em soluções decrescentes de 100\%, 96\%, 70\% por 03- 05 minutos e então, lavados em água destilada. 


\subsubsection{Coloração por Hematoxilina de Harris e Eosina (HE)}

Após a desparafinização e hidratação dos materiais, descrita acima, as lâminas foram submersas em uma cuba histológica contendo hematoxilina de Harris previamente filtrada por 05 minutos. Em seguida, os cortes foram lavados em água corrente por 05 minutos, e então corados com eosina durante 1 minuto. Os cortes corados foram submersos na solução álcool etílico 95\% rapidamente, e durante 03 minutos em álcool etílico 100\%, e por último, em 03 banhos de xilol de 05 minutos cada. As lâminas foram montadas com Goma de Damar e cobertas com lamínulas de tamanho apropriado para cada corte (Fisherfinest Premium Cover Glass, FISHER SCIENTIFIC, Estados Unidos).

\subsubsection{Coloração por Picro Sirius Red}

A coloração com Picro Sirius Red foi utilizada para evidenciação das fibras colágenas. Após a desparafinização e hidratação, descrita acima, os cortes foram corados com DirectRed 80 (Sigma Aldrich, Spruce Street, St Louis, USA), previamente filtrado, durante 1 hora. Em seguida, os cortes corados foram submersos na solução álcool etílico $95 \%$ rapidamente e durante 3 minutos em álcool etílico 100\%, e por último em 03 banhos de xilol por 05 minutos cada. As lâminas foram então montadas com Goma de Damar e cobertas com lamínulas de tamanho apropriado para cada corte (Fisherfinest Premium Cover Glass, FISHER SCIENTIFIC, Estados Unidos).

\subsubsection{Coloração de Weigert}

A coloração com hematoxilina férrica de Weigert foi utilizada para detecção de fibras elásticas. Após a desparafinização, os cortes foram hidratados por 10 minutos em água destilada, e então corados com a hematoxilina férrica de Weigert durante 10 minutos seguidos por mais 10 minutos em água corrente. O corante Fucsinaresorcina foi utilizado durante 20 minutos, ou mais, dependendo do resultado na observação ao microscópio, em que as fibras elásticas deveriam aparecer coradas em preto. Lâminas com cortes de pele foram utilizadas no mesmo momento, como controle da coloração. Os cortes foram desidratados em álcool 95\%, 100\%, e então 
submersos em 03 banhos consecutivos de xilol. As lâminas foram montadas com Goma de Damar e cobertas com lamínulas de tamanho apropriado para cada corte (Fisherfinest Premium Cover Glass, FISHER SCIENTIFIC, Estados Unidos). Para a coloração de Weigert com uso de ácido oxálico, o material foi submetido a tratamento prévio a coloração com permanganato de potássio durante 10 minutos, seguidos de lavagem em água destilada por 1 minuto, e submersos em solução de ácido oxálico $3 \%$ durante 1 minuto, e novamente lavados em água destilada por 1 minuto.

\section{$\underline{\text { 5.6.6 Coloração de Verhoeff's Van-Gieson }}$}

A coloração com hematoxilina de Verhoefffoi utilizada para detecção de fibras elásticas. Após a desparafinização, os cortes foram hidratados por 5 minutos em água destilada, e então corados com a hematoxilina de Verhoeff's durante 15-30 minutos, até os cortes atingirem uma coloração negra, seguidos por mais 5 minutos em água corrente. A coloração foi diferenciada utilizando solução de Cloreto de Ferro $2 \%$ controlando a coloração pela observação no microscópio óptico. Em seguida, as lâminas foram lavadas em água corrente. Lâminas com cortes de pele foram utilizadas no mesmo momento, como controle da coloração. Os cortes passaram rapidamente em álcool 95\%, e tratados com solução de hipossulfito de sódio $5 \%(\mathrm{v} / \mathrm{v})$ durante 5 minutos seguidos de lavagem em água destilada por 5 minutos e água corrente durante 5 minutos. Os cortes foram desidratados em álcool $95 \%$, álcool 100\%, e então submersos em 03 banhos consecutivos de xilol. As lâminas foram montadas com Goma de Damar e cobertas com lamínulas de tamanho apropriado para cada corte (Fisherfinest Premium Cover Glass, FISHER SCIENTIFIC, Estados Unidos).

\subsubsection{Obtenção e Análise das Imagens}

Todas as imagens foram adquiridas utilizando microscópio óptico (Olympus, modelo BX51), com câmera acoplada (LG - CCD- modelo GC-415N-MD) e software ImagePro®Plus 5.2 (Media Cybernetics, Bethesda, Estados Unidos). Para representação dos resultados foram utilizadas imagens de todos os grupos 
montadas com o auxílio do Software Adobe Photoshop CS3, e, cabe salientarmos que não houve modificações ou aprimoramento virtual das imagens representadas.

\subsection{Expressão dos genes CCND1, CDC42, HIF1A, MYCC, SIRT1, SMAD2, SMAD3, SMAD4, RPL27, S100A4}

\subsubsection{Extração de RNA e Transcrição Reversa}

O RNA total foi extraído utilizando aproximadamente 350 a 500 mg de tecido adiposo subcutâneo armazenado no freezer $-80{ }^{\circ} \mathrm{C}$. As amostras foram homogeneizadas com $1 \mathrm{ml}$ de TRIzo|® Reagent, em tubos livres de RNAse eDNAse, e centrifugadas a 14000 RPM por 15 minutos a $4{ }^{\circ} \mathrm{C}$. Após o fracionamento das fases, foi descartada a camada superior de gordura "fat layer" e transferido para um novo tubo a camada sobrenadante contendo o RNA. O sobrenadante foi homogeneizado com $200 \mu \mathrm{l}$ de clorofórmio, incubado durante 2 minutos na temperatura ambiente, e então as amostras foram centrifugadas a 14000 RPM durante 10 minutos a $4^{\circ} \mathrm{C}$. A fase aquosa translúcida e limpa de resquícios do fenol foi transferida a um novo tubo livre de RNAse e DNAse. A precipitação do RNA ocorreu por adicionar e misturar vigorosamente, à fase aquosa, $500 \mu \mathrm{de}$ isopropanol $100 \%$, as amostras foram incubadas então à temperatura ambiente durante 10 minutos, e centrifugadas a 10000 RPM por 10 minutos, a $4{ }^{\circ} \mathrm{C}$. Após a centrifugação, o RNA pôde se tornar visível, em formato de pellet gelatinoso aderido à parede do tubo. Após a precipitação do RNA e sucedendo uma lavagem, descartou-se o sobrenadante do tubo e descartado, e então se adicionou $1 \mathrm{ml}$ de álcool etílico $75 \%$. A amostra foi agitada vigorosamente e centrifugada a 7500 RPM por 5 minutos, a $4{ }^{\circ} \mathrm{C}$. O sobrenadante foi novamente descartado e o RNA ressuspendido (20-50 $\mu \mathrm{l})$ em água ultrapura livre de RNAse e DNAse. A concentração do RNA total foi avaliada em espectrofotômetro Synergy ${ }^{\mathrm{TM}} \mathrm{H} 1$ (BIOTEK, Estados Unidos),sob comprimento de onda de $260 \mathrm{~nm}$.

O DNA complementar (cDNA) do RNA foi gerado utilizando High Capacity cDNA- Reverse Transcription Kit (Applied Biosystems, Thermo Scientific, Estados Unidos) e, segundo as recomendações do fabricante. Para tanto, foram usados $2 \mu \mathrm{g}$ de RNA por amostra em adicionadas $2 \mu \mathrm{l}$ de tampão de transcrição reversa, 0,8 $\mu \mathrm{l}$ de 25X dNTP a $100 \mathrm{nM}, 2 \mu \mathrm{l}$ de primer randômico 10X, $1 \mu$ l de transcriptase reversa 
MultiScribe $^{\mathrm{TM}}, 1 \mu \mathrm{l}$ de inibidor de RNAse completados com água ultrapura e livre de nucleases para o volume final de $10 \mu \mathrm{l}$ por amostra. A reação de transcrição reversa foi realizada em termociclador Vereti em ciclo único, composto pelos seguintes passos: a) $25^{\circ} \mathrm{C}$ por 10 minutos; b) $37^{\circ} \mathrm{C}$ por 120 minutos; c) $85^{\circ} \mathrm{C}$ por 5 minutos; d) $4{ }^{\circ} \mathrm{C}$ até a retirada das amostras do aparelho. As amostras foram armazenadas em freezer $-20^{\circ} \mathrm{C}$.

\subsubsection{Expressão Gênica}

A análise da expressão dos genes foi realizada utilizando FAST SYBR Green PCR Master Mix (Applied Biosystems, Foster City, Canadá) em aparelho QuantiStudio $^{\text {TM }} 12 \mathrm{~K}$ Flex Real Time PCR System (Applied Biosystems, Thermo Scientific, Estados Unidos) para a seqüência de primers (detalhados na Tabela 1), desenhadas conforme a seqüência descrita no banco de dados GenBank. A expressão gênica do gene alvo foi normalizada utilizando o gene de referência RPL27 (NM 000988.3). Os dados foram analisados com o método 2- $\Delta \Delta \mathrm{CT} \mathrm{e}$ expressos como a razão do gene normalizado para o gene alvo.

Tabela 1. Seqüência de Primers.

\begin{tabular}{llll} 
Gene & \multicolumn{2}{l}{ Número de Referência NCBI } & Sequência \\
\hline CCND1 & NM 053056.2 & Reverse & 5' AGC TTG TTC ACC AGG AGC AG 3' \\
& & Foward & 5'ACC TGG ATG CTG GAG GTC T 3' \\
\hline CDC42 & NM 001791.3 & Foward & 5' TCC TTT CTT GCT TGT TGG GAC T 3' \\
& & Reverse & 5' AGG CCT TTC TGT GTA AGT GCA 3' \\
\hline HIF1A & NM 001530.3 & Reverse & 5' AGG CCA TTT CTG TGT GTG TAA GC 3' \\
& & Foward & 5' CTC AGT TTG AAC TAA CTG GAC ACA 3' \\
\hline MYCC & NM 002467.4 & Reverse & 5' CCT CCT CAG AGT CGC TGCT 3' \\
& & Foward & 5' TCC ACC TCC AGC TTG TAC CT 3' \\
\hline RPL27 & NM. 000988.3 & Foward & 5' CCG AAA TGG GCA AGT TCA T 3' \\
& & Reverse & 5'CCA TCA TCA ATG TTC TTC ACG A 3' \\
\hline SIRT1 & NM 012238.4 & Reverse & 5' CCT AGG ACA TCG AGG AAC TAC C 3' \\
& & Foward & 5' CAG TGT CAT GGT TCC TTT GC 3'
\end{tabular}




\begin{tabular}{llll}
\hline SMAD 4 & NM 005359.5 & Reverse & 5' AAT CCA TTC TGC TGC TGT CC 3' \\
& & Foward & 5' CAC AAG TCA GCC TGC CAG TAT 3' \\
\hline SMAD2 & NM 001003652.3 & Reverse & 5' TGG AGA CGA CCA TCA AGA GA 3' \\
& & Foward & 5' AGC ACT TGC TCT GAA ATT TGG 3' \\
\hline SMAD3 & NM 005902.3 & Reverse & 5' AGG TTT GGA GAA CCT GCG TC 3' \\
& & Foward & 5' CTA CAG CCA TTC CAT CCC CG 3' \\
\hline S100A4 & NM 002961.2 & Reverse & 5' GTC CTT TCC CCC AAG AAG CTG 3' \\
& & Foward & 5' TCT TGG TTT GAT CCT GAC TGC T 3'
\end{tabular}

NM. Número de Referência no site National Center for Biotechnology Information, U.S. National Library of Medicine.

\subsection{Expressão Proteica}

\subsubsection{Reações de Imunohistoquímica}

Os cortes já desparafinizados $(6 \mu \mathrm{M})$ de tecido adiposo subcutâneo foram mantidos na incubadora a $37^{\circ} \mathrm{C}$ durante a noite anterior à realização do protocolo de imuno-histoquímica. Posteriormente, as lâminas foram hidratadas com PBS 0,05M à temperatura ambiente. $O$ processo de recuperação de antígeno foi realizado utilizando os seguintes tampões: $10 \mathrm{mM}$ de tampão de citrato $(\mathrm{pH} 6,0)$, ou tampão de Tris-EDTA $\left(\mathrm{pH} \mathrm{9,0)} \mathrm{em} \mathrm{panela} \mathrm{de} \mathrm{pressão} \mathrm{a} 95{ }^{\circ} \mathrm{C}\right.$ durante 20 minutos. A atividade da peroxidase endógena foi bloqueada em solução contendo metanol em0,3\% de peróxido de hidrogênio ( $/ v / v)$, sob proteção da luz. Todas as reações foram realizadas utilizando Histostain-Plus, kit de IHC, HRP ampla Spectrum ${ }^{\circledR}$ (Life Technologies, Thermo Scientific, Estados Unidos), seguindo as instruções do fabricante. Após a aplicação do substrato de bloqueio a partir do kit, os cortes foram incubados em câmara umidificada durante a noite $\left(4{ }^{\circ} \mathrm{C}\right)$ com os seguintes anticorpos primários: Anti-Collagen I rabbit monoclonal antibody [EPR7785] (1:100, Abcam), Anti-Collagen type III rabbit polyclonal antibody (1:100, Rockland Immunochemicals Inc), Anti-Collagen type VI rabbit polyclonal antibody (1:40, Millipore), Anti-Human Fibronectin mouse monoclonal antibody (1:50, Millipore), AntiAlpha Smooth Muscle Actin (1:100, Abcam) TGFB1 (V) rabbit polyclonal antibody (1:50, Santa Cruz Biotechnology) e Smad4 (B-8) mouse monoclonal antibody (1:100, Santa Cruz Biotechnology). O anticorpo secundário biotinilado, componente B do kit 
foi aplicado por 20 minutos. Os controles negativos foram obtidos com omissão do anticorpo primário. A atividade da peroxidase foi revelada com substrato IMMPACT ${ }^{\text {TM }}$ DAB (Vector Laboratories, Burlingame, CA, Estados Unidos). O substrato foi incubado por menos de 1 minuto, e sem luz incidente sobre as lâminas. A hematoxilina de Mayer foi utilizada para contracoloração da reação, e após a coloração a hematoxilina foi diferenciada utilizando solução saturada de carbonato de lítio (Merck Millipore). Foram utilizadas o total de 05 lâminas por grupo para cada anticorpo, somando ao controle negativo, aproximadamente 16 lâminas por reação.

\subsubsection{Reações de Imunofluorescência em cortes parafinizados}

Os cortes já desparafinizados $(6 \mu \mathrm{M})$ de tecido adiposo subcutâneo foram mantidos na incubadora a $37^{\circ} \mathrm{C}$ durante a noite anterior à realização do protocolo de imunohistoquímica. Posteriormente, as lâminas foram hidratadas com PBS $0,05 \mathrm{M}$ à temperatura ambiente. $O$ processo de recuperação de antígeno foi realizado utilizando os seguintes tampões: $10 \mathrm{mM}$ de tampão de citrato $(\mathrm{pH} \mathrm{6,0)}$, ou tampão de Tris-EDTA $\left(\mathrm{pH} \mathrm{9,0)} \mathrm{em} \mathrm{panela} \mathrm{de} \mathrm{pressão} \mathrm{a} 95{ }^{\circ} \mathrm{C}\right.$ durante 20 minutos. A atividade da peroxidase endógena foi bloqueada em solução com metanol: $0,3 \%$ de peróxido de hidrogênio ( $\mathrm{v} / \mathrm{v})$, sob proteção da luz. O bloqueio de sítios inespecíficos foi realizado utilizando soro normal de cabra a 10\% (Referência: $50197 Z$ Life Technologies, Thermo Scientific, Estados Unidos), adicionado a $1 \%$ de albumina em tampão fosfato $0,1 \mathrm{M}$ com $0,2 \%$ de TRITON X-100, durante 1 hora em temperatura ambiente. Os anticorpos primários: Smad2 (86F7) Rabbit mAb (1:400, Referência: \#3122, Cell Signalling); Smad2 (86F7) Rabbit mAb (1:50, Referência:\#3122, Cell Signalling); c-Myc (D3N8F) Rabbit mAb (1:400, Referência \#13987, Cell Signalling)foram incubados em câmara úmida durante a noite. A seguir, os anticorpos foram retirados, e os cortes foram lavados por três vezes, sendo a primeira em tampão fosfato $0,1 \mathrm{M}$ com $0,2 \%$ de TRITON X-100 durante 5 minutos, e as duas últimas utilizando somente tampão fosfato $0,1 \mathrm{M}$. $\mathrm{O}$ anticorpo secundário de cabra anti-coelhofoi incubado durante 1 hora; Secondary Antibody Alexa 546 (1:100, Thermo Fischer, Thermo Scientific, Estados Unidos) protegido da luz. As lâminas foram montadas utilizando meio de montagem com DAPI, ProLong® Gold Antifade Montant (Número de catálogo:P36931 Molecular Probes, Life Technologies, Thermo Scientific, Estados Unidos). 


\subsubsection{Western Blotting}

Aproximadamente $100 \mathrm{mg}$ de tecido adiposo foi homogeneizado com tampão de extração (100 mM de base de Trizma, pH 7,5, EDTA 10 mM, SDS a 10\%, fluoreto de sódio $100 \mathrm{mM}$, pirofosfato de sódio $10 \mathrm{mM}$, ortovanadato de sódio $10 \mathrm{mM}$ ). Após centrifugação a 12.000 rpm durante 40 minutos, $4{ }^{\circ} \mathrm{C}$. A concentração de proteína que quantificada pelo reagente de ensaio de Bradford (BioRad) e os lisados foram separados em géis de $10 \%$ de Bis-Tris com Tricina SDS e eletrotransferidas para membranas de PVDF (GE Healthcare). O bloqueio da membrana foi realizado com tampão Tris-salina (137 mM Cloreto de Sódio, $20 \mathrm{mM}$ Tris, $\mathrm{pH}$ 7,6) contendo 0,5\% de Tween®20 (v/v) e 5\% de leite desnatado durante 2 horas. Os anticorpos foram diluídos em tampão Tris-salina/0,5\% Tween $\AA 20$, $5 \%$ albumina bovina, e as membranas incubadas com os anticorpos durante a noite sob agitação orbital. Foram utilizados os seguintes anticorpos: TGFßRII (C16:sc220) (Santa Cruz Biotechnology) e TGF $\beta$ (Cell Signaling). A intensidade de sinal de cada proteína foi detectada utilizando ECL Clarity reagente para detecção de Western Blotting (BioRad), e as imagens foram obtidas no gerador de imagens LAS4000 (GE Healthcare). A densitometria das bandas foi obtida com auxílio do software Image $\mathrm{J}$ (https://imagej.nih.gov/ij/index.html).

\subsubsection{Expressão das proteínas do tecido adiposo, adipócitos e plasma utilizando a tecnologia Luminex ${ }^{\circledR}$}

Aproximadamente 100-200 mg de tecido adiposo subcutâneo de cada biópsia foram homogeneizados em $300 \mu$ de tampão de extração RIPA (base Tris $10 \mathrm{mM}$, EDTA a 0,01 mM, 0,1 mM de cloreto de sódio e 1\% de Triton®X-100) contendo um tablete (1 comprimido a cada $50 \mathrm{~mL}$ de tampão de extração) de inibidor de protease:cOmplete Protease Inhibitor Cocktail Tablets in EASYpacks (Roche Diagnostics) em rotor homogeneizador. Os adipócitos isolados foram homogeneizados com $150 \mu \mathrm{L}$ de tampão de extração, descrito acima. Os homogenatos foramcentrifugados a 14.000 RPM durante 40 minutos a $4{ }^{\circ} \mathrm{C}$ e camada de gordura "fat layer" foi descartada. O sobrenadante foi coletado e armazenado em alíquotas a $-80^{\circ} \mathrm{C}$. O ensaio de citocinas Human Magnetic Painel Bead Milliplex® MAP (HCYTMAG-60K-PX29, Merck Millipore), e Multi-espécies TGF 
3 plex Human Magnetic Painel Bead Milliplex® MAP (TGFBMAG-64K-03, Merck Millipore) foram utilizados. Antes do ensaio, todas as amostras foram centrifugadas para remover os detritos. Para o ensaio de TGF, todas as amostras foram acidificadas com $\mathrm{HCl} 1 \mathrm{~N}$, após a centrifugação. Todos os padrões de trabalho foram submetidos a diluições em série, após a reconstituição da solução padrão do kit. No ensaio das amostras de plasma, os padrões foram diluídos em uma matriz específica fornecida pelo fabricante. O imunoensaio consistiu em adição à placa de $25 \mu \mathrm{l}$ de beads de MagPlex® adicionadas a $25 \mu \mathrm{l}$ do sobrenadante das amostras ou $25 \mu \mathrm{l}$ dos padrões apropriados em cada poço seguido por 2 horas de incubação num agitador de placas à temperatura ambiente. Após lavagem da placa, o anticorpo de detecção foi adicionado ao ensaio e incubado durante 1 hora em um agitador de placas. A Estreptavidina-ficoeritina foi utilizada para detectar a intensidade repórter fluorescente de cada microesfera emite quando vinculada a amostra. $O$ equipamento Luminex $200^{\mathrm{TM}}$ com sistema de tecnologia $\mathrm{xMAP} \circledast$ e software de aquisição xPONENT® foram utilizado para capturar a detecção de fluorescência presente em cada amostra na placa de 96 poços. O software MILLIPLEX® Analyst 5.1 foi utilizado para integrar a aquisição dos dados obtidos com a análise dos mesmos.

\subsection{Processamento e Isolamento de Células do Tecido Adiposo}

\section{$\underline{\text { 5.9.1 Isolamento de Adipócitos }}$}

O isolamento de adipócitos foi realizado, de acordo com o método descrito por Rodbell adaptado (Rodbell, 1964). As amostras coletadas no centro cirúrgico foram colocadas em tubo cônico estéril contendo $5 \mathrm{ml}$ de Dulbecco Modified Eagle Medium (DMEM). Em fluxo laminar, os fragmentos de tecido adiposo foram obtidos com o auxílio de uma tesoura e colocados em um novo tubo cônico contendo $5 \mathrm{ml}$ de DMEM adicionados a $615 \mathrm{U} / \mathrm{ml}$ de colagenase tipo IV, e incubados durante 60 minutos em banho seco a $37^{\circ} \mathrm{C}$ com agitação orbital. Após a dissociação do tecido, esse foi filtrado em peneira para separar o tecido que não foi digerido, e colocados em novo tubo cônico, então foram adicionados $5 \mathrm{ml}$ de meio DMEM novo e centrifugados durante 10 minutos a 1200 RPM. Os adipócitos foram coletados na fase sobrenadante "fat layer", e transferidos para novos eppendorfs contendo soro 
fetal bovino com $5 \%$ de dimetilsulfóxido (SIGMA), e então congelados no $-20{ }^{\circ} \mathrm{C}$, passando para $-80^{\circ} \mathrm{C}$ e armazenados em nitrogênio líquido $\left( \pm-197^{\circ} \mathrm{C}\right)$, para análises posteriores.

\subsubsection{Explantes Ex-Vivo e Cultura de Fibroblastos do Tecido Adiposo}

Os fragmentos de tecido adiposo subcutâneo foram coletados durante 0 procedimento cirúrgico e armazenados em tubo cônico de $15 \mathrm{ml}$ estéril contendo $5 \mathrm{ml}$ de meio de cultura Dulbecco Modified Eagle Medium(DMEM)/Nutriente F-12 (Thermo Scientific, Life Technologies, EUA) suplementado com: $20 \%$ de soro fetal bovino de origem da América do Sul (Gibco®), aminoácidos não- essenciais MEM (Gibco®), L-Glutamina $200 \mathrm{mM}$ (Gibco®), $5 \mu \mathrm{g} / \mathrm{ml}$ de fungizona (Amphotericina B) de $250 \mu \mathrm{g} / \mathrm{ml}$ (Gibco®), $200 \mathrm{U} / \mathrm{mL} / 200 \mathrm{~g} / \mathrm{ml}$ de estreptomicina-Penincilina com 10.000 unidades $/ \mathrm{ml}$ de Penincilina e $10.000 \mu \mathrm{g} / \mathrm{ml}$ de estreptomicina (Gibco®). No fluxo laminar, os fragmentos de tecido adiposo foram cortados em pequenos fragmentos com tesoura estéril, e distribuídos em placas de cultura de células NUNC 35×10mm, com auxílio de pinça cirúrgica estéril, as quais possuíam $500 \mu \mathrm{L}$ do mesmo meio de cultura DMEM/F12 suplementado, já descrito acima. A troca de meio foi realizada a cada 2 dias, e os explantes foram mantidos em incubadora a $37{ }^{\circ} \mathrm{C}$, com $8 \%$ de $\mathrm{CO}_{2}$ em torno de 7-12 dias até que os fibroblastos migrassem do tecido e aderissem às placas. Após esse período, os explantes foram retirados das placas e as células mantidas em cultura até atingir $50-60 \%$ de confluência. Os fibroblastos foram cultivados durante 2-3 semanas, e todos os experimentos foram realizados utilizando as células após 2-6 passagens. Todos os reagentes utilizados foram da Life Technologies (Thermo Scientific, Estados Unidos).

\subsubsection{Análise de Imunofluorescência em células isoladas}

Os fibroblastos foram plaqueados $1 \times 10^{4}$ por poço, contendo 1 lâminula de $13 \mathrm{~mm}$ previamente limpa e esterilizada, por 24 horas. Após o período, as células foram fixadas durante 30 minutos em paraformaldeído a $4 \%$ em tampão fosfato $0,1 \mathrm{M}$ $(\mathrm{pH} 7,4)$ preparado no momento do experimento e aquecido a $37^{\circ} \mathrm{C}$. Em seguida, as células foram permeabilizadas durante 20 minutos com tampão fosfato $0,1 \mathrm{M}$ com $0,2 \%$ de X-TRITON e incubadas com Vimentin XP® Rabbit mAb Alexa Fluor ${ }^{\circledR} 488$ 
Conjugate (Cell Signaling Technology, Estados Unidos). A marcação com F-actina foi feita utilizando-se Rodamina Phalloindin (Thermo Scientific, Life Technologies Inc, Estados Unidos). As lâminas foram montadas usando ProLong® Gold Antifade Mountant with Dapi (Molecular Probes, Thermo Scientific, Life Technologies Inc, Estados Unidos), com a presença de Dapi para marcação dos núcleos.

\section{$\underline{5.9 .4 \text { Viabilidade celular }}$}

Foram plaqueadas $2 \times 10^{3}$ células por welle incubadas com Hoechst 33342 corante (Thermo Scientific, Life Technologies Inc, EUA) durante 30 minutos. As células foram cultivadas durante 24,48 e 72 horas e imagens foram obtidas e analisadas com o CELL Analyser IN 2200 Imaging System (GE Healthcare Life Sciences, EUA).

\subsubsection{Ensaio de Migração}

Os ensaios de migração foram realizados com o sistema de TRANSWELL® de Corning (Corning Inc, EUA). Foi realizado o coating com fibronectina com 0,25 ug / $\mathrm{ml}$ na superfície da placa de cultura durante 1 hora a $37 \stackrel{\circ}{\circ}$. Foram plaqueadas 2 $\times 10^{4}$ em cada inserto contendo meio de cultura durante 6 horas, e então fixadas com paraformaldeído a $4 \%$. O violeta de cristal foi usado para coloração das células presentes nas membranas. $O$ índice de migração representa o número de células plaqueadas pelo número de células que migraram e aderiram à membrana, a contagem foi realizada Imagem ${ }^{\circledR P}$ Pro-Plus (Imagem ${ }^{\circledR}$ Pro-Plus versão 6.0 para Windows, Media Cybernetics Inc, EUA).

\subsection{Estatística}

Os dados de caracterização dos grupos foram expressos como média e desvio padrão. Utilizou-se Análise de Variância (ANOVA) um fator (grupos) e, quando necessário, seguida do pós-teste de Tukey. Os dados, em geral, foram expressos como mediana [1‥ quartil; $3^{\circ}$. quartil]. Os grupos foram comparados empregando-se o teste de Kruskal-Wallis, seguido, quando necessário, pelo pósteste de Dunn. O coeficiente de correlação de Spearman foi obtido para avaliar a 
relação linear entre as variáveis de interesse. A análise estatística foi realizada com o auxílio do software GraphPad PRISM (GraphPad Prism versão 5.00 para Windows, GraphPad Software, San Diego, Califórnia, EUA,www.graphpad.com) e Statgraphics ${ }^{\circledR}$ Centurion XVI versão 2.16.04, Statpoint Technologies, Inc. Warrenton, Virginia. O nível de significância adotado foi $p<0,05$. Os procedimentos estatísticos foram realizados com o auxílio da estatística Rosana Prisco do Setor de Estatística do Instituto de Ciências Biomédicas da USP. 


\section{RESULTADOS}

\subsection{Características Gerais dos Grupos de Estudo e Parâmetros Clínicos}

\subsubsection{Caracterização dos grupos}

As características dos grupos do presente estudo estão apresentadas na Tabela 2. No total, 59 pacientes fizeram parte do estudo, e foram distribuídos de acordo com a classificação adequada, previamente descrita na seção 5.1-5.3. Dessa forma, 21 pacientes foram inclusos no grupo controle e no grupo $C C$, e 17 no grupo WSC. Todos os pacientes apresentaram idade e altura semelhantes. A massa corporal prévia ao estudo (6 a 12 meses), informada pelos pacientes, não apresentou alterações significativas entre os grupos. A massa corporal atual que foi aferida no momento da internação de cada paciente, também não demonstrou diferenças.

Tabela 2 -Caracterização dos grupos de estudo.

\begin{tabular}{lcccc}
\hline & Controle & WSC & CC & $\boldsymbol{P}$ \\
\hline $\mathbf{N}$ & 21 & 17 & 21 & \\
Homem/Mulher & $16 / 5$ & $9 / 8$ & $13 / 8$ & \\
Altura (m) & $1,65 \pm 0,09$ & $1,62 \pm 0,09$ & $1,63 \pm 0,1$ & 0,6735 \\
Idade (anos) & $54,10 \pm 14,89$ & $62,13 \pm 11,78$ & $63,00 \pm 11,0$ & 0,0642 \\
Massa Corporal Prévia (Kg) & $71,43 \pm 13,32$ & $73,50 \pm 13,28$ & $73,78 \pm 13,86$ & 0,8431 \\
Massa Corporal Atual (Kg) & $71,43 \pm 13,32$ & $69,28 \pm 12,19$ & $63,62 \pm 12,90$ & 0,1577 \\
$\Delta$ Massa Corporal(Kg) & $0,00[0,00 ; 0,00]$ & $0,00[-7,2 ; 0,0]$ & $-8,0[-12,50 ;-7,0]$ & $\mathrm{P}<0,0001^{*}$ \\
$\Delta$ Massa Corporal (\%) & $0 \%$ & $4 \%$ & $14 \%$ & \\
IMC (Kg/m2) & $25,82 \pm 3,27$ & $25,79 \pm 4,62$ & $23,68 \pm 3,49$ & 0,1558 \\
\hline
\end{tabular}

Dados como média e \pm desvio padrão. ${ }^{*} p<0,0001$ CC vs C; CC vs WSC. ${ }^{1}$ Kruskal-Wallis; Dados como mediana e $1^{\text {st }} ; 3^{\text {st }}$ quartil.

Para calcular a perda de peso de cada paciente foi empregado o delta de variação de massa corporal, a partir da subtração de massa corporal prévia ao início do estudo da massa corporal atual. Houve acentuada perda de peso corporal no grupo CC (-8,0 [-12,5;-7,0]), resultando em uma variação de $14 \%$. Os pacientes com câncer apresentaram também, variação no peso, no entanto esta foi inferior a 4\%.Não houve variação para os pacientes controles. O Índice de Massa Corporal (IMC) não demonstrou diferença significativa entre os grupos. Apesar de o consenso 
indicar a média $<20 \mathrm{~kg} / \mathrm{m}^{2}$ para os pacientes caquéticos, o grupo CC apresentou uma média maior $(23,68 \pm 3,49)$. Assim, esse valor talvez deva ser re-discutido em esforços de consensos futuros, ao ponto que a média de IMC da população vem aumentando nos últimos anos.

\subsubsection{Parâmetros bioquímicos e clínicos}

Para determinarmos as características dos pacientes e, em especial caracterizar o grupo câncer e caquexia, aferimos os níveis de hemoglobina, albumina, proteína C-Reativa (PCR) (Figura 7). Além disso, a razão entre a PCR, e albumina foi empregada, como ferramenta adicional no diagnóstico de caquexia. Os resultados demonstram que a hemoglobina estava reduzida em ambos os grupos de pacientes com câncer, em relação ao controle. No grupo CC, os níveis estavam menores que $12 \mathrm{~g} / \mathrm{dL}$, indicando a presença de anemia nos pacientes caquéticos. A concentração de albumina estava reduzida somente no grupo câncer e caquexia $(3,93[2,75 ; 4,58])$. Já a PCR mostrou-se significantemente aumentada nos pacientes caquéticos $(11,80[8,3 ; 13,0] \mathrm{mg} / \mathrm{L})$, em relação ao grupo controle e WSC $(p<0,0001)$, evidenciando a presença de inflamação sistêmica no grupo câncer e caquexia. A razão entre PCR /albumina demonstrou aumento no grupo CC, em comparação aos demais grupos. Dessa forma, essa razão parece ser eficaz para ser utilizada como um parâmetro adicional no diagnóstico da caquexia.

A concentração de colesterol e triglicérides foi semelhante entre os grupos. No entanto, houve uma tendência $(p<0,06)$ para a diferença na concentração da lipoproteína de densidade alta (HDL), cabe relatarmos ainda,que os valores para os pacientes caquéticos estavam abaixo de $40 \mathrm{mg} / \mathrm{dL}$. As enzimas hepáticas alanina aminotransferase e aspartato aminotransferase que podem indicar dano hepático, também não sofreram alterações de concentração entre os grupos (Tabela 3). 
Tabela 3 -Parâmetros Clínicos: Perfil Lipídico e Enzimas Hepáticas

\begin{tabular}{lcccc}
\hline & Controle & WSC & CC & $\boldsymbol{P}$ \\
\hline Colesterol (mg/dL) & $197,0[161,0 ; 213,0]$ & $190,5[164,8 ; 232,0]$ & $153,5[125,0 ; 245,5]$ & 0,335 \\
TAG (mg/dL) & $162,0[90,0 ; 207]$ & $146,0[78,0 ; 193,0]$ & $98,0[72,25 ; 128,3]$ & 0,268 \\
HDL (mg/dL) & $36,00[31,50 ; 40,50]$ & $45,00[28,50 ; 52,50]$ & $31,50[21,75 ; 37,0]$ & 0,060 \\
ALT (U/L) & $20,00[16,25 ; 23,0]$ & $15,00[9,0 ; 19,0]$ & $18,00[8,5 ; 21,5]$ & 0,109 \\
AST (U/L) & $24,0[18,75 ; 30,25]$ & $25,0[20,0 ; 32,0]$ & $22,0[15,0 ; 38,5]$ & 0,757 \\
\hline
\end{tabular}

Dados como mediana e $1^{\text {st }} ; 3^{\text {st }}$ quartil. TAG: triglicérides; HDL: Lipoproteína de alta densidade; ALT: alanina aminotransferase; AST: aspartato aminotransferase.

Figura 7 -Parâmetros Clínicos e da Caracterização dos grupos.

A

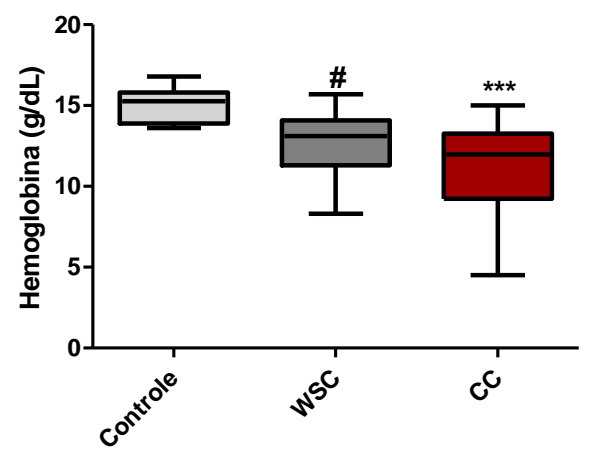

C

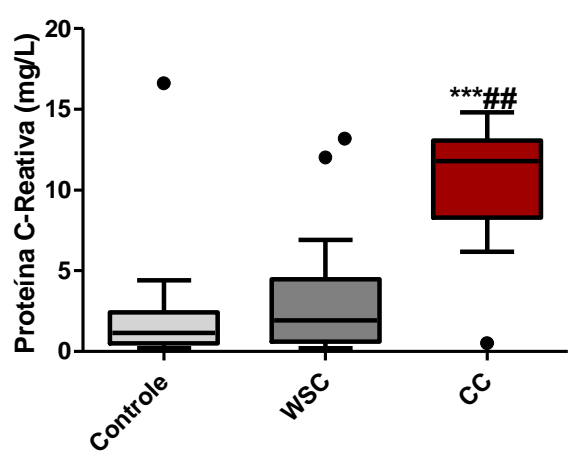

B

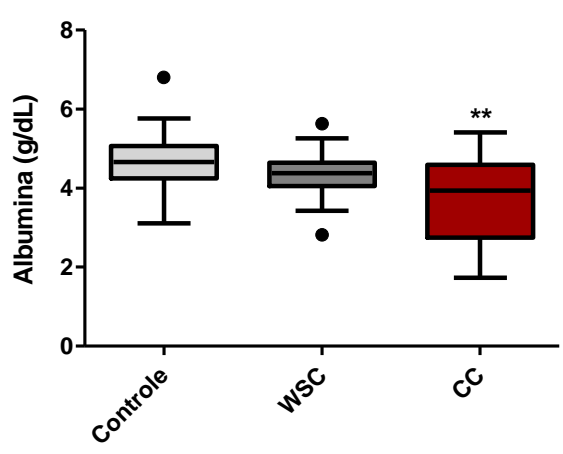

D

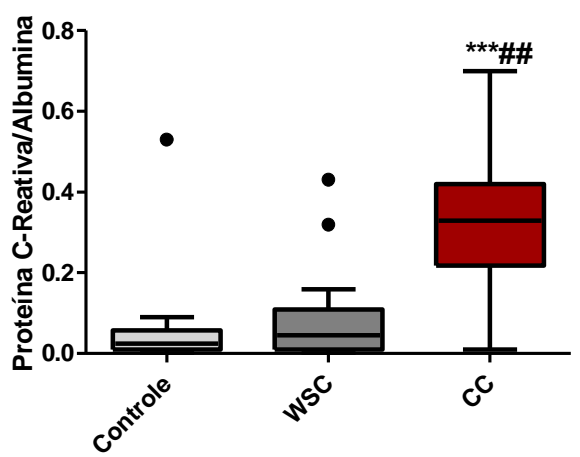

Figura 7 - Parâmetros Clínicos e da Caracterização dos grupos. A. Hemoglobina; B. Albumina; C. Proteína C-Reativa; D. Razão da Proteína C-Reativa por Albumina. Controle $(n=20)$; WSC $(n=16)$; CC $(n=20)$. Dados expressos como mediana, $1^{\text {st }}$ e $3^{\text {st }}$ quartil. ${ }^{* *} p<0,009$ CC vs Controle $;{ }^{* * *} p<0,0001 \mathrm{CC}$ vs Controle; \#p<0,05 WSC vs Controle; \# $\mathrm{p}<0,0001$ WSC vs Controle.

Uma das características clínicas da caquexia é a redução na qualidade de vida do paciente, que o impossibilita de realizar atividades diárias básicas, tais como 
sentar ou levantar. Os resultados do questionário QLQC30 (Figura 8), que afere uma escala funcional e de qualidade de vida, demonstraram que todos os pacientes com câncer estavam com esse parâmetro comprometido em relação ao grupo controle; contudo, no grupo câncer e caquexia houve maior agravamento no score ( $p>0,0001$ ), em relação ao grupo controle. Além disso, no grupo $\mathrm{CC}$, de $30 \%$ dos pacientes foram a óbito, enquanto que para WSC, apenas $16 \%$ não sobreviveram em um intervalo médio de 35 dias e máximo de 5 meses, após o procedimento cirúrgico.

Figura 8 - Qualidade de Vida dos Pacientes.

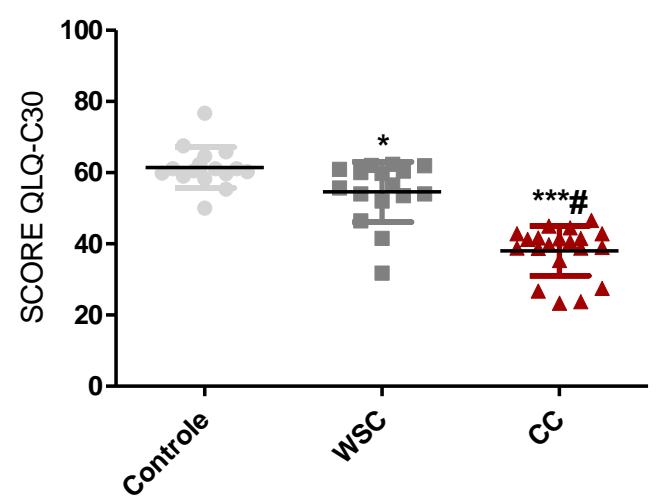

Figura 8 - Qualidade de Vida dos Pacientes pelo Score do questionário QLQC30. Controle $(n=16)$, WSC ( $n=16), C C(n=20)$. Dados expressos como média e desvio padrão. ${ }^{*} p<0,05$ WSC vs Controle ${ }^{* * *} p<0,0001$ CC vs Controle \# $p<0,05$ CC vs WSC.

\subsection{Características do Tecido Adiposo na Caquexia associada ao câncer}

\subsubsection{Análises Morfológicas e Morfométricas do Tecido Adiposo}

Com a finalidade de investigar os aspectos do tecido adiposo subcutâneo na caquexia associada ao câncer, e se essas são exclusivas à síndrome, foi realizada primeiramente, a caracterização morfológica e as análises morfométricas à microscopia de luz, utilizando-se a coloração por hematoxilina e eosina. As imagens representativas dos grupos de estudo, e as análises estão ilustradas na Figura 9. A morfologia do tecido adiposo encontra-se marcadamente alterada no grupo $\mathrm{CC}$, em comparação com os outros grupos. Podemos notar, no grupo Controle, a morfologia característica do tecido adiposo, com os adipócitos esféricos e a presença de uma matriz extracelular entre os adipócitos extremamente delicada. No grupo WSC, os 
adipócitos eram esféricos e de diâmetro semelhante ao Controle, havendo um pequeno acúmulo de MEC em relação ao controle, observável apenas em algumas áreas. No entanto, no grupo $\mathrm{CC}$, nota-se a presença de adipócitos menores, e poligonais, e a presença de outros tipos celulares entre os adipócitos. Além disso, há o acúmulo em grandes áreas de fibras do tecido conjuntivo. As análises morfométricas demonstraram a diminuição dos adipócitos dos pacientes caquéticos em relação ao grupo câncer de peso estável. As medidas de área, diâmetro médio e perímetro do grupo $\mathrm{CC}$ foram significantemente reduzidas, apenas em relação ao grupo WSC $(p<0,05)$. Em conjunto, essas características indicam a possibilidade do remodelamento tecidual. 
Figura 9 - Aspectos Morfológicos e Morfométricos do Tecido Adiposo Subcutâneo na Caquexia Associada ao Câncer.

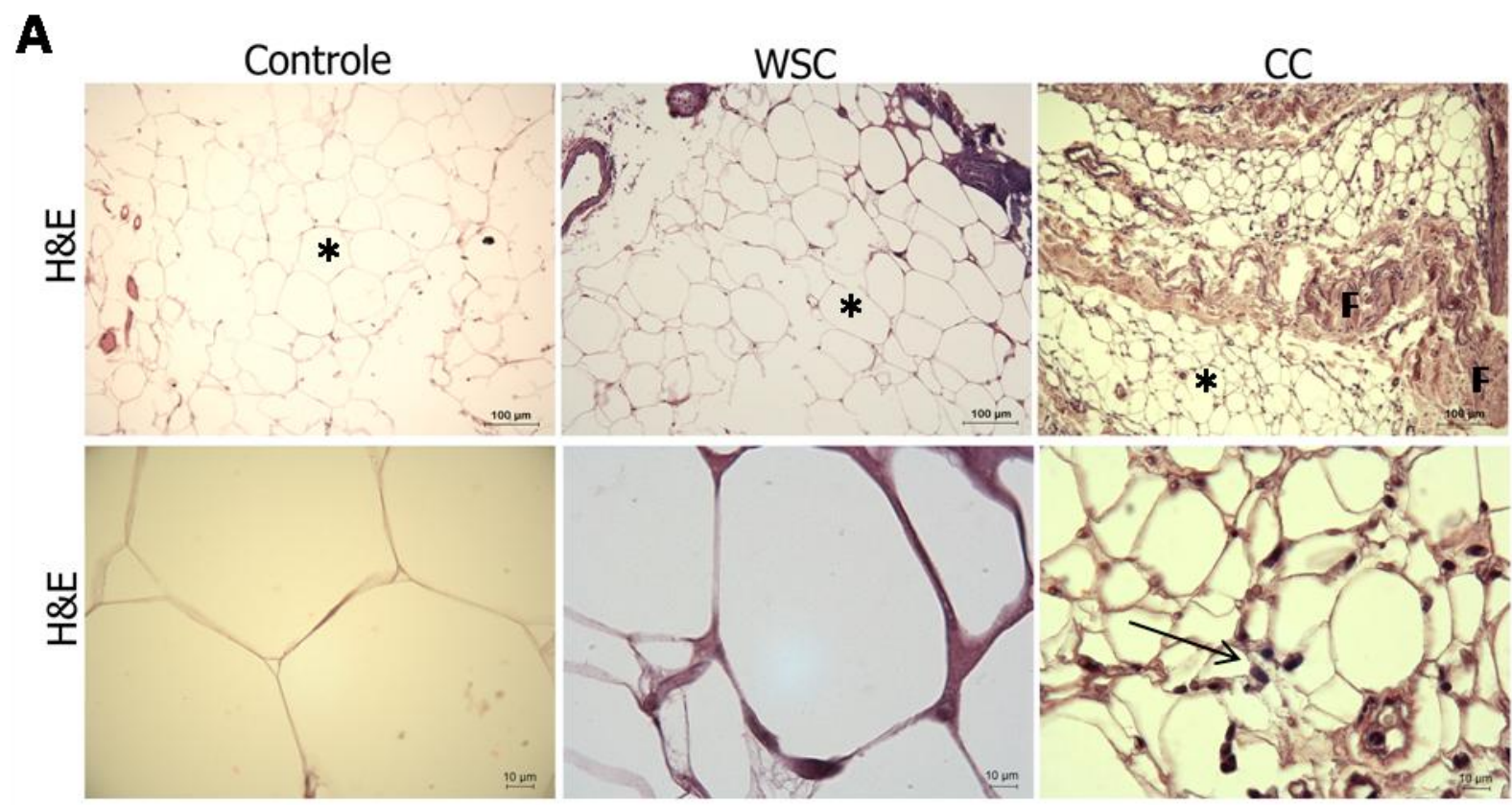

B

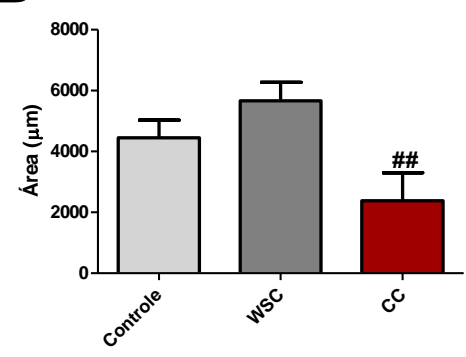

C

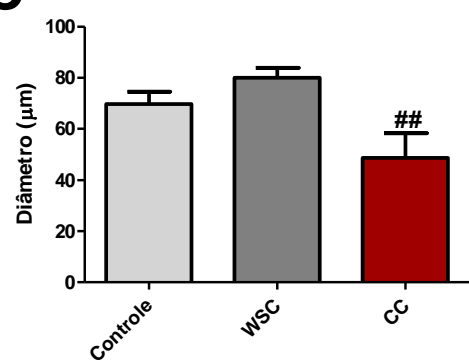

D

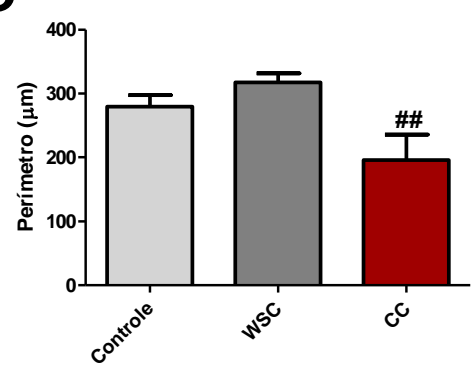

Figura 9 - Aspectos Morfológicos e Morfométricos do Tecido Adiposo Subcutâneo na Caquexia Associada ao Câncer. A. Coloração com Hematoxilina e Eosina; Controle $(n=12)$, WSC $(n=10)$, CC $(\mathrm{n}=10) .{ }^{*}$ Indicam os adipócitos. F-Indica a presença de áreas fibróticas; com grande acúmulo de MEC. As setas indicam a presença de outras células entre os adipócitos. Análises Morfométricas dos Adipócitos em Área (B), Diâmetro (C) e Perímetro (D); Controle $(n=4)$, WSC $(n=4), C C(n=4)$. \#\#p<0,05 CC vs WSC. 


\subsection{Remodelamento da MEC do Tecido Adiposo na Caquexia}

\subsubsection{Análise do Conteúdo Total de Colágeno no tecido Adiposo}

O conteúdo total de colágeno no tecido adiposo foi determinado utilizando a coloração Picro Sirius Red. Na figura 10-A, notamos no grupo Controle, a presença de fibras colágenas, mas a coloração é muito discreta. Observamos intensidade semelhante da coloração, e da presença de colágeno no tecido adiposo do grupo WSC. Em contraste, no grupo CC, distinguimos maior intensidade de coloração, com o acúmulo de fibras colágenas entre os adipócitos, e o aumento na deposição de MEC (demarcados com F) fortemente marcadas, como característica singular dos pacientes caquéticos. No entanto, a quantificação da área positiva para colágeno não demonstrou diferenças entre os grupos.

\subsubsection{Detecção de Fibras Reticulares no Tecido Adiposo}

A fim de observar diferenças qualitativas no conteúdo de fibras reticulares no tecido adiposo foi realizada a marcação com ácido periódico de Schiff (PAS). Ao analisar as imagens representativas dos grupos (Figura 11-A), percebemos maior intensidade da reação exclusivamente no tecido adiposo do grupo $\mathrm{CC}$, o que reflete no conteúdo total maior de fibras de colágeno do tipo III, associadas à glicoproteínas e proteoglicanos.

\subsubsection{Análise do Sistema Elástico no Tecido Adiposo}

Finalmente, as fibras do sistema elástico foram detectadas no tecido adiposo, empregando-se os métodos de Verhoeff's Van-Gieson para fibras elásticas maduras, e de Weigert para as fibras elaunínicas, bem como o de Weigert resorcinafucsina (oxona),para as fibras oxitalânicas. A figura 12 ilustra que, no tecido adiposo subcutâneo, todas as fibras do sistema elástico puderam ser evidenciadas, contudo, não há formação de agregados da proteína elastina no grupo controle, uma vez que há maior discrição na coloração de Verhoeff's no próprio. Não foi observada diferença entre as fibras oxitalânicas e elaunínicas entre o grupo controle e WSC. A intensidade da coloração no grupo $\mathrm{CC}$ revela que todo o sistema elástico é 
comprometido na caquexia. Houve maior deposição dos três tipos de fibras no CC em relação ao Controle e WSC, sendo mais notáveis, as fibras oxitalânicas na matriz intercelular, e as elaunínicas na MEC. Todas as alterações demonstram que o tecido adiposo é remodelado na caquexia.

Figura 10 -Conteúdo Total De Colágeno por Picro Sirius Red.
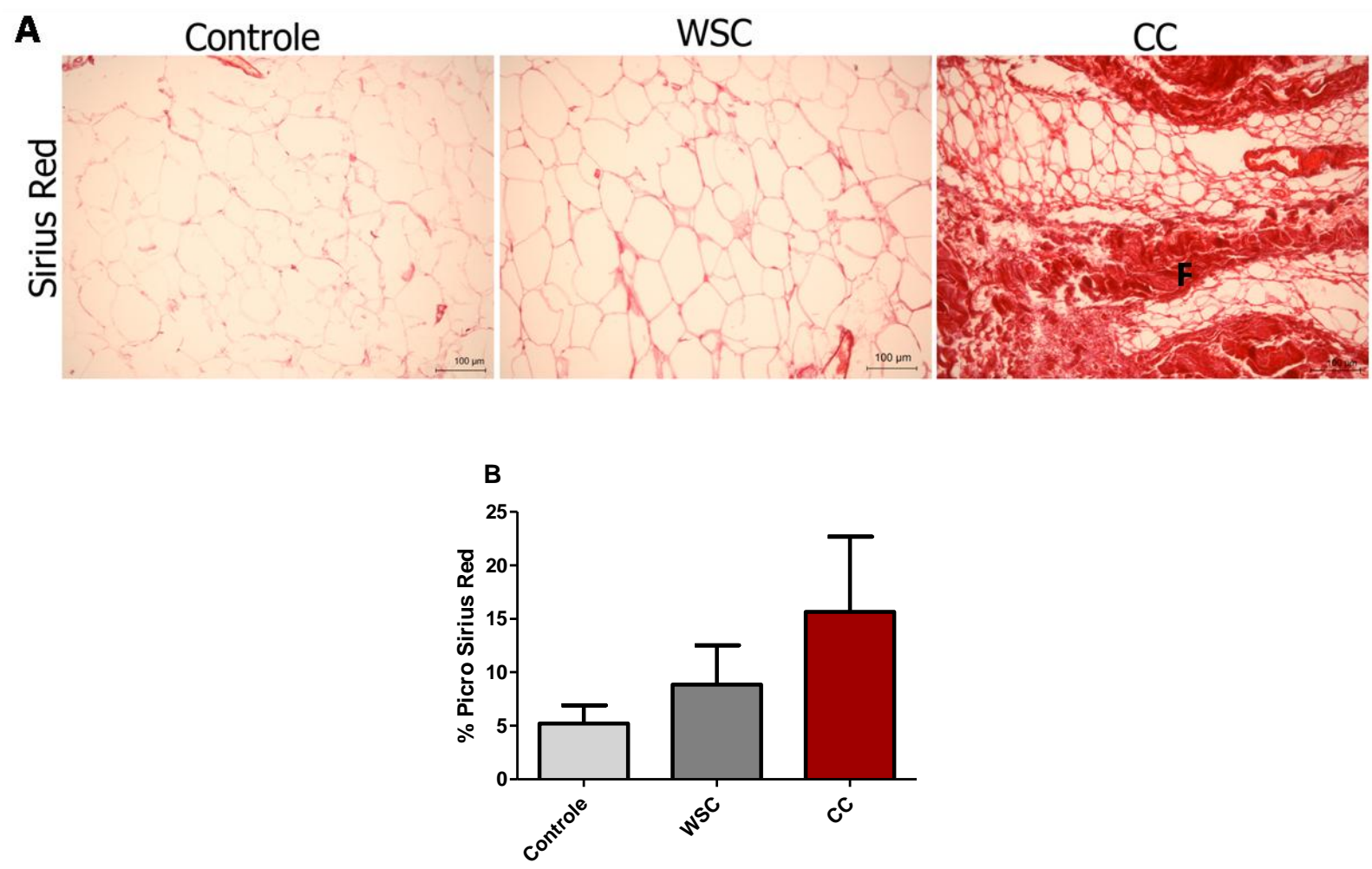

Figura 10 -Determinação do Conteúdo Total de Colágeno por Picro Sirius Red. A. Detecção de colágeno com a coloração Picro Sirius Red. Controle $(n=4)$, WSC $(n=4)$, CC $(n=4)$. Note F para áreas fibróticas B. Quantificação da área positiva para Picro Sirius Red. Controle $(n=4)$, WSC $(n=4)$, CC $(n=4)$.

Figura 11 - Detecção do Conteúdo de Fibras Reticulares.

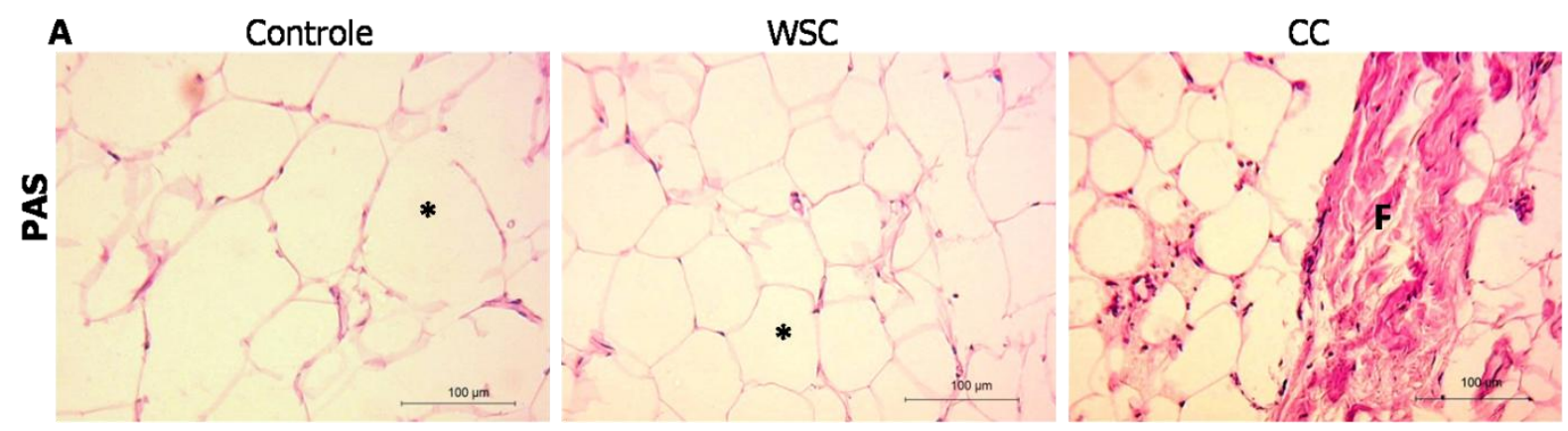

Figura 11 -Detecção do Conteúdo total de Fibras Reticulares por reação com ácido periódico de Schiff. Controle $(n=5)$, WSC $(n=5), C C(n=5)$. Note F para áreas fibróticas. * Adipócitos. 
Figura 12 -Detecção do Sistema Elástico no Tecido Adiposo.

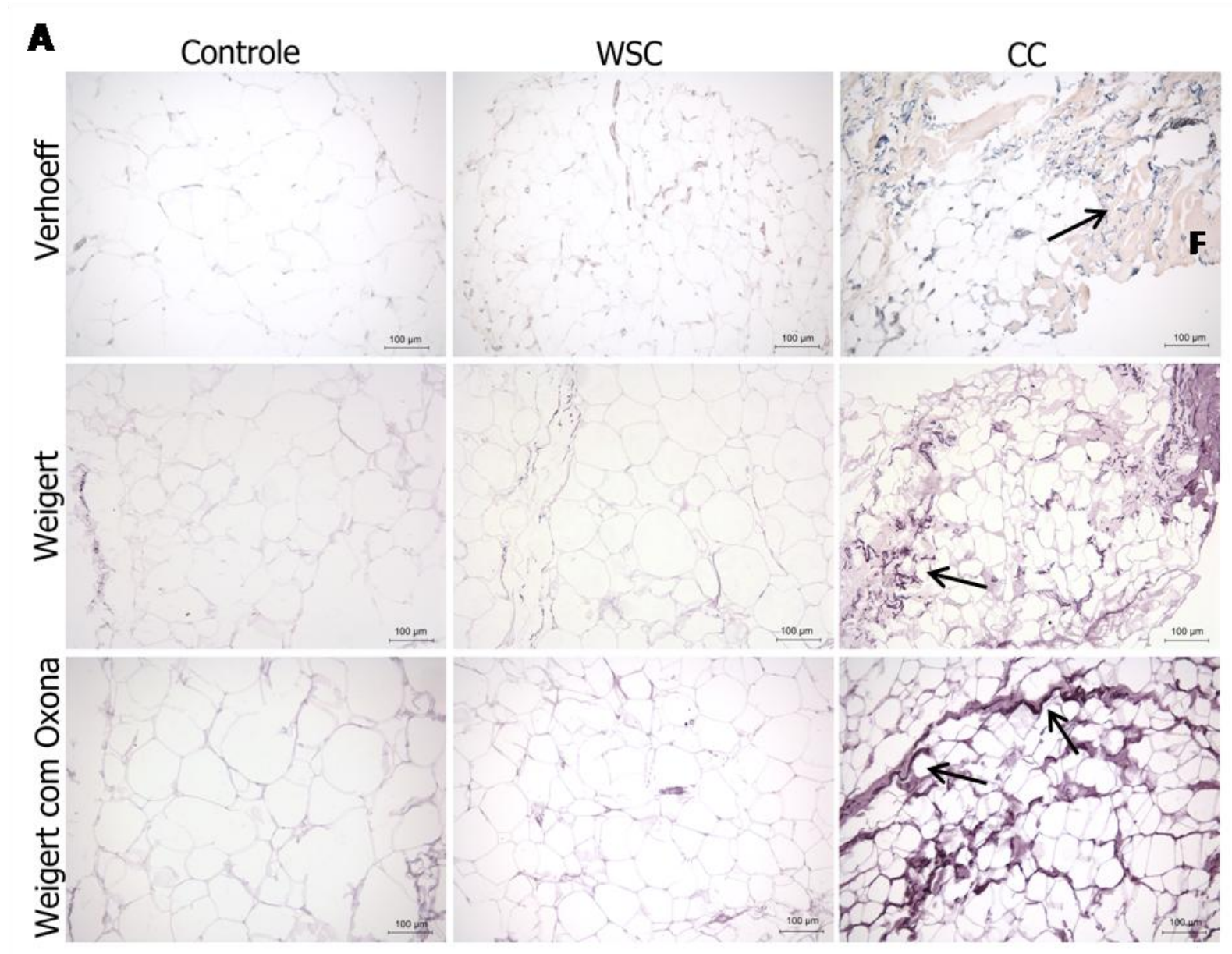

Figura 12 - Detecção do Sistema de Fibras Elásticas no Tecido Adiposo utilizando Verhoeff's e Weigert. A. Detecção de fibras elásticas com a coloração Verhoeff's Van-Gieson, fibras elaunínicas com a coloração de Weigert, e oxitalânicas pelo método de Weigert resorcina-fucsina com o emprego de ácido oxálico (oxona). Controle $(n=5)$, WSC $(n=5), C C(n=5)$. Note o acúmulo de fibras $(F)$ no tecido adiposo do paciente com câncer e caquexia. Setas indicam fibras elásticas. 


\subsection{Identificação da Fibrose no Tecido Adiposo}

Para caracterizar a presença de fibrose no tecido adiposo foi avaliado o conteúdo dos colágenos do tipo I, III, VI e fibronectina por imunohistoquímica, em associação com a determinação do conteúdo de citocinas plasmáticas e teciduais associadas à fibrose, bem como, a presença de fibroblastos ativados no tecido.

\subsubsection{Imunomarcação de componentes da MEC envolvidos na fibrose tecidual.}

A figura 13 A-D representa os resultados da imunohistoquímica para os colágenos: tipo I alfa1 (COL1A1), III alfa1 (COL3A1), VI alfa1 (COL6A1), e para a fibronectina. Podemos observar que não houve diferença de marcação para todas as proteínas entre os grupos Controle e WSC; porém, a marcação para COL1A1, e COL3A1 foi mais evidente em relação às demais proteínas. A imunomarcação do COL1A1, COL3A1, COL6A1, e fibronectina foi detectada como drasticamente mais positiva no grupo CC. Além disso, notamos que as marcações dos COL1A1, COL3A1, COL6A1 foram evidentes entre os adipócitos e nas áreas fibróticas, enquanto que a positividade da reação para fibronectina estava mais restrita às áreas fibróticas. Adicionalmente, observamos a presença de algumas células infiltrantes no tecido adiposo dos pacientes caquéticos. 
Figura 13 - Detecção por imunohistoquímica de marcadores de fibrose tecidual.
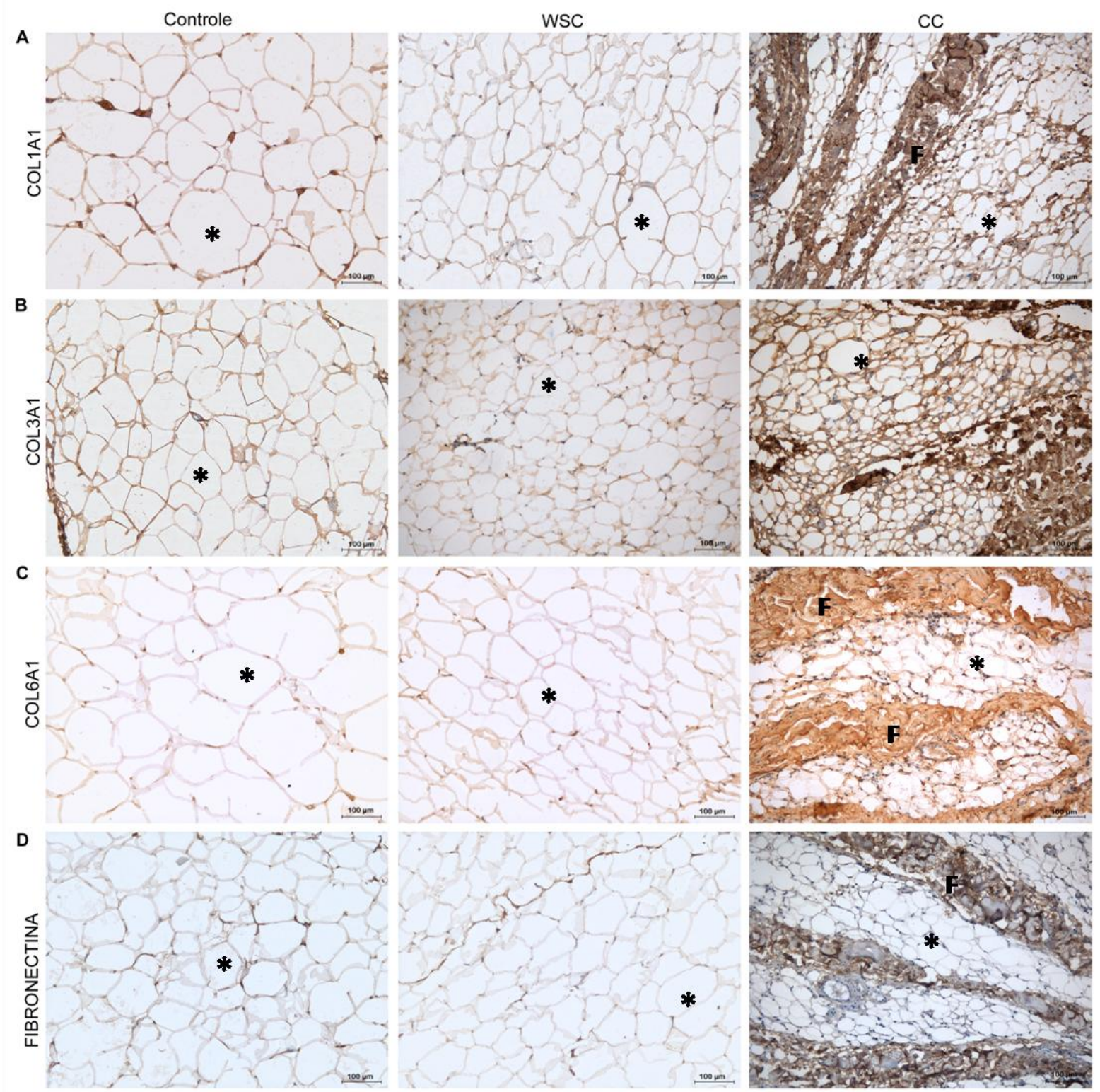

Figura 13 - Detecção por imunohistoquímica de marcadores de fibrose tecidual. A. Imunohistoquímica do colágeno tipo I (COL1A1). B. Imunohistoquímica do colágeno tipo III (COL3A1). C. Imunohistoquímica do colágeno tipo VI (COL6A1). D. Imunohistoquímica da fibronectina. Controle $(n=5)$, WSC $(n=5)$, CC $(n=5) .{ }^{*}$ Adipócitos (F) Áreas fibróticas. 
6.4.2 Conteúdo das Citocinas Inflamatórias relacionadas à fibrose.

$\mathrm{Na}$ tabela 4, estão demonstrados os resultados referentes às concentrações plasmáticas de citocinas inflamatórias e antiinflamatórias. Como esperado, as concentrações de TNFa e IL6 estavam aumentadas nos pacientes caquéticos. O conteúdo de TNFa no grupo CC aumentou em relação ao grupo WSC (8,82 [6,08;13,87], $p<0,05)$, enquanto que os níveis de IL6 $(4,10$ [1,25;9,74]) estavam mais altos em relação ao grupo WSC $(p<0,05)$, sendo essa a diferença exacerbada em relação ao grupo Controle $(p<0,0008)$. Não foram detectadas citocinas de IL1 $\beta$ e IL2 em todos os grupos de estudo. Houve um aumento significativo $(p<0,05)$ no conteúdo plasmático de IL5, e da citocina anti-inflamatória IL10, no grupo CC em comparação ao WSC. As alterações encontradas no grupo CC, da IL7 foi somente em relação ao grupo controle. A concentração da IL8 mostrou-se alterada, com aumento de 55 vezes nos pacientes caquéticos $(28,91$ [17,36; 68,86]) em relação ao grupo Controle $(0,52[0,35 ; 2,16], p>0,0001)$, e ainda, com diferença estatística em relação ao WSC $(4,79[2,02 ; 6,47]$, p>0,05). Em relação à IL15, não foi possível medi-la nos grupos Controle e WSC,mas apenas no grupo câncer e caquexia (resultados de 05 pacientes).

Tabela 4 -Concentração plasmática de citocinas inflamatórias e anti-inflamatórias.

\begin{tabular}{|c|c|c|c|c|}
\hline $\begin{array}{l}\text { Citocinas } \\
\text { (pg/ml) }\end{array}$ & CONTROLE & WSC & CC & $\boldsymbol{P}$ \\
\hline TNFa & $5,42[4,16 ; 6,15]$ & $6,01[3,92 ; 7,52]$ & $8,82[6,08 ; 13,87]$ & $p<0,05 \#$ \\
\hline IL6 & $0,00[0,00 ; 0,84]$ & $0,62[0,00 ; 1,77]$ & $4,10[1,25 ; 9,74]$ & $p<0,0008^{*} \#$ \\
\hline TNF $\beta$ & $0,09[0,07 ; 0,11]$ & $0,09[0,07 ; 0,11]$ & $0,12[0,07 ; 0,14]$ & 0,3939 \\
\hline IL1 $\alpha$ & $15,60[2,75 ; 48,39]$ & $6,52[2,44 ; 18,58]$ & $15,60[2,14 ; 78,01]$ & 0,5328 \\
\hline IL1 $\beta$ & ND & ND & ND & \\
\hline IL2 & ND & ND & ND & \\
\hline IL5 & $0,00[0,00 ; 0,73]$ & $0,00[0,00 ; 0,58]$ & $0,85[0,00 ; 1,36]$ & $\mathrm{p}<0,0282 \#$ \\
\hline IL7 & $0,05[0,03 ; 0,11]$ & $0,05[0,05 ; 0,12]$ & $0,17[0,11 ; 0,27]$ & $p<0,0336^{*}$ \\
\hline IL8 & $0,52[0,35 ; 2,16]$ & $4,79[2,02 ; 6,47]$ & $28,91[17,36 ; 68,86]$ & $\mathrm{p}<0,0001^{*} \#$ \\
\hline IL10 & $0,02[0,01 ; 0,11]$ & $0,01[0,005 ; 0,04]$ & $0,19[0,06 ; 0,86]$ & $p<0,0268 \#$ \\
\hline IL12p40 & $0,06[0,03 ; 0,12]$ & $0,06[0,04 ; 0,07]$ & $0,09[0,02 ; 0,14]$ & 0,6236 \\
\hline IL12p70 & $0,21[0,21 ; 0,78]$ & $0,21[0,21 ; 2,36]$ & $1,29[0,35 ; 1,75]$ & 0,2589 \\
\hline IL13 & $0,03[0,03 ; 0,05]$ & $0,04[0,03 ; 0,04]$ & $0,07[0,02 ; 0,105]$ & 0,2947 \\
\hline IL15t† & ND & ND & $0,00[0,00 ; 0,01]$ & $\mathrm{p}<0,0075^{*} \#$ \\
\hline IL17† & $0,79[0,71 ; 1,28]$ & 1,09[0,79;1,41] & $1,56[0,87 ; 2,31]$ & 0,1305 \\
\hline
\end{tabular}

Dados expressos como mediana, $1^{\text {st }}$ e $3^{\text {st }}$ quartil. Controle $(n=17)$, WSC $(n=13), C C(n=12)$. †Controle $(n=10)$, WSC $(n=9), C C(n=10) \dagger+C C(n=5) .{ }^{*}$ CC vs Controle \# CC vs WSC. TNFa: Fator de necrose 


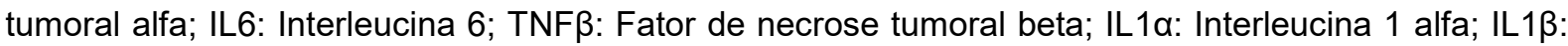
Interleucina 1 beta; IL2: Interleucina 2; IL5: Interleucina 5; IL7: Interleucina 7; IL8: Interleucina 8; IL10: Interleucina 10; IL12p40: Interleucina 12 sub-unidade p40; IL12p70: Interleucina 12 sub-unidade p70; IL13: Interleucina 13; IL15: Interleucina 15; Interleucina 17. ND: Não detectado pelo método.

$\mathrm{Na}$ tabela 5, estão demonstrados os resultados da concentração de citocinas medidas no tecido adiposo subcutâneo. Não houve diferenças nas concentrações de TNFa e IL6 entre os grupos de estudo. Já o conteúdo tecidual de TNF $\beta$ esteve reduzido 2,5 vezes no grupo WSC, em relação ao Controle. Em relação à concentração de IL1 $\beta$, encontramos uma redução significativa no grupo WSC $(0,084$ [0,062; 0,094]), comparado-se com o grupo Controle. Não encontramos diferenças

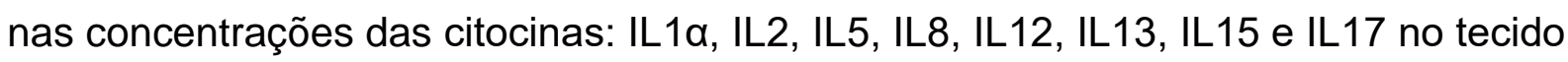
adiposo dos grupos de estudo.

Tabela 5 - Concentração de citocinas inflamatórias e anti-inflamatórias no tecido adiposo subcutâneo.

\begin{tabular}{|c|c|c|c|c|}
\hline $\begin{array}{l}\text { Citocinas } \\
\text { (pg/mg) }\end{array}$ & CONTROLE & WSC & CC & $P$ \\
\hline TNF $\alpha$ & $0,073[0,053 ; 0,130]$ & $0,048[0,040 ; 0,060]$ & $0,050[0,030 ; 0,104]$ & 0,111 \\
\hline IL6 & $0,13[0,076 ; 0,238]$ & $0,089[0,068 ; 0,142]$ & $0,096[0,039 ; 0,342]$ & 0,434 \\
\hline TNF $\beta$ & $0,142[0,072 ; 0,188]$ & $0,058[0,045 ; 0,101]$ & $0,078[0,049 ; 0,193]$ & $p<0,046^{*}$ \\
\hline IL1 $\alpha$ & $0,012[0,001 ; 0,120]$ & $0,006[0,001 ; 0,040]$ & $0,008[0,002 ; 0,107]$ & 0,575 \\
\hline IL1 $\beta$ & $0,144[0,107 ; 0,245]$ & $0,084[0,062 ; 0,094]$ & $0,082[0,067 ; 0,234]$ & $\mathrm{p}<0,037^{*}$ \\
\hline IL2 & $0,048[0,025 ; 0,068]$ & $0,029[0,019 ; 0,038]$ & $0,029[0,021 ; 0,09]$ & 0,180 \\
\hline IL5 & $0,061[0,039 ; 0,083]$ & $0,029[0,021 ; 0,04]$ & $0,033[0,021 ; 0,074]$ & 0,058 \\
\hline IL8 & $0,172[0,037 ; 4,807]$ & $0,092[0,032 ; 6,408]$ & $0,278[0,109 ; 11,41]$ & 0,505 \\
\hline IL10 & $0,177[0,095 ; 0,427]$ & $0,090[0,059 ; 0,199]$ & $0,092[0,062 ; 0,240]$ & 0,187 \\
\hline IL12 p40 & $1,695[0,384 ; 4,042]$ & $0,202[0,100 ; 2,956]$ & $2,285[0,170 ; 4,830]$ & 0,182 \\
\hline IL12 p70 & $0,318[0,187 ; 0,407]$ & $0,122[0,098 ; 0,185]$ & $0,159[0,085 ; 0,243]$ & 0,014 \\
\hline IL13 & $0,356[0,087 ; 1,086]$ & $0,888[0,168 ; 4,465]$ & $0,393[0,148 ; 0,679]$ & 0,405 \\
\hline IL15 & $0,092[0,067 ; 0,208]$ & $0,088[0,07 ; 0,145]$ & $0,101[0,056 ; 0,244]$ & 0,902 \\
\hline IL17 & $0,041[0,022 ; 0,120]$ & $0,025[0,022 ; 0,029]$ & $0,024[0,015 ; 0,048]$ & 0,286 \\
\hline
\end{tabular}

Dados expressos como mediana, $1^{\text {st }}$ e $3^{\text {st }}$ quartil. Controle $(n=15)$, WSC $(n=12), C C(n=15)$. ${ }^{*} p<0,05$ em relação à WSCvs Controle.TNFa: Fator de necrose tumoral alfa; IL6: Interleucina 6; TNF $\beta$ : Fator de necrose tumoral beta; IL1 $\alpha$ : Interleucina 1 alfa; IL1 $\beta$ : Interleucina 1 beta; IL2: Interleucina 2; IL5: Interleucina 5; IL7: Interleucina 7; IL8: Interleucina 8; IL10: Interleucina 10; IL12p40: Interleucina 12 sub-unidade p40; IL12p70: Interleucina 12 sub-unidade p70; IL13: Interleucina 13; IL15: Interleucina 15; Interleucina 17. ND: Não detectado pelo método.

Os dados referentes às concentrações das citocinas em adipócitos isolados estão representados na tabela 6 . Não houve detecção da IL10 nos adipócitos de quaisquer dos grupos de estudo. A expressão proteica da IL2 foi encontrada diminuída no grupo WSC $(0,022[0,008 ; 0,037])$, em relação ao Controle 
$(0,080[0,063 ; 0,157])$. Foi observado um valor 10 vezes inferior da concentração de IL17 nos adipócitos de pacientes caquéticos, comparados com grupo Controle $(p<0,02)$.

Tabela 6 - Concentração de citocinas inflamatórias e anti-inflamatórias em adipócitos isolados do tecido adiposo subcutâneo.

\begin{tabular}{|c|c|c|c|c|}
\hline $\begin{array}{l}\text { Citocinas } \\
\text { (pg/mg) }\end{array}$ & Controle & WSC & CC & $p$ \\
\hline TNF $\alpha$ & $0,088[0,066 ; 0,152]$ & $0,063[0,0301 ; 0,170]$ & $0,048[0,034 ; 3,428]$ & 0,4538 \\
\hline IL6 & $0,120[0,094 ; 0,202]$ & $0,076[0,032 ; 0,623]$ & $0,037[0,032 ; 0,840]$ & 0,4677 \\
\hline TNF $\beta$ & $56,60[7,049 ; 96,71]$ & $29,99[7,898 ; 101,3]$ & $48,39[5,43 ; 54,58]$ & 0,8694 \\
\hline IL1 $\alpha$ & $0,089[0,052 ; 0,291]$ & $0,069[0,004 ; 1,944]$ & $0,003[0,00 ; 13,23]$ & 0,2887 \\
\hline IL1 $\beta$ & $0,040[0,031 ; 0,072]$ & $0,011[0,004 ; 0,054]$ & $0,018[0,004 ; 1,694]$ & 0,1637 \\
\hline IL2 & $0,080[0,063 ; 0,157]$ & $0,022[0,008 ; 0,037]$ & $0,042[0,015 ; 0,050]$ & $0,0126^{*}$ \\
\hline IL5 & $0,120[0,060 ; 0,139]$ & $0,038[0,016 ; 0,079]$ & $0,060[0,031 ; 0,417]$ & 0,1212 \\
\hline IL7 & $0,096[0,075 ; 0,529]$ & $0,154[0,016 ; 0,668]$ & $0,052[0,023 ; 1,711]$ & 0,5273 \\
\hline IL8 & $0,476[0,242 ; 5,126]$ & $0,223[0,144 ; 5,774]$ & $1,008[0,110 ; 14,45]$ & 0,9704 \\
\hline IL10 & ND & ND & ND & \\
\hline IL12p40 & $4,372[2,435 ; 10,59]$ & $3,284[1,183 ; 8,235]$ & $1,397[0,8127 ; 39,37]$ & 0,5326 \\
\hline IL12p70 & $2,400[1,173 ; 50,12]$ & $1,62[0,865 ; 87,00]$ & $1,650[1,220 ; 46,84]$ & 0,990 \\
\hline IL13 & $0,00[0,00 ; 1,818]$ & $0,134[0,00 ; 3,492]$ & $0,061[0,028 ; 3,573]$ & 0,7014 \\
\hline IL15 & $0,802[0,603 ; 1,632]$ & $0,624[0,232 ; 0,864]$ & $0,103[0,090 ; 0,776]$ & 0,1142 \\
\hline IL17 & $0,583[0,496 ; 1,408]$ & $0,192[0,082 ; 0,520]$ & $0,056[0,049 ; 0,356]$ & $0,0299 * *$ \\
\hline
\end{tabular}

Dados expressos como mediana, $1^{\text {st }}$ e $3^{\text {st }}$ quartil.Controle $(n=5)$, WSC $(n=5), C C(n=5) .{ }^{*} p<0,05$ em relação WSC vs Controle ${ }^{* *} p<0,05$ em relação CC vs Controle. TNFa: Fator de necrose tumoral alfa;

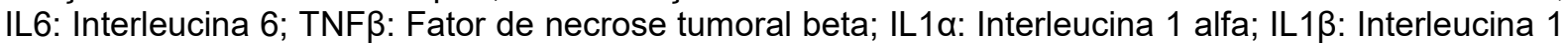
beta; IL2: Interleucina 2; IL5: Interleucina 5; IL7: Interleucina 7; IL8: Interleucina 8; IL10: Interleucina 10; IL12p40: Interleucina 12 sub-unidade p40; IL12p70: Interleucina 12 sub-unidade p70; IL13: Interleucina 13; IL15: Interleucina 15; Interleucina 17. ND: Não detectado pelo método

\subsubsection{Detecção de Miofibroblastos e da proliferação celular no Tecido Adiposo Subcutâneo}

$\mathrm{Na}$ figura 14 estão apresentados os resultados de imunohistoquímica para detecção de miofibroblastos (aSMA), e de proliferação celular (ki67), e os resultados da expressão gênica da proteína específica para fibroblastos (FSP1).

A marcação de aSMA (figura14A) foi discreta no grupo Controle em relação ao grupo WSC, e podemos notar pontos isolados entre os adipócitos. No tecido adiposo do grupo CC, houve intensa marcação, em comparação aos outros grupos, não somente entre os adipócitos, mas também em alguns pontos nas áreas fibróticas. Para confirmarmos nossos achados, realizamos a análise da expressão do gene S100A4 (figura 14B), e os resultados demonstram que para o grupo CC, 
esse parâmetro estava aproximadamente 20 vezes maior do que no Controle $(p<0,03)$. A imunomarcação do ki67 foi positiva em células infiltradas entre os adipócitos no grupo WSC, enquanto no grupo CC podemos observar maior densidade de células marcadas.

Figura 14 - Expressão gênica e proteica de marcadores de ativação de miofibroblastos e proliferação celular.

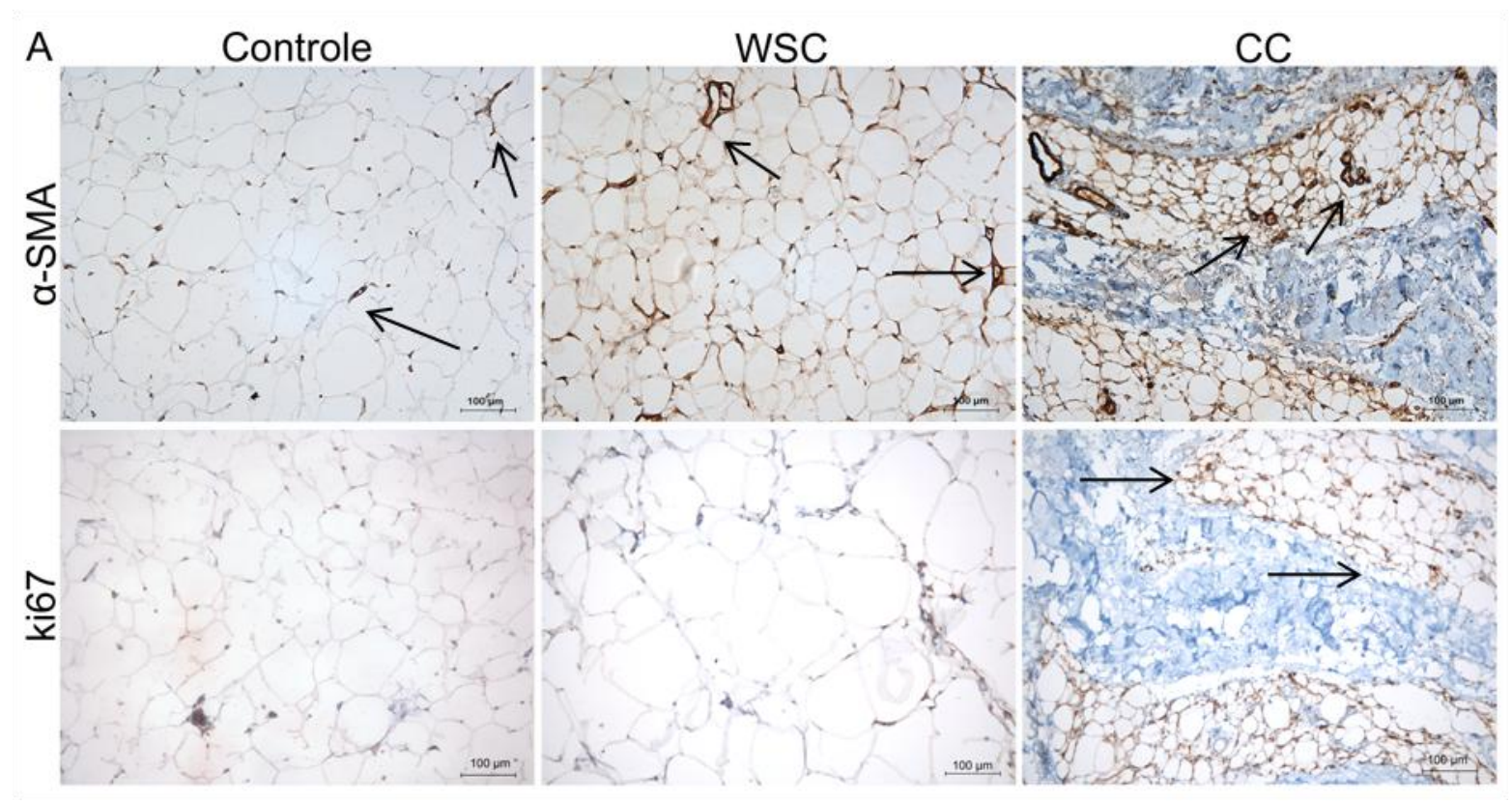

B

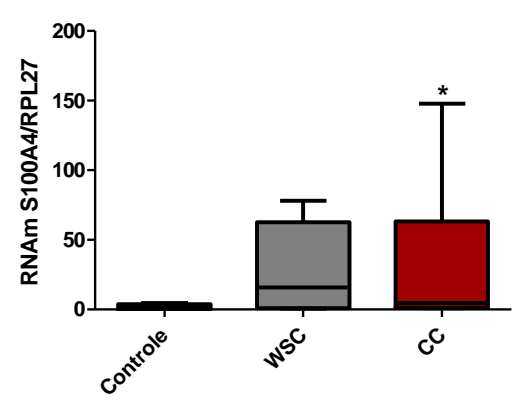

Figura 14 -Expressão gênica e proteica de marcadores de ativação de miofibroblastos, hipóxia e proliferação celular. A. Imunohistoquímca para alfa actina de músculo liso (aSMA) e ki67. Controle $(n=5)$, WSC $(n=5)$ e $C C(n=5)$. Setas indicam a marcação positiva. B. Expressão gênica da proteína específica de fibroblastos (S100A); Controle $(n=13)$, WSC $(n=6)$ e CC $(n=12)$. Dados expressos como mediana, $1^{\text {st }}$ e $3^{\text {st }}$ quartil. ${ }^{*} p<0,05$ CC vs Controle. 
Figura 15 -Detecção de marcadores de fibroblastos ativados, migração e proliferação.
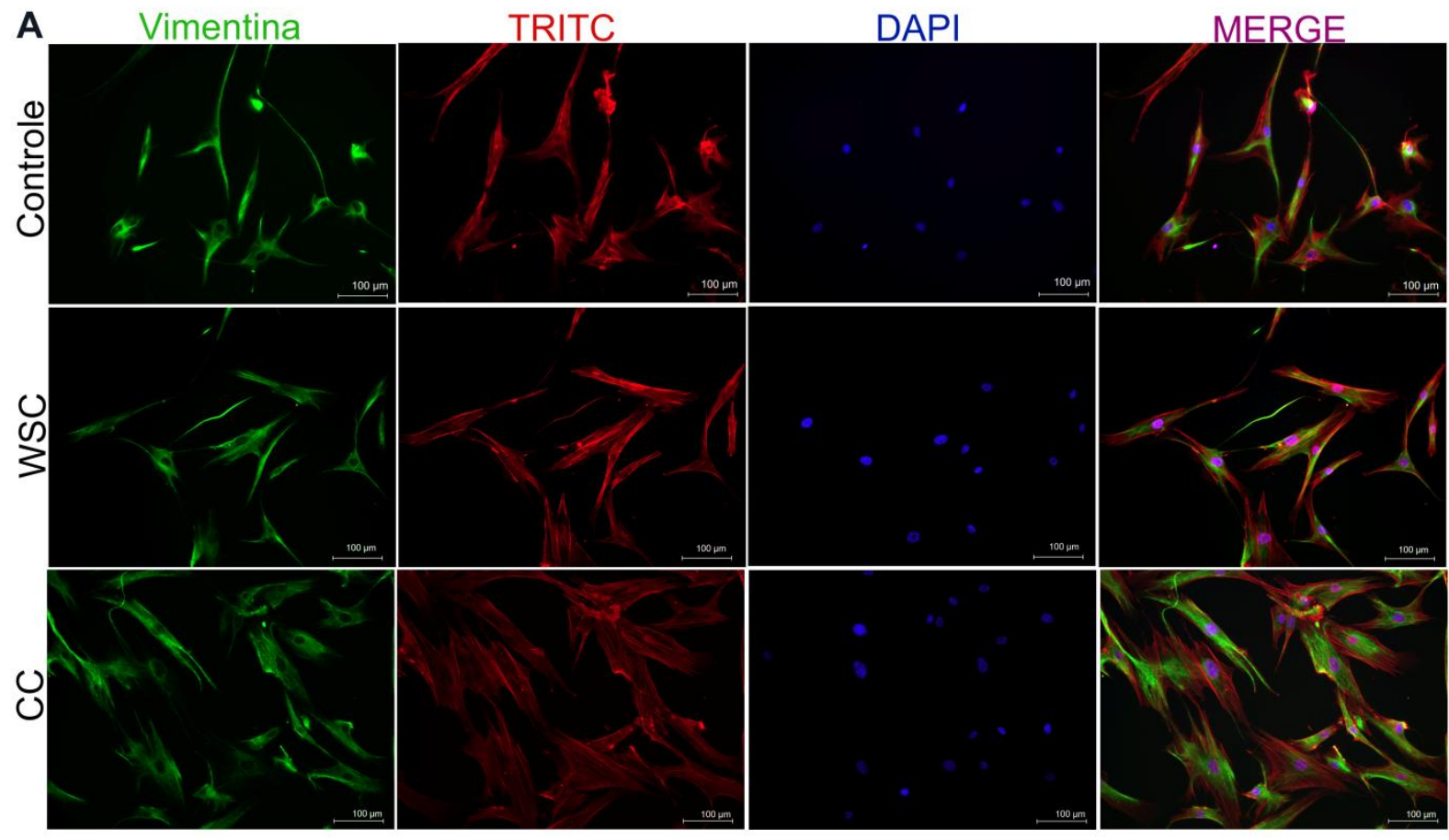

B

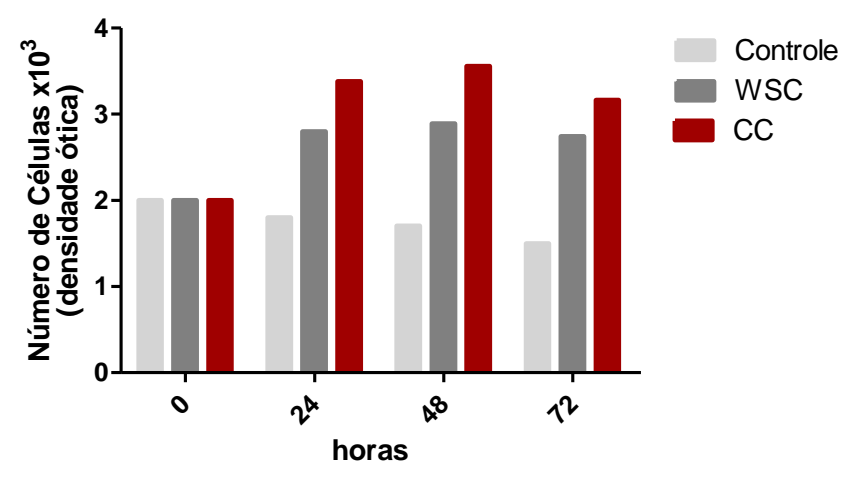

C

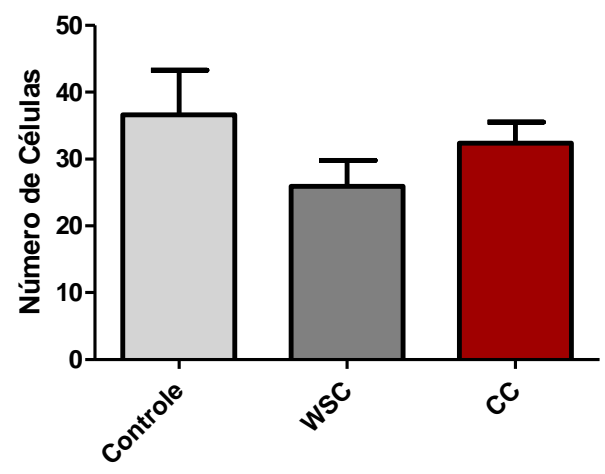

Figura 15 -Detecção de por imunohistoquímica para vimentina, migração e proliferação. A. Imunofluorescência para Vimentina (verde) e marcação para Rodamina-faloidina (TRITC, vermelho). Núcleo marcado com DAPI (azul) em fibroblastos isolados do tecido adiposo subcutâneo. B. Proliferação celular $0,24,48,72$ horas. Controle $(n=1)$, WSC $(n=1), C C(n=1)$, Ensaio realizado três vezes. C. Índice de Migração Celular. Controle $(n=3)$, WSC $(n=3), C C(n=3)$. Ensaio realizado três vezes. 


\subsection{TGF $\beta$ Como Contribuinte Na Fibrose do Tecido Adiposo.}

\subsubsection{Expressão do TGFß e das SMADs}

A figura 16 representa a expressão proteica das três isoformas do TGF $\beta$ : TGF $\beta 1$, TGF $\beta 2$ e TGF 3 , obtida por ensaio de multiplex no tecido adiposo subcutâneo e em adipócitos isolados, bem como, a imunomarcação para o TGF $\beta 1$. A expressão gênica das SMADs: SMAD2, SMAD3 e SMAD4 e a imunomarcação para SMAD4.

Nossos achados demonstram forte marcação imunohistoquímica para o TGFß1 (figura 16A) no tecido adiposo do grupo CC áreas fibróticas, com maior deposição de MEC, como, entre as células adiposas. Contudo, a detecção no ensaio de Multiplex dessa isoforma não resultou em diferenças entre os grupos $(p=0,6055)$. Não foi encontrada diferença entre os grupos para isoforma $\beta 2$ (figura 16C). Houve o aumento dos níveis de TGF $\beta 3$ no grupo CC, em relação ao grupo Controle $(p<0,03)$. Já nos adipócitos isolados, os resultados do ensaio de Multiplex (figura16E-G) mostram o aumento de 4,4 vezes nas concentrações do TGFß1 e de 3,4 vezes nas concentrações de TGFß3 no grupo com câncer e caquexia em comparação com o grupo Controle. Na figura 17 A-B estão demonstrados os resultados da detecção por Western blotting para o receptor TGFRII e TGF $\beta$. Os resultados foram relativizados pela proteína GAPDH. A expressão proteica de TGFRII não mostrou diferença significante, e a expressão proteica de TGFß1 mostrou tendência a aumentar no grupo CC $(p<0,07)$.

A expressão do RNAm para SMAD2 e SMAD3 (figura 16H-I) não apresentou alterações nos grupos, apesar de notarmos uma tendência ao aumento para SMAD3 no grupo WSC, especialmente em relação ao CC. A imunofluorescência realizada para SMAD2 ( figura 18), no entanto, resultou na mínima localização da proteína no grupo Controle, e foi de maior intensidade nos grupos WSC e CC, não havendo, contudo diferenças entre os mesmos. A figura 19 ilustra os resultados de imagens de imunofluorescência para SMAD3. Diferentemente dos achados na expressão gênica, a imunolocalização da SMAD3 observada no tecido adiposo mostrou-se mais evidente no grupo Controle em relação ao grupo WSC. Podemos notar ainda, que no grupo CC houve forte marcação sempre co-localizada ao núcleo das células adiposas, mas também, nas células infiltrantes. 
A expressão gênica de SMAD4 (figura 16J) esteve aumentada significantemente no grupo WSC e no $\mathrm{CC}$, em comparação ao grupo Controle $(p<0,003)$. Não houve marcação imunohistoquímica positiva de SMAD4 nos grupos Controle e WSC (figura 16A). As setas demonstram a marcação mais intensa presente no grupo $\mathrm{CC}$, também encontrada nas áreas fibróticas $(F)$ e entre as células infiltrantes. 
Figura 16 - Expressão Gênica e Proteica da Via de Sinalização do TGFß.
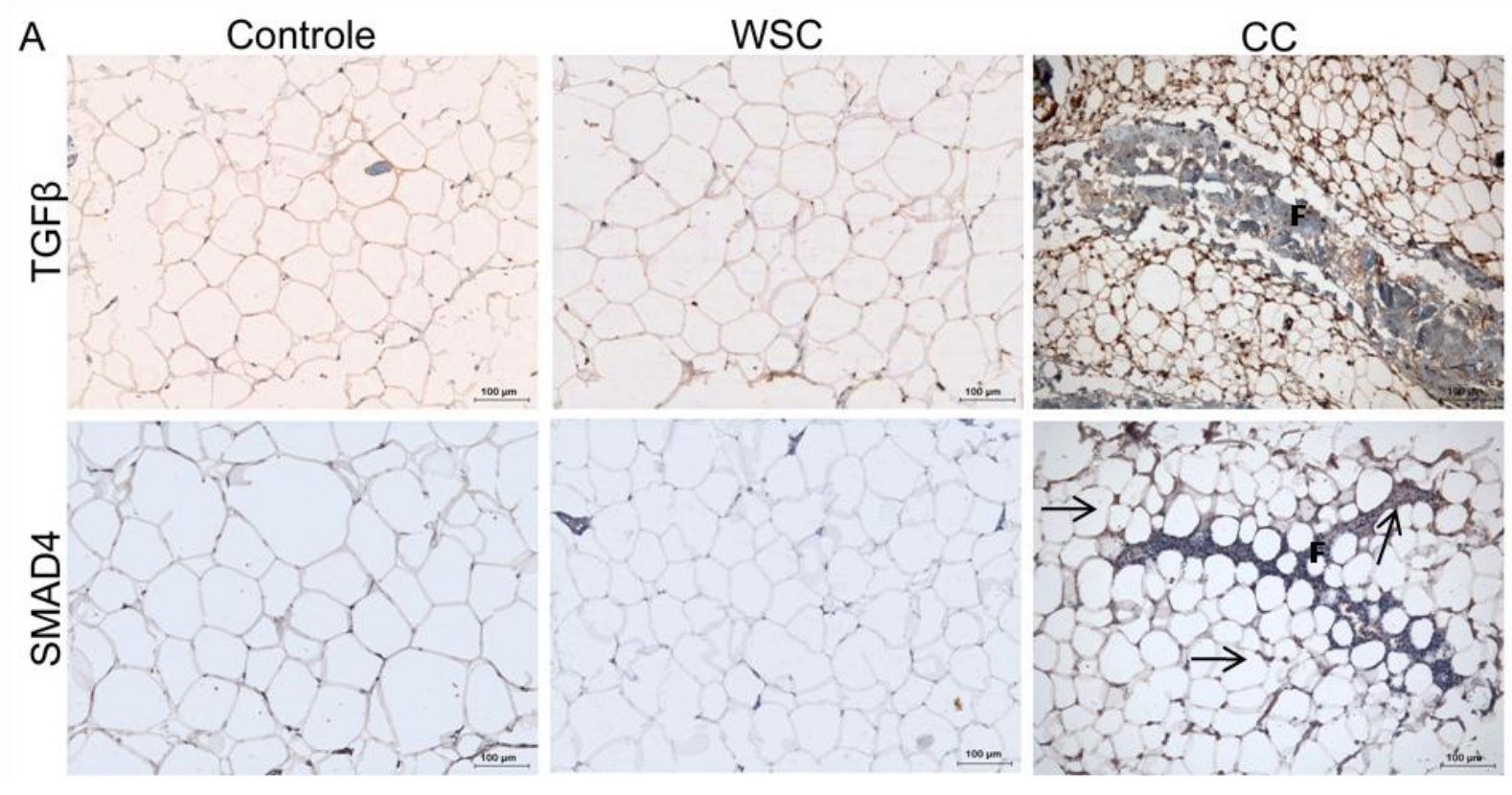

B

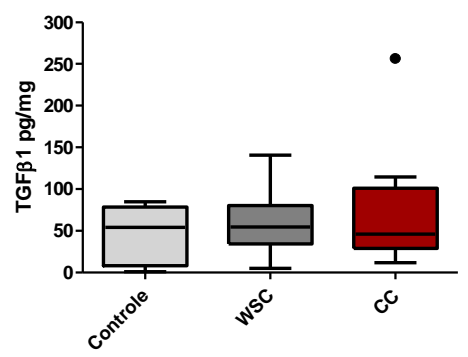

E

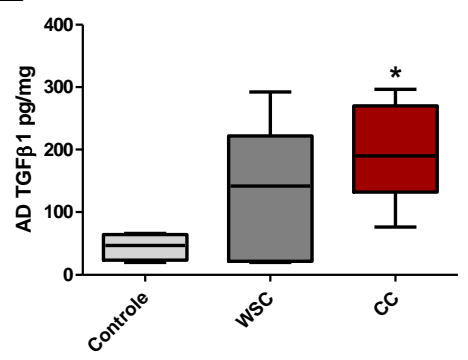

H

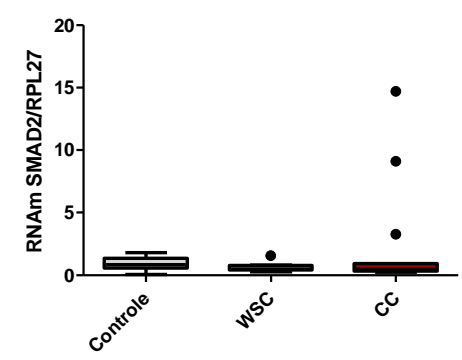

C

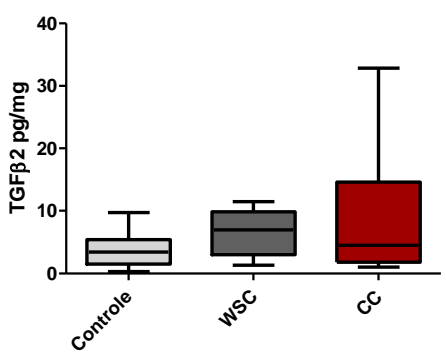

$\mathbf{F}$

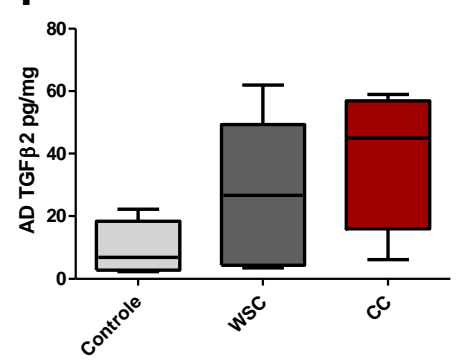

I

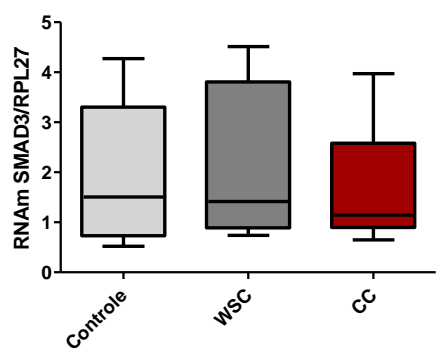

D

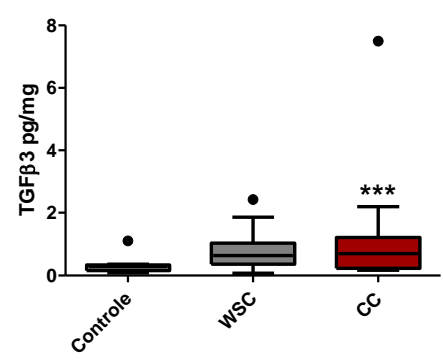

G

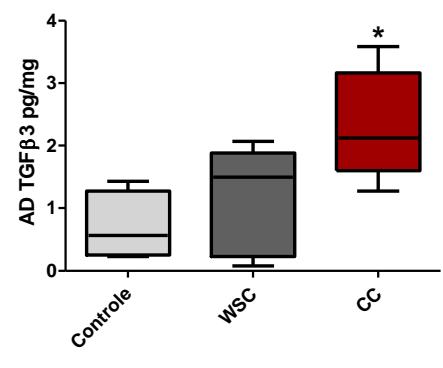

J

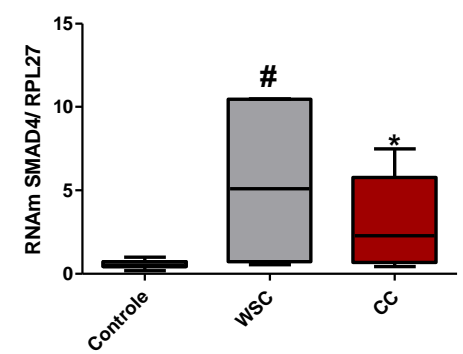

Figura 16 - Expressão Gênica e Proteica da Via de Sinalização do TGF $\beta$. A. Imunohistoquímica do TGF $\beta$ e SMAD4. Controle $(n=5)$, WSC $(n=5), C C(n=5)$. (F) Notar a presença de área fibrótica. As setas indicam positividade na marcação. B. Expressão Proteica do TGFß1 no tecido adiposo. C. 
Expressão Proteica do TGF $\beta 2$ no tecido adiposo. D. Expressão Proteica do TGF $\beta 3$ no tecido adiposo. Controle $(n=14), W S C(n=12), C C(n=14)$. E. Expressão Proteica do TGF $\beta 1$ em adipócitos. $F$. Expressão Proteica do TGF $\beta 2$ em adipócitos. G. Expressão Proteica do TGF $\beta 3$ em adipócitos. Controle $(n=5)$, WSC $(n=5), C C(n=5)$. H. Expressão Gênica de SMAD2. I. Expressão Gênica de SMAD3. J. Expressão Gênica de SMAD4. Dados expressos como mediana, $1^{\text {st }}$ e $3^{\text {st }}$ quartil. ${ }^{*} p<0,05$ CC vs Controle. ${ }^{* *} p<0,03$ CC vs Controle. \# WSC vs Controle.

Figura 17 - Detecção do TGFR2 e TGFß1 por Western Blotting no tecido adiposo.

A

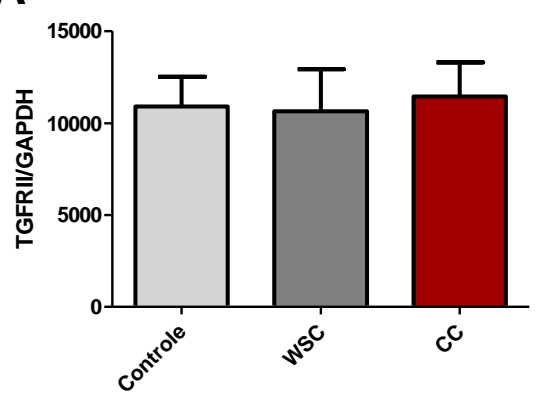

Controle WSC CC

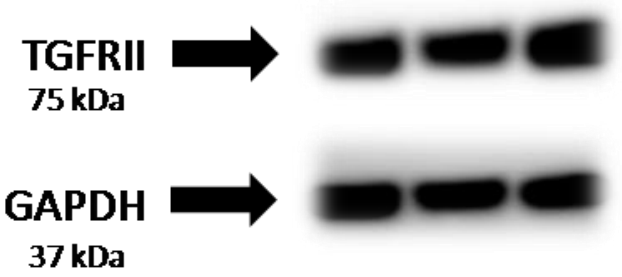

B

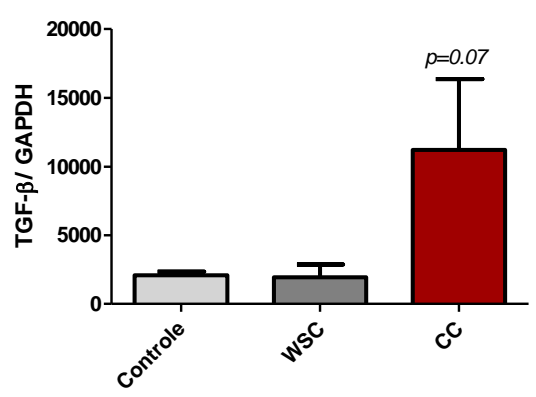

Controle WSC CC

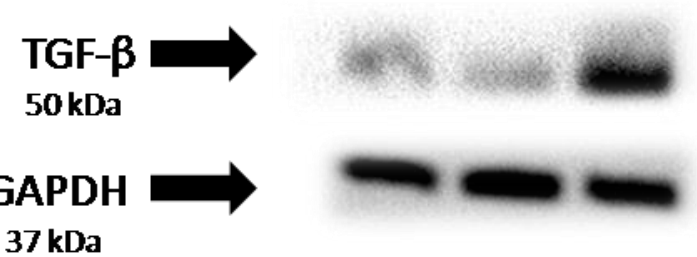

Figura 17 - Detecção do TGFRII e TGF $\beta 1$ por Western Blotting no tecido adiposo subcutâneo. A. Quantificação TGFRII em relação à GAPDH. B. TGF Quantificação do TGFß1 em relação à GAPDH. Controle $(n=4)$, WSC $(n=3)$, CC $(n=3)$. 
Figura 18 - Imunofluorescência para detecção de SMAD2 no tecido adiposo.

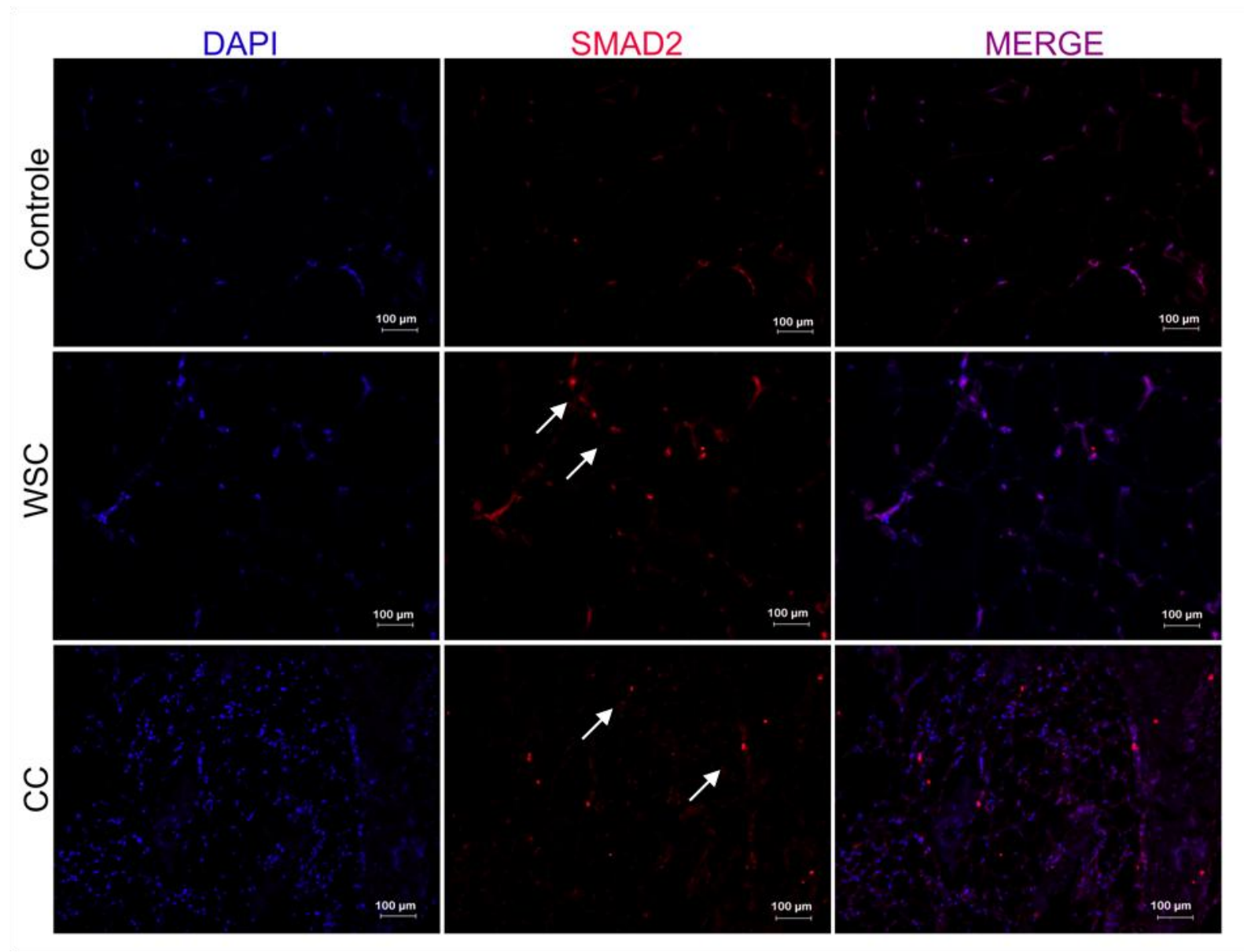

Figura 18 - Imunofluorescência para detecção de SMAD2 (vermelho) e marcação nuclear com DAPI (azul) no tecido adiposo subcutâneo. Controle $(n=5), \operatorname{WSC}(n=5), \operatorname{CC}(n=5)$. As setas indicam marcação positiva para SMAD2. 
Figura 19 - Imunofluorescência para detecção de SMAD3 no tecido adiposo.

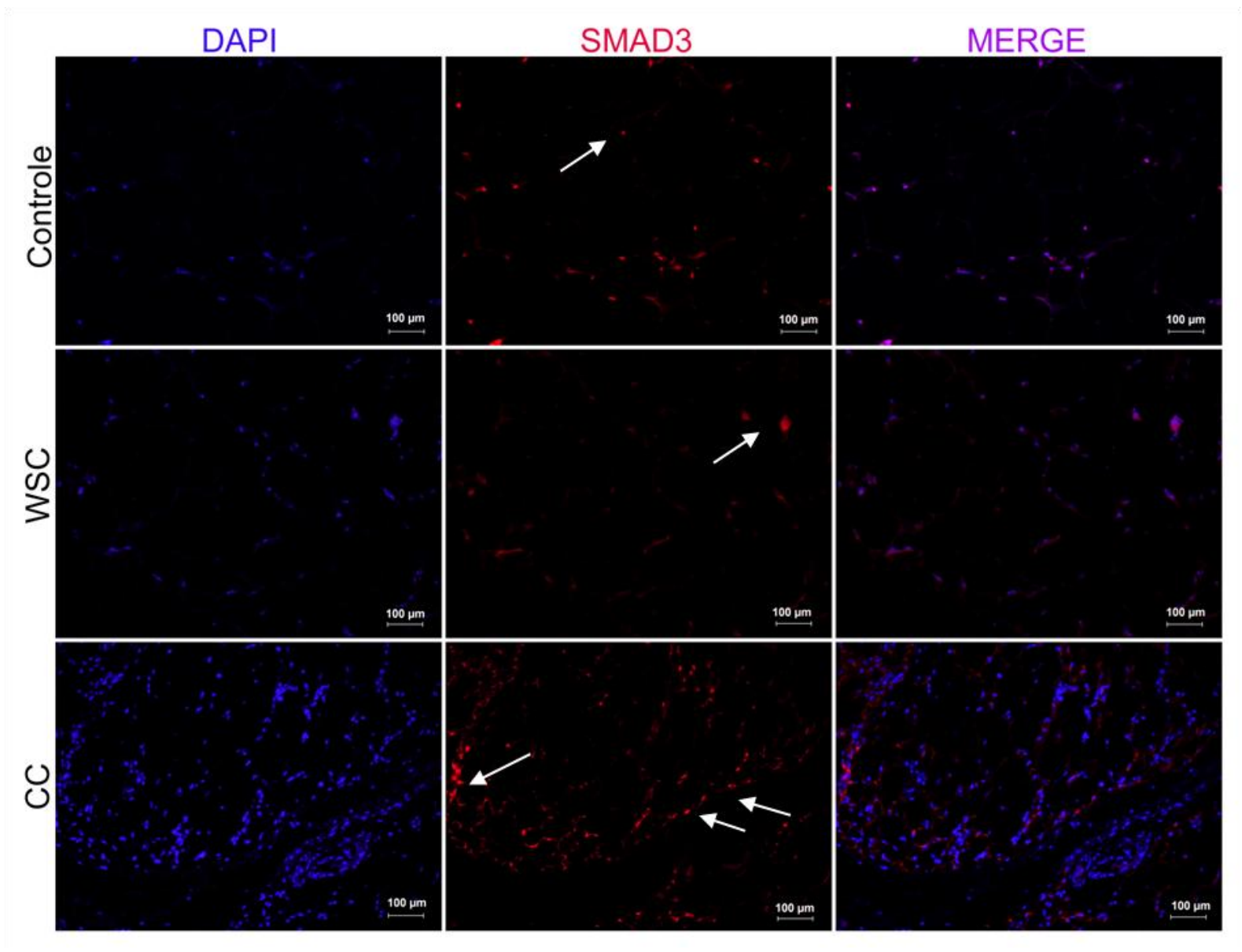

Figura 19 - Imunofluorescência para detecção de SMAD3 (vermelho) e marcação nuclear com DAPI (azul) no tecido adiposo subcutâneo. Controle $(n=5)$, WSC $(n=5), C C(n=5)$. As setas indicam áreas com marcação positiva para SMAD3. 


\subsubsection{Fatores relacionados ao TGFB.}

A figura 20 apresenta os resultados da imunolocalização por fluorescência de c-Myc e a expressão dos genes c-Myc, ciclina D1 (CCND1), fator indutor de hipóxia (HIF1A) e a histona desacetilase sirtuin (SIRT1).

A imunofluorescência de c-Myc foi detectada em todos os grupos (figura 20A). Podemos notar a crescente marcação entre os grupos, sendo esta pouco intensa no grupo Controle e de maior intensidade no grupo WSC. Já no grupo CC, houve uma marcação mais acentuada de c-Myc em relação aos demais grupos e igualmente localizada nas áreas fibróticas. A expressão gênica desse fator (figura 20B), no entanto, esteve aumentada 50 vezes no grupo WSC, em comparação ao Controle, e 30 vezes no grupo CC, em relação ao grupo Controle. Não foi encontrada diferença entre os grupos WSC e CC. Os resultados da expressão gênica da CCND1 demonstram que houve um aumento bastante expressivo no grupo CC, comparado ao grupo Controle $(\mathrm{p}<0,002)$. Além disso, a expressão do gene HIF1A (figura 20C) relacionado à hipóxia, e do gene SIRT1 (figura 20D) que pode atuar na regulação da transcrição de SMAD3, não demonstrou alteração entre os grupos de estudo. 
Figura 20 - Imunolocalização e Expressão Gênica de fatores de transcrição relacionados ao TGF $\beta$.
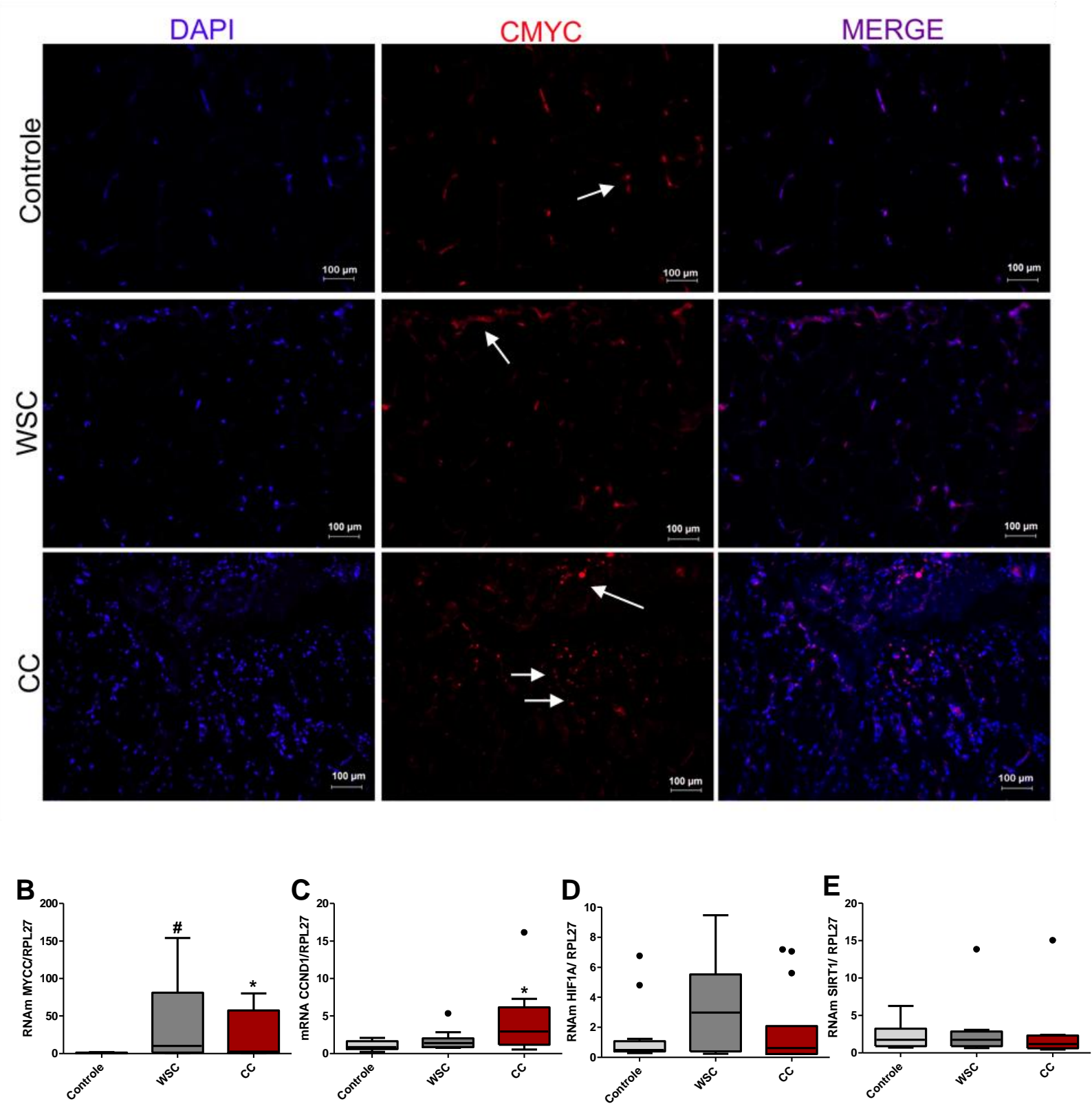

Figura 20 - Imunolocalização e Expressão Gênica de fatores de transcrição relacionados ao TGF $\beta$. A. Imunofluorescência de c-Myc (vermelho) e marcação nuclear com DAPI (azul). Controle $(n=5)$, WSC $(n=5), C C(n=5)$. As setas indicam marcação positiva. B. Expressão gênica de c-Myc. Controle $(n=12), W S C(n=8), C C(n=15)$. C. Expressão Gênica de Ciclina D1. Controle $(n=11), W S C(n=10)$, $C C(n=13)$. C. Expressão gênica de HIF1A; Controle $(n=12)$, WSC $(n=9)$ e $C C(n=15)$. D. Expressão gênica de SIRT1; Controle $(n=10)$, WSC $(n=8)$ e $C C(n=12)$. Dados expressos como mediana, $1^{\text {st }}$ e $3^{\text {st }}$ quartil * $p<0,05$ CC vs Controle. \# $p<0,05$ WSC vs Controle. 


\section{$\underline{6.5 .3}$ Correlação entre as citocinas e o TGF $\beta$}

As figuras 21-28, representam respectivamente os achados em relação as citocinas inflamatórias e anti-inflamatórias, e as correlações entre as três isoformas do TGF $\beta$ em todos os grupos de estudo.

Primeiramente, nas figuras 21-23, encontram-se os resultados correspondentes ao grupo controle. Não houve nenhuma correlação encontrada entre as citocinas dosadas à expressão de TGF $\beta 1$, TGF $\beta 2$ e TGFß3 no grupo. Apenas podemos relatar uma tendência entre TGF $\beta 1$ e IL6 $(p=0,059)$.

No grupo WSC (figuras 24-26), houve correlação positiva entre a concentração de TGF $\beta 1$ com IL1 $\beta(R=0,66 ; p=0,02)$ e IL5 $(R=0,67 ; p=0,02)$. Também podemos relatar uma correlação negativa entre TGF $\beta 2$ e IL7 $(R=-0,69 ; p<0,02)$. A citocina IL6 se correlacionou com a expressão de TGF $\beta 2(R=0,69 ; p<0,02)$ e TGF $\beta 3$ $(R=0,59 ; p<0,04)$.

Por último, o grupo CC (figuras 27-28) apresentou correlação positiva entre as concentrações de TGF $\beta 1$ e as citocinas: TNFa $(R=0,65 ; p<0,01)$, TNF $\beta$ $(R=0,60 ; p<0,02), I L 1 \beta(R=0,50 ; p<0,04)$, IL2 ( $R=0,72 ; p<0,007)$, IL5 ( $R=0,57 ; p<0,03)$, IL12p70 ( $R=0,53 ; p<0,04)$, IL15 $(R=0,59 ; p<0,02)$ e IL17 $(R=0,61 ; p<0,02)$. Entre todas essas citocinas, a IL2 foi a que apresentou mais forte correlação $(R=0,72$; $p<0,007)$ com o TGF $\beta 1$. A citocina IL15 foi a única a se correlacionar com as três isoformas de TGF $\beta$ (TGF $\beta$ 1 ( $R=0,59 ; p<0,02)$ TGF $32(R=0,69 ; p<0,009)$ TGF 3 ( $R=$ $0,78 ; p<0,003)$. Já a expressão de TGF $\beta 3$ foi correlacionada à IL $1 \alpha \quad(R=0,56$; $p<0,03)$, IL2 ( $R=0,58 ; p<0,02)$, IL15 ( $R=0,78 ; p<0,003)$, e IL17 $(R=0,53 ; p<0,04)$. 
Figura 21 - Correlação entre TGFß1 e Citocinas no Tecido Adiposo do grupo Controle.
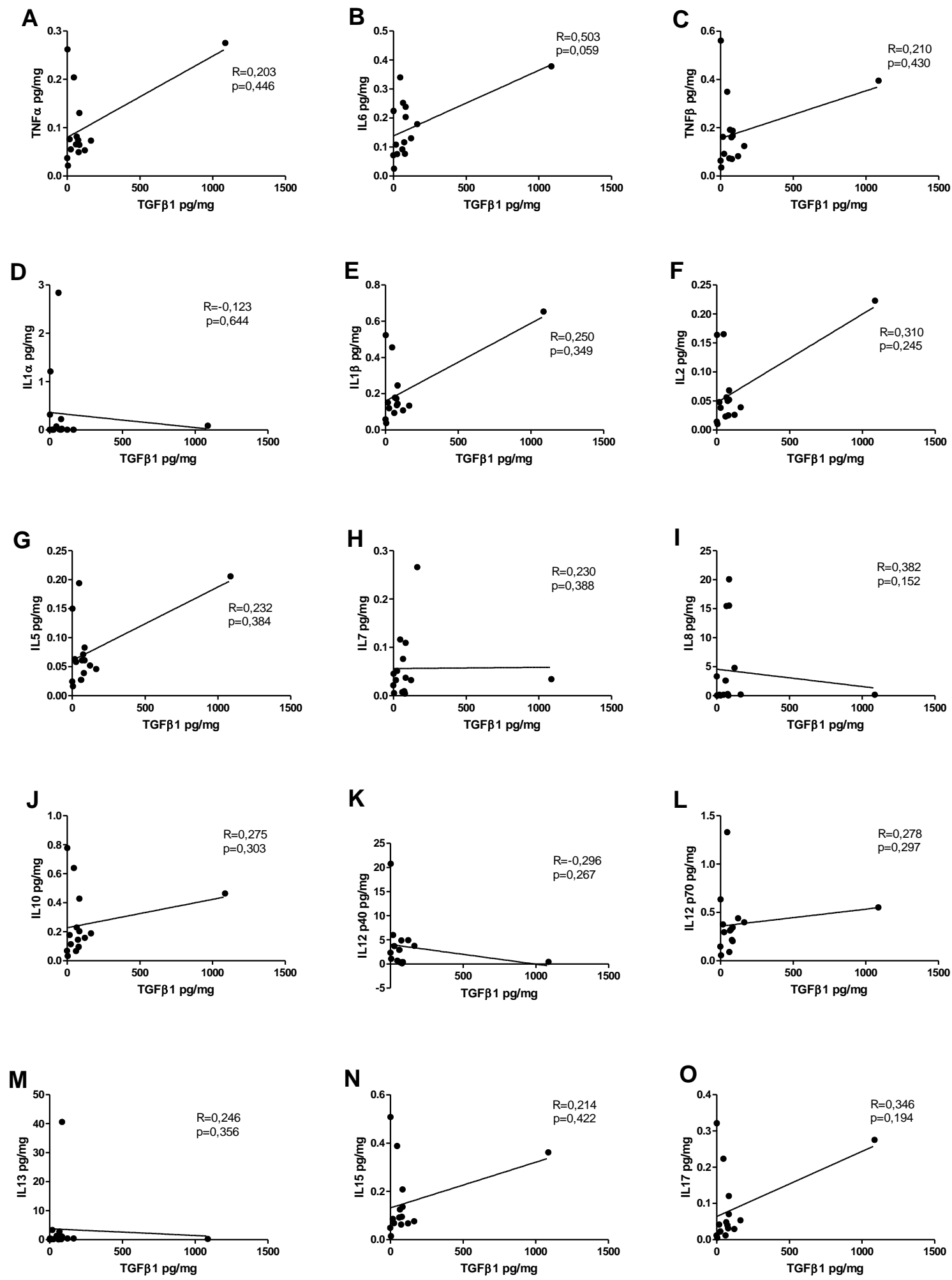

Figura 21 - Correlação entre TGF $\beta 1$ e Citocinas no Tecido Adiposo do grupo Controle. A. TGF $\beta 1$ vs TNFa. B. TGF $\beta 1$ vs IL6. C. TGF $\beta 1$ vs TNF $\beta$. D. TGF $\beta 1$ vs IL1 $\alpha$. E. TGF $\beta 1$ vs IL1 $\beta$. F. TGF $\beta 1$ vs IL2. G. TGF $\beta 1$ vs IL5. H. TGF $\beta 1$ vs IL7. I. TGF $\beta 1$ vs IL8. J. TGF $\beta 1$ vs IL10. K. TGF $\beta 1$ vs IL12 p40 L. TGF 1 1 vs IL12 p70. M. TGF $\beta 1$ vs IL13. N. TGF $\beta 1$ vs IL15. O. TGF 1 vs IL17. Valores do coeficiente da Correlação de Spearman (R) e nível de significância $(p) .{ }^{*} p<0,05$. 
Figura 22 - Correlação entre TGFß2 e Citocinas no Tecido Adiposo do grupo Controle.
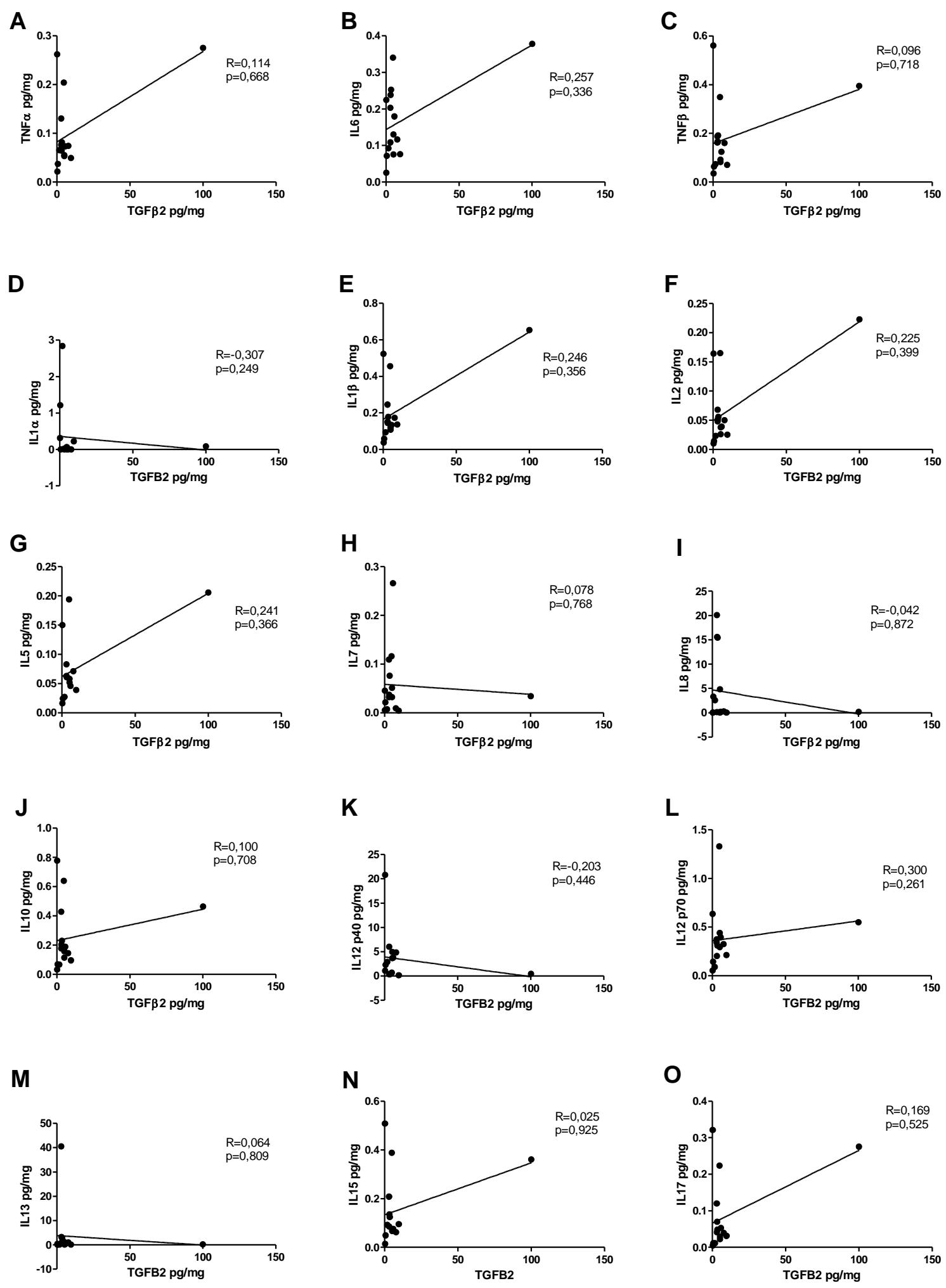

Figura 22 - Correlação entre TGF $\beta 2$ e Citocinas no Tecido Adiposo do grupo Controle. A. TGF $\beta 2$ vs TNFa. B. TGF $\beta 2$ vs IL6. C. TGF $\beta 2$ vs TNF $\beta$. D. TGF $\beta 2$ vs IL1 $\alpha$. E. TGF $\beta 2$ vs IL1 $\beta$. F. TGF $\beta 2$ vs IL2. G. TGF $\beta 2$ vs IL5. H. TGF $\beta 2$ vs IL7. I. TGF 32 vs IL8. J. TGF $\beta 2$ vs IL10. K. TGF 32 vs IL12 p40 L. TGF $\beta 2$ vs IL12 p70. M. TGF $\beta 2$ vs IL13. N. TGF $\beta 2$ vs IL15. O. TGF $\beta 2$ vs IL17. Valores do coeficiente da Correlação de Spearman (R) e nível de significância $(p)$. ${ }^{*} p<0,05$. 
Figura 23 - Correlação entre TGFß3 e Citocinas no Tecido Adiposo do grupo Controle.

A

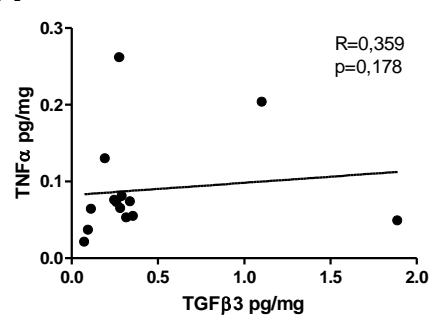

D

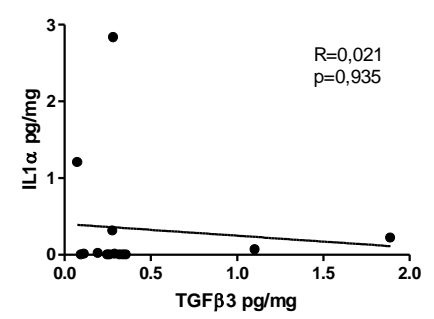

G

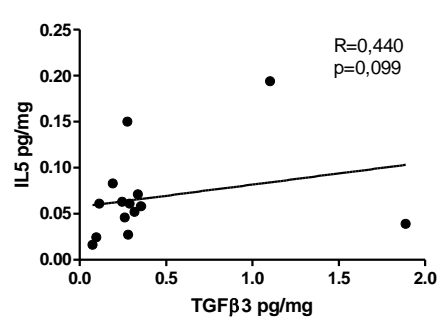

$\mathbf{J}$

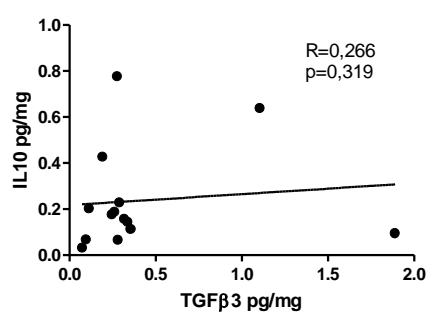

M

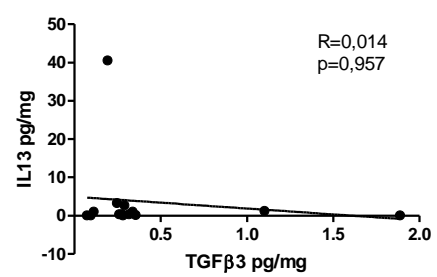

B

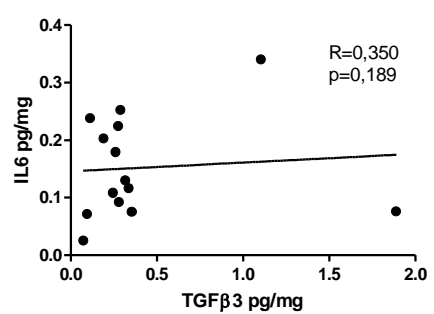

E

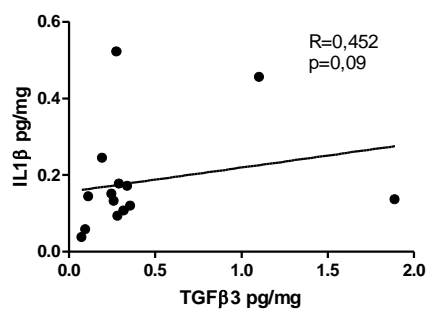

H

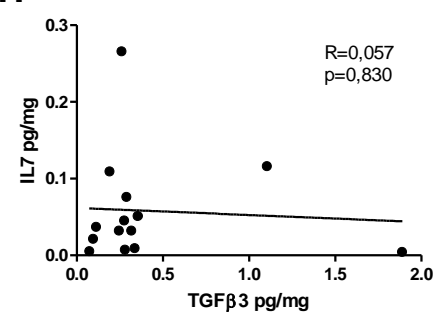

K

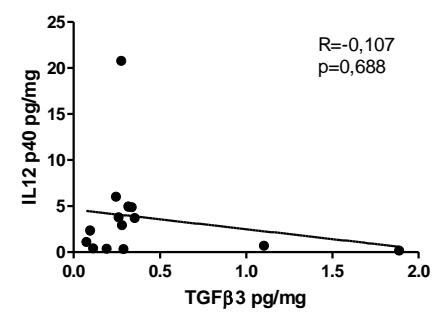

N

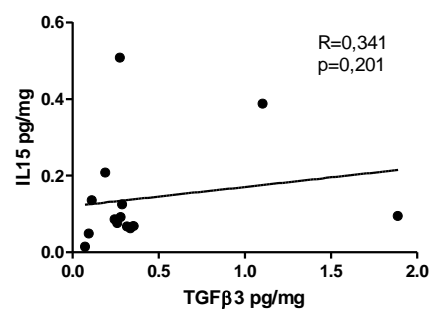

C

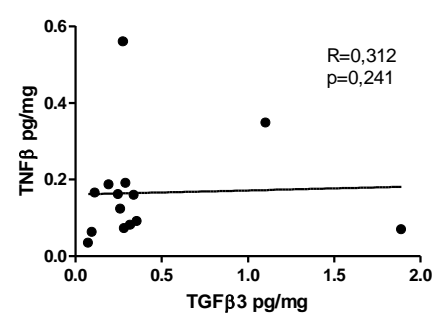

$\mathbf{F}$

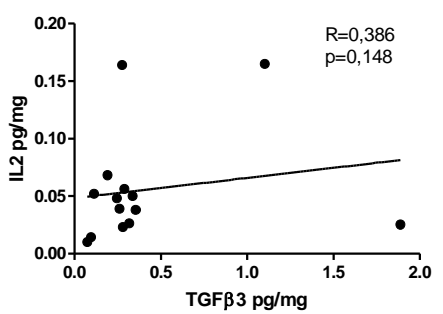

I

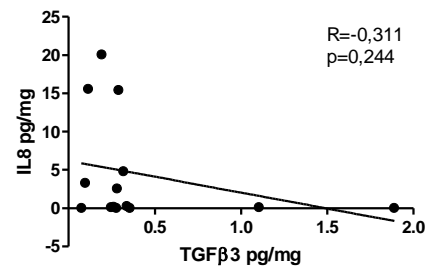

$\mathbf{L}$

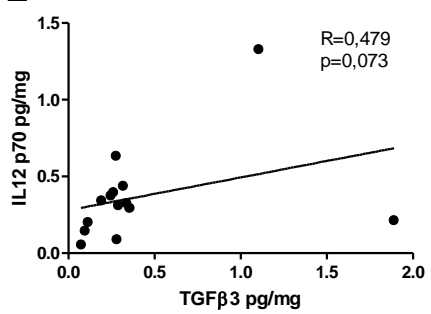

0

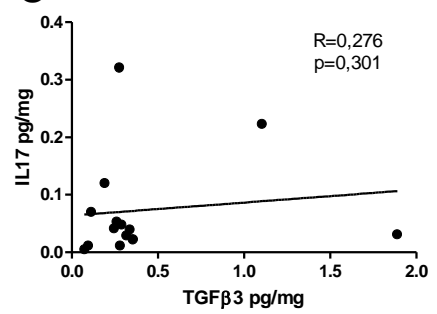

Figura 23 - Correlação entre TGF $\beta 3$ e Citocinas no Tecido Adiposo do grupo Controle. A. TGF $\beta 3$ vs TNF $\alpha$. B. TGF $\beta 3$ vs IL6. C. TGF $\beta 3$ vs TNF $\beta$. D. TGF $\beta 3$ vs IL1 1 . E. TGF $\beta 3$ vs IL1 $\beta$. F. TGF 33 vs IL2. G. TGF 33 vs IL5. H. TGF 33 vs IL7. I. TGF 33 vs IL8. J. TGF 33 vs IL10. K. TGF 33 vs IL12 p40 L. TGF 33 vs IL12 p70. M. TGFß3 vs IL13. N. TGFß3 vs IL15. O.TGFß3 vs IL17. Valores do coeficiente da Correlação de Spearman (R) e nível de significância $(p)$. ${ }^{*} p<0,05$. 
Figura 24 - Correlação entre TGF $\beta 1$ e Citocinas no Tecido Adiposo do grupo WSC.

A

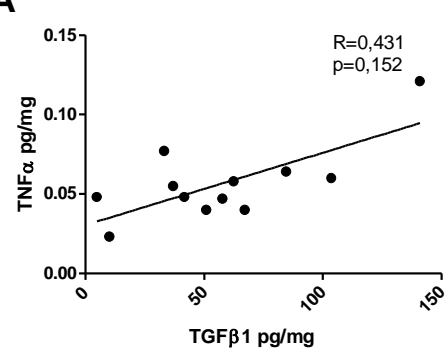

D

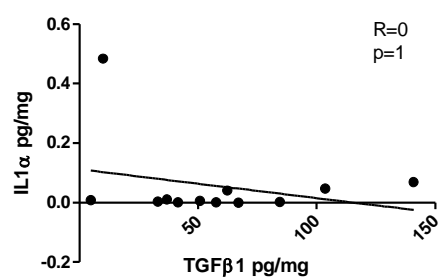

G

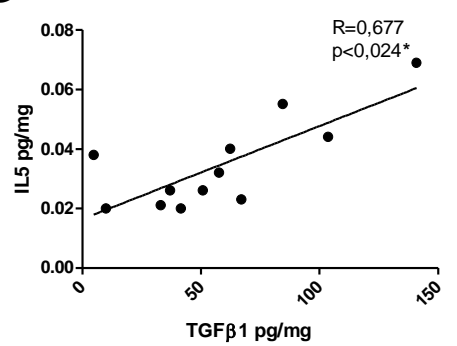

$\mathbf{J}$

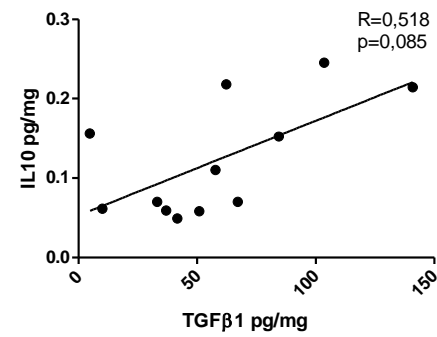

M

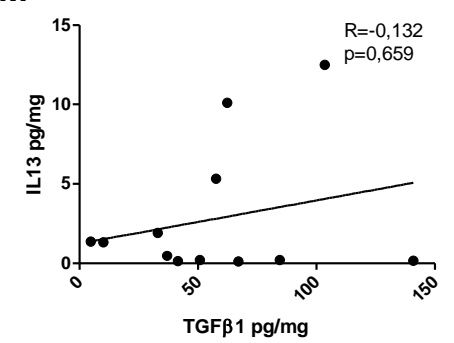

B

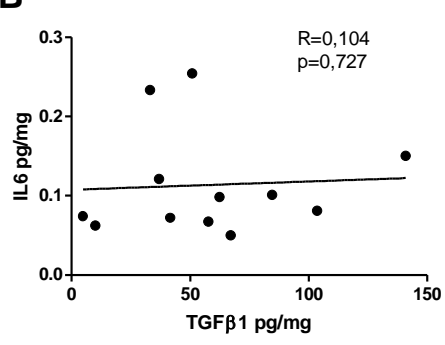

E

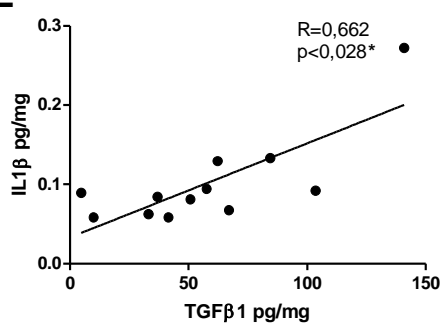

H

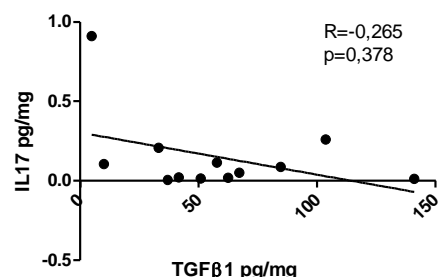

K

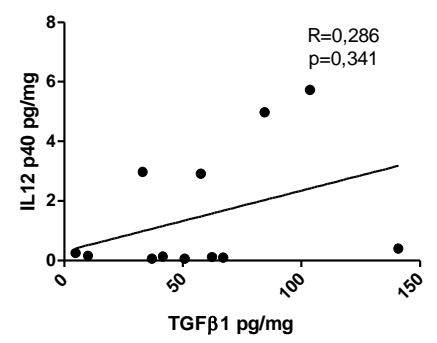

N

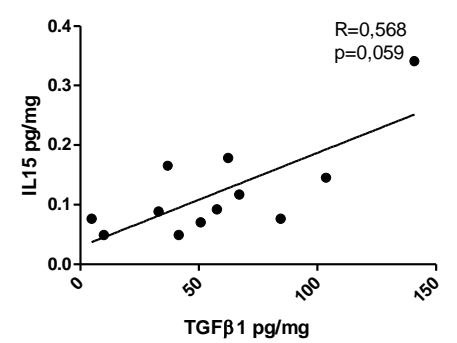

C

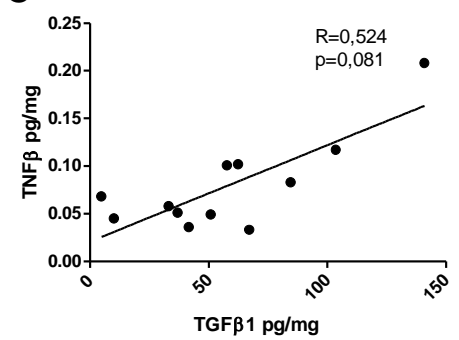

$\mathbf{F}$

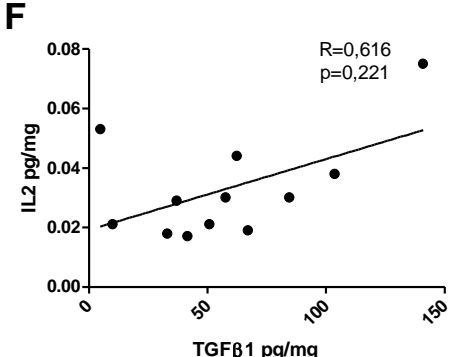

I

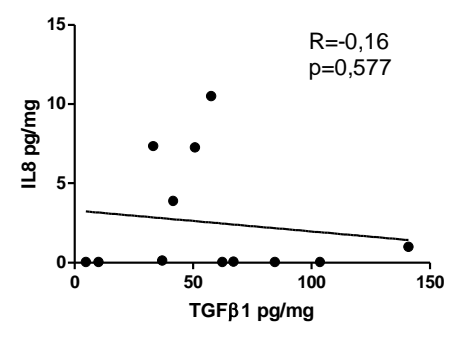

$\mathbf{L}$

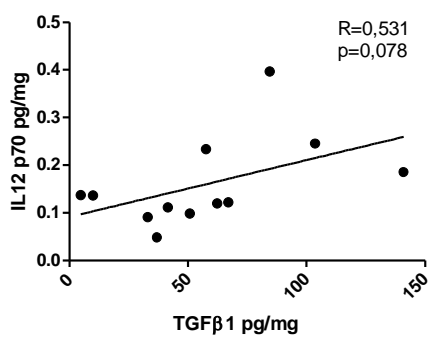

O

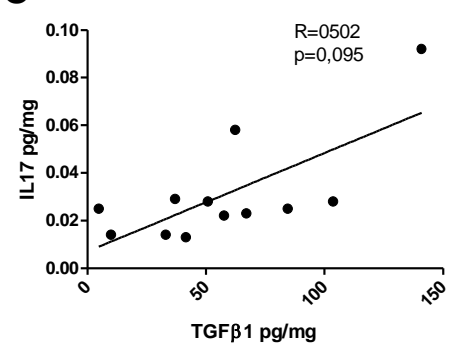

Figura 24 - Correlação entre TGF $\beta 1$ e Citocinas no Tecido Adiposo do grupo WSC. A. TGF $\beta 1$ vs TNFa. B. TGF $\beta 1$ vs IL6. C. TGF $\beta 1$ vs TNF $\beta$. D. TGF $\beta 1$ vs IL1a. E. TGF $\beta 1$ vs IL1 $\beta$. F. TGF $\beta 1$ vs IL2. G. TGF $\beta 1$ vs IL5. H. TGF $\beta 1$ vs IL7. I. TGF $\beta 1$ vs IL8. J. TGF $\beta 1$ vs IL10. K. TGF $\beta 1$ vs IL12 p40 L. TGF $\beta 1$ vs IL12 p70. M. TGF $\beta 1$ vs IL13. N. TGF $\beta 1$ vs IL15. 0 . TGF $\beta 1$ vs IL17. Valores do coeficiente da Correlação de Spearman (R) e nível de significância (p). * $p<0,05$. 
Figura 25 - Correlação entre TGFß2 e Citocinas no Tecido Adiposo do grupo WSC.

A

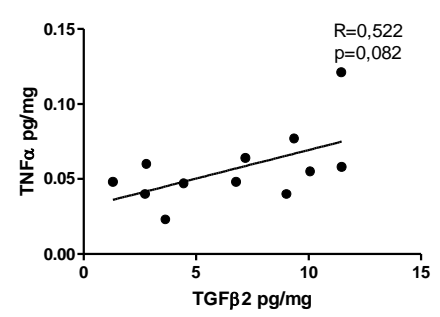

D

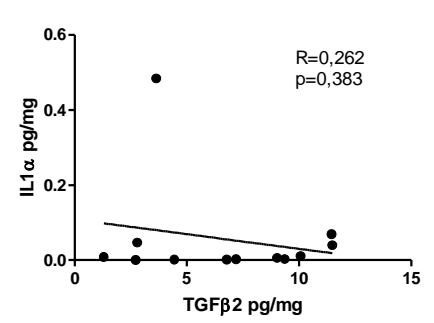

G

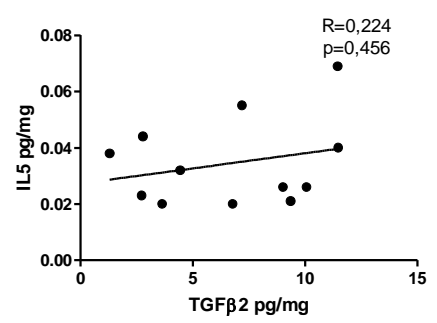

J

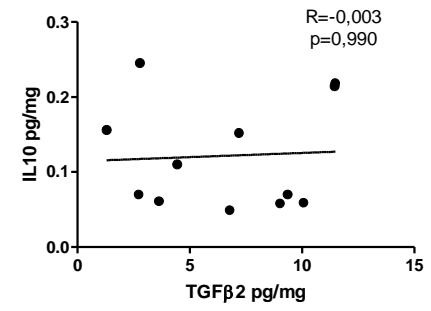

M

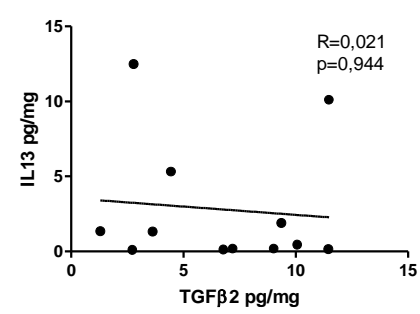

B

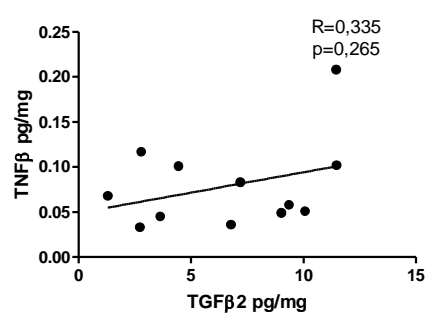

E

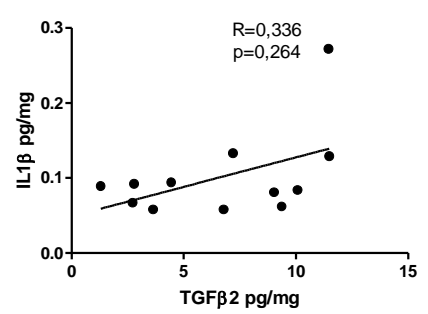

H

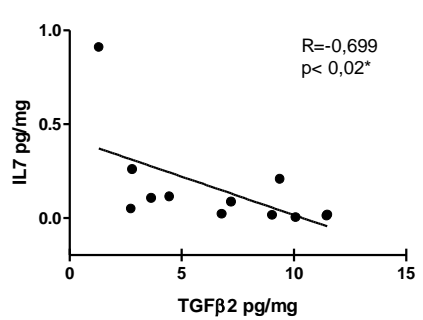

K

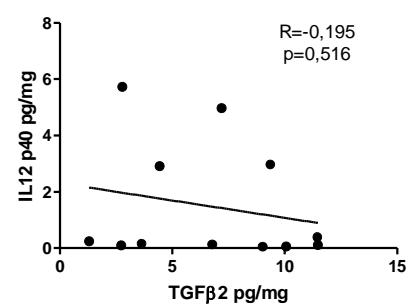

$\mathbf{N}$

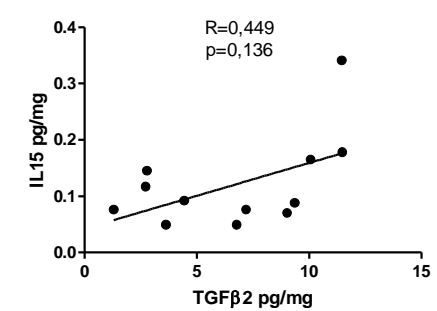

C

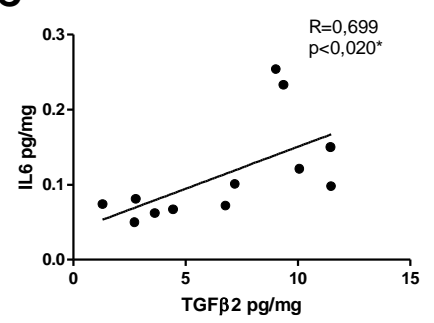

$\mathbf{F}$

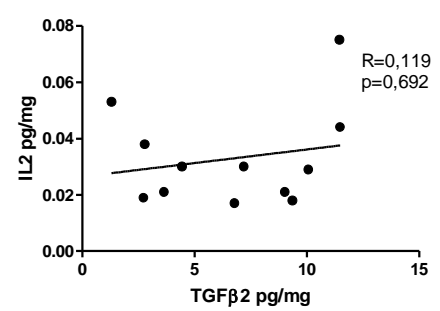

I

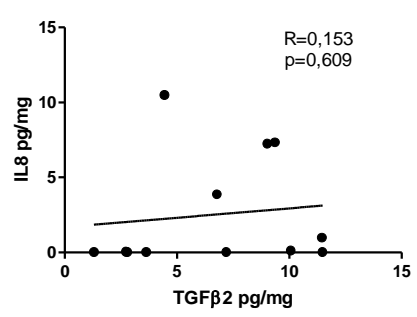

$\mathbf{L}$

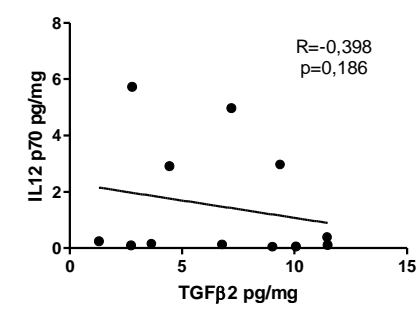

0

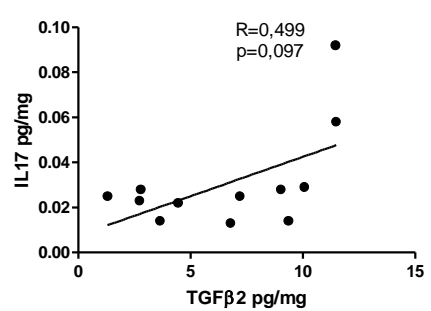

Figura 25 - Correlação entre TGF $\beta 2$ e Citocinas no Tecido Adiposo do grupo WSC. A. TGF $\beta 2$ vs

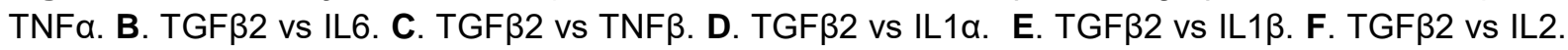
G. TGF $\beta 2$ vs IL5. H. TGF 22 vs IL7. I. TGF $\beta 2$ vs IL8. J. TGF $\beta 2$ vs IL10. K. TGF $\beta 2$ vs IL12 p40 L. TGF $\beta 2$ vs IL12 p70. M. TGF 32 vs IL13. N. TGF $\beta 2$ vs IL15. O. TGF $\beta 2$ vs IL17. Valores do coeficiente da Correlação de Spearman (R) e nível de significância $(p)$. ${ }^{*} p<0,05$. 
Figura 26 - Correlação entre TGF $\beta 3$ e Citocinas no Tecido Adiposo do grupo WSC.

A

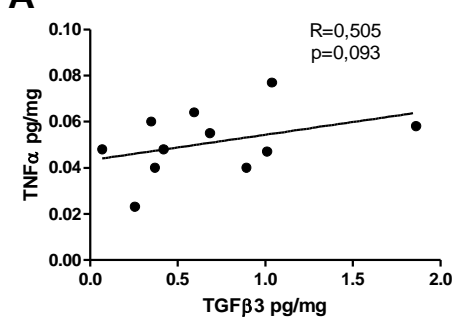

D

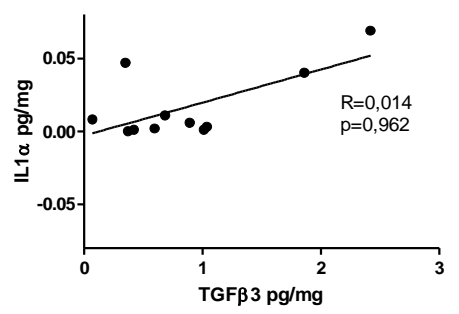

G

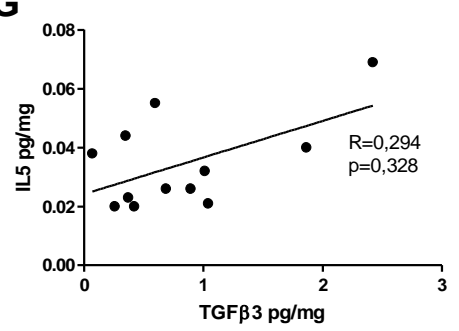

$\mathbf{J}$

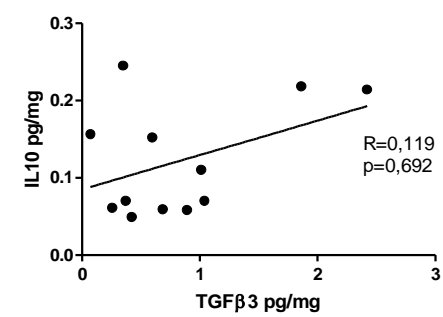

M

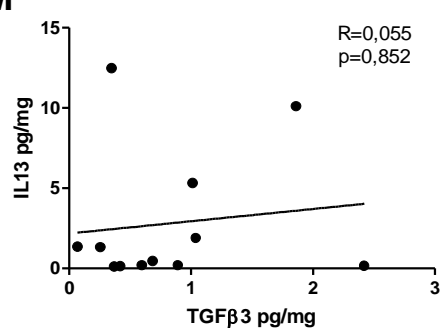

B

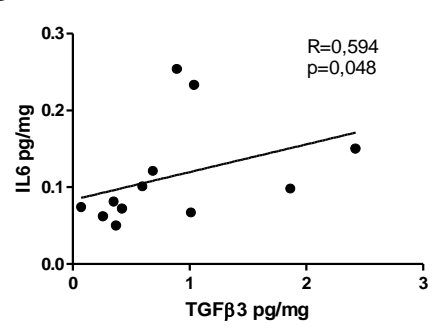

E

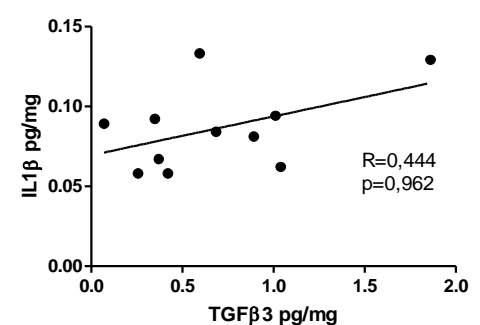

H

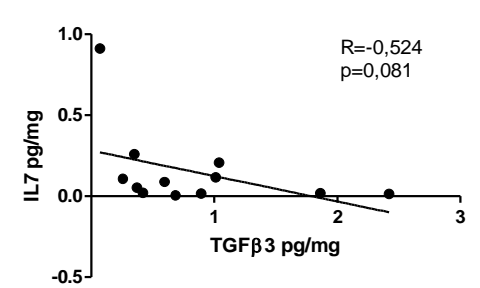

K

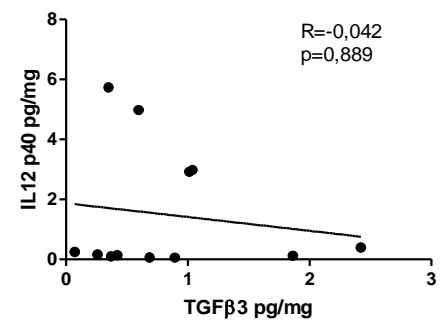

N

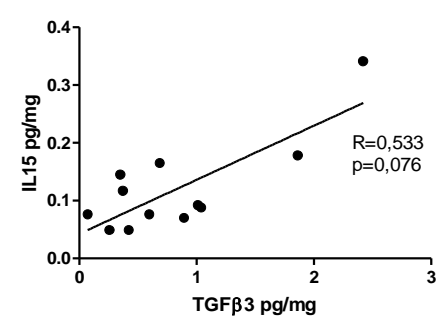

C

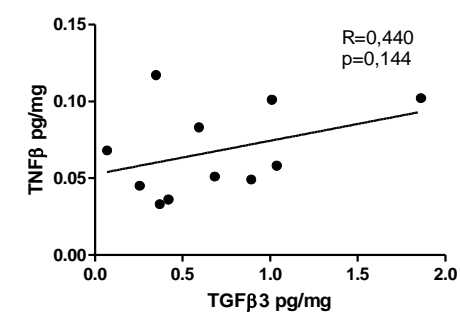

F

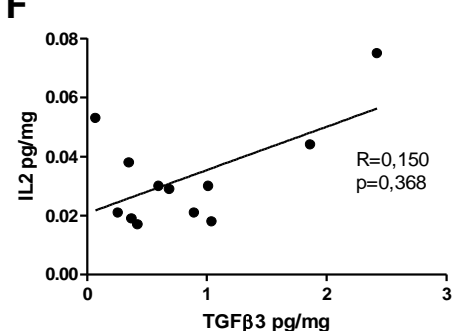

I

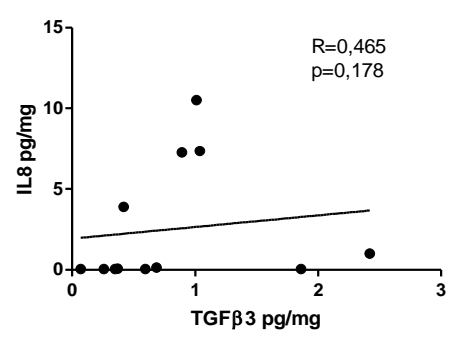

L

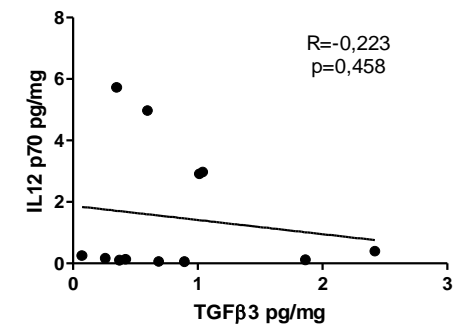

0

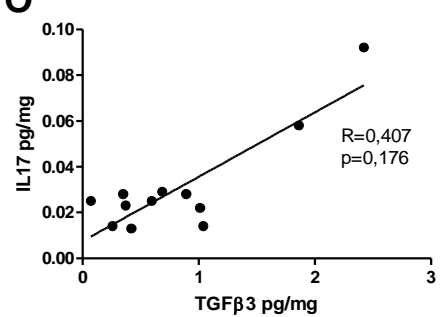

Figura 26 - Correlação entre TGFß3 e Citocinas no Tecido Adiposo do grupo WSC. A. TGF $\beta 3$ vs

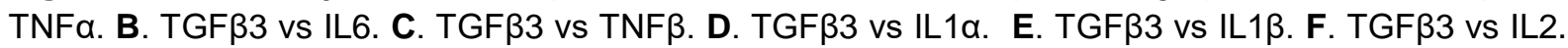
G. TGF $\beta 3$ vs IL5. H. TGF 33 vs IL7. I. TGF 33 vs IL8. J. TGF 33 vs IL10. K. TGFß3 vs IL12 p40 L. TGF $\beta 3$ vs IL12 p70. M. TGF $\beta 3$ vs IL13. N. TGFß3 vs IL15. O. TGFß3 vs IL17. Valores do coeficiente da Correlação de Spearman (R) e nível de significância (p). ${ }^{*} p<0,05$. 
Figura 27 - Correlação entre TGF $\beta 1$ e Citocinas no Tecido Adiposo do grupo CC.

A

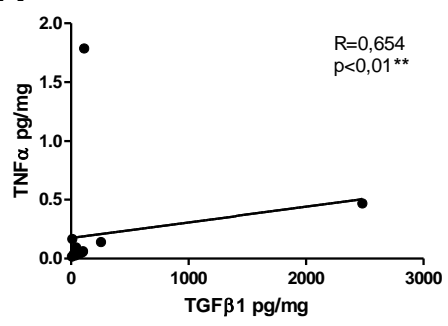

D

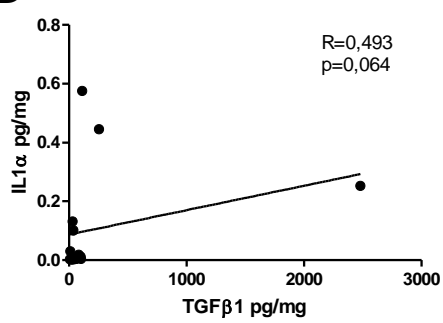

G

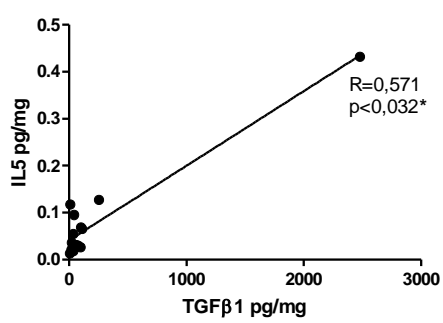

J

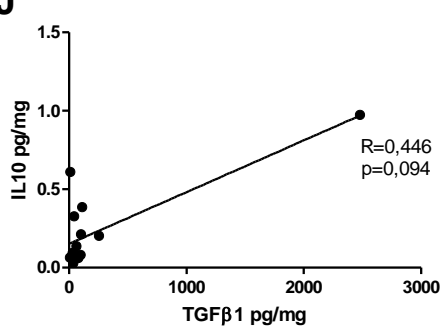

M

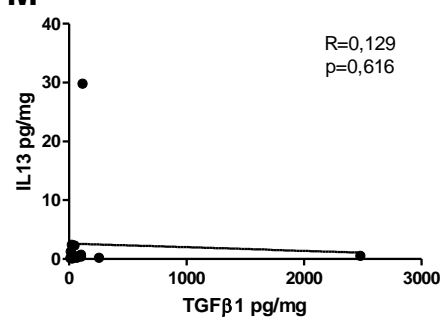

B

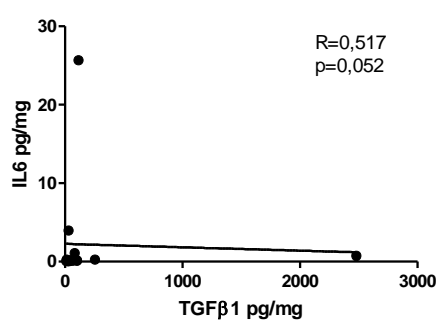

E

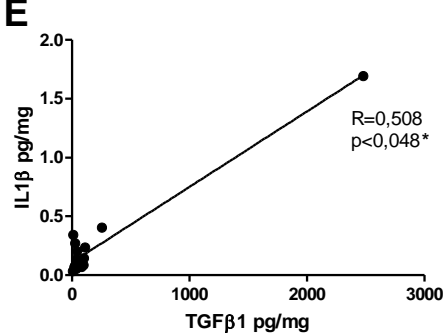

H

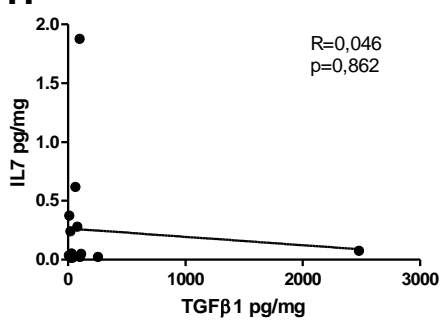

K

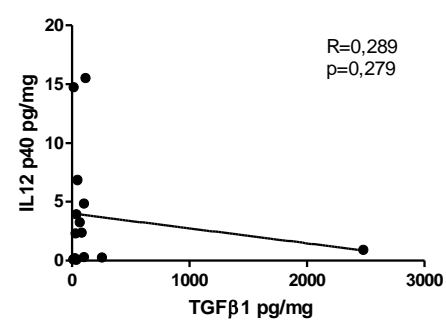

$\mathbf{N}$

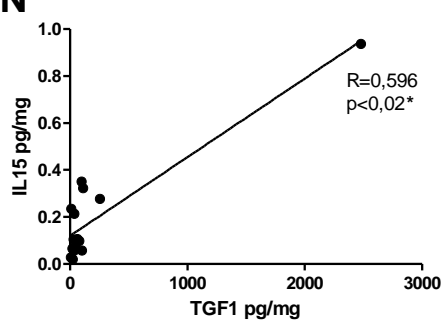

C

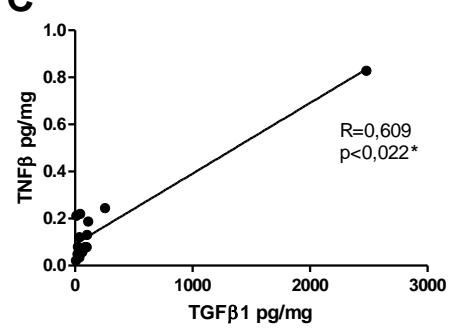

$\mathbf{F}$

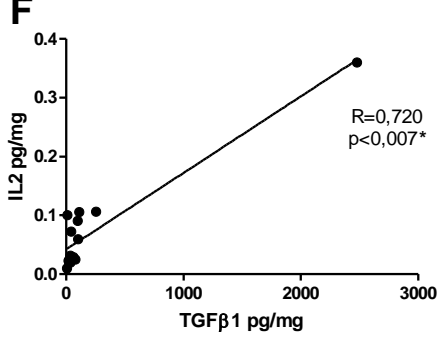

I

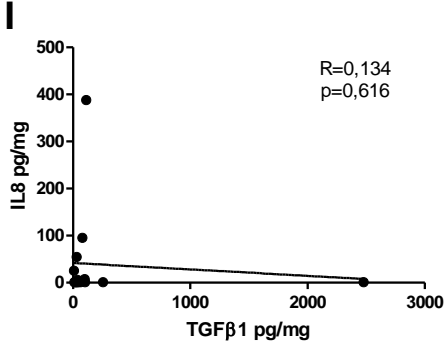

L

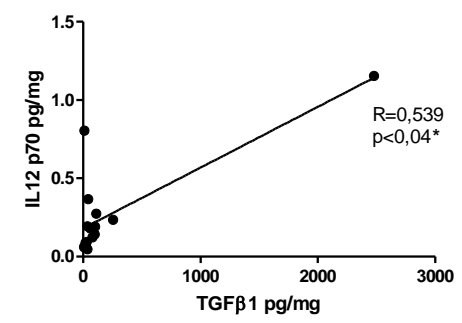

O

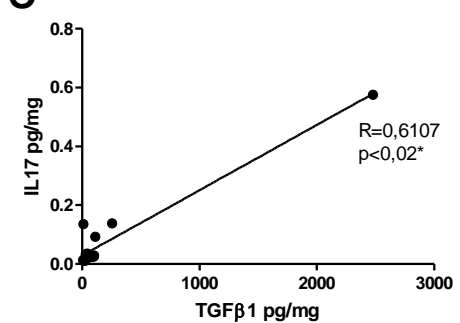

Figura 27 - Correlação entre TGF $\beta 1$ e Citocinas no Tecido Adiposo do grupo CC. A. TGF $\beta 1$ vs TNFa. B. TGF $\beta 1$ vs IL6. C. TGF $\beta 1$ vs TNF $\beta$. D. TGF $\beta 1$ vs IL1 $\alpha$. E. TGF $\beta 1$ vs IL1 $\beta$. F. TGF $\beta 1$ vs IL2. G. TGF $\beta 1$ vs IL5. H. TGF $\beta 1$ vs IL7. I. TGF $\beta 1$ vs IL8. J. TGF $\beta 1$ vs IL10. K. TGF $\beta 1$ vs IL12 p40 L. TGF $\beta 1$ vs IL12 p70. M. TGF $\beta 1$ vs IL13. N. TGF $\beta 1$ vs IL15. O.TGF $\beta 1$ vs IL17. Valores do coeficiente da Correlação de Spearman (R) e nível de significância $(p)$. * $p<0,05$. 
Figura 28 - Correlação entre TGFß2 e Citocinas no Tecido Adiposo do grupo CC.

A

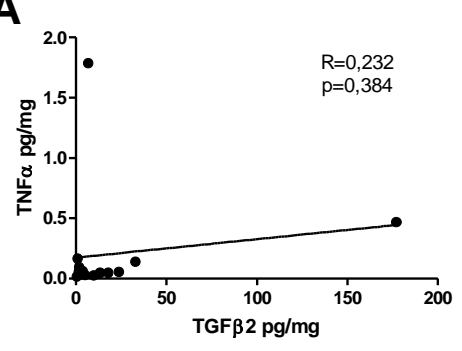

D

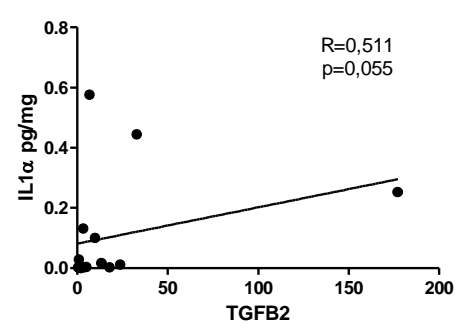

G

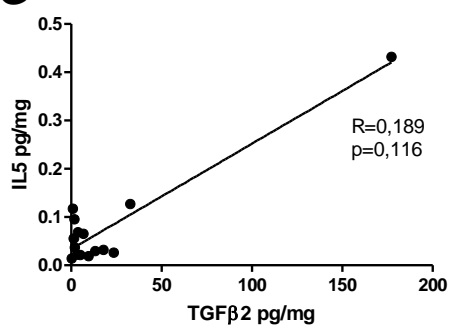

J

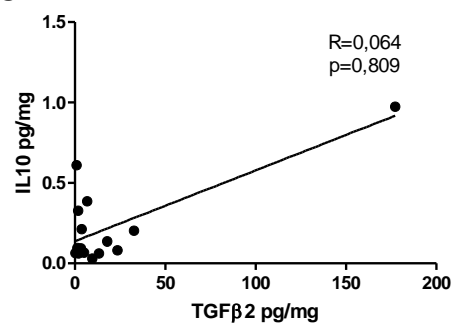

M

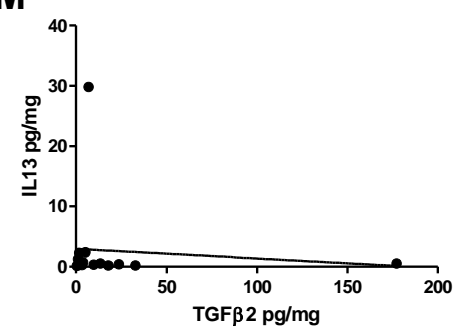

B

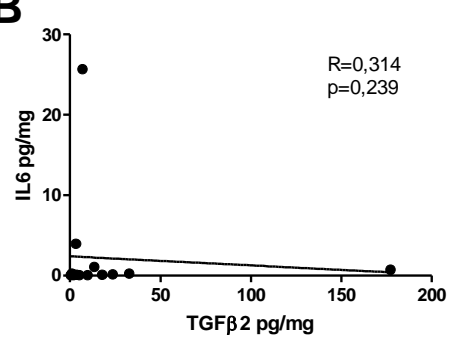

E

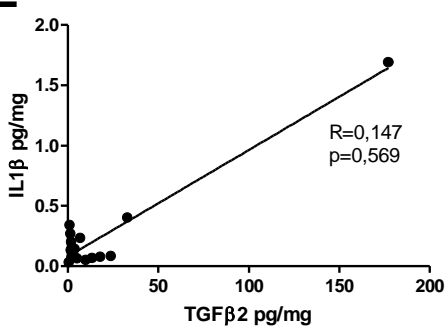

H

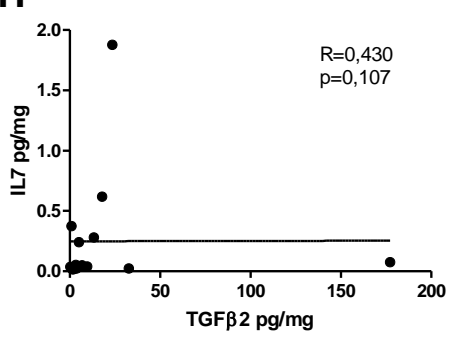

$\mathbf{K}$

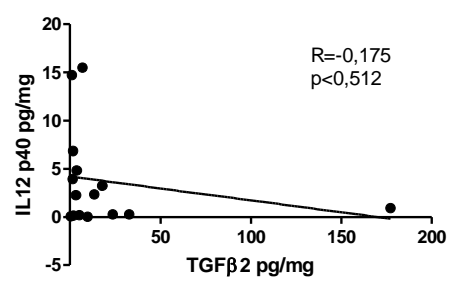

N

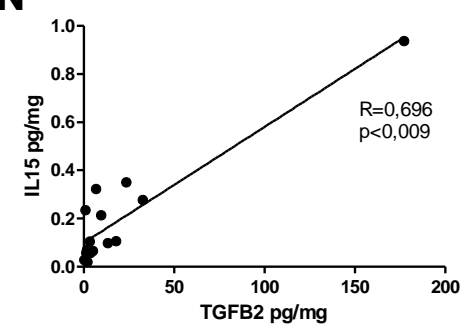

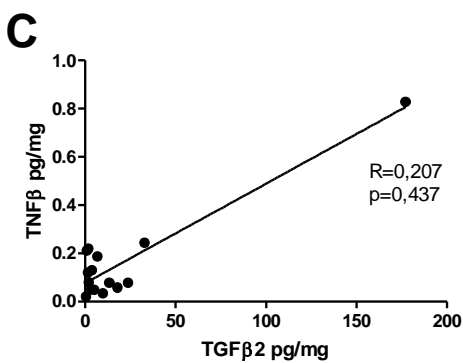

$\mathbf{F}$

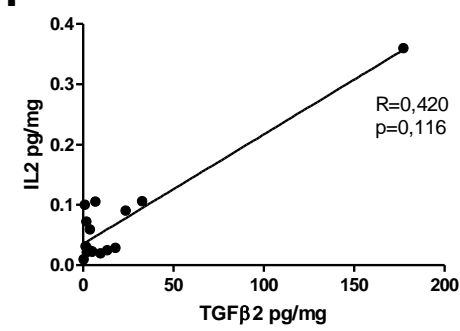

I

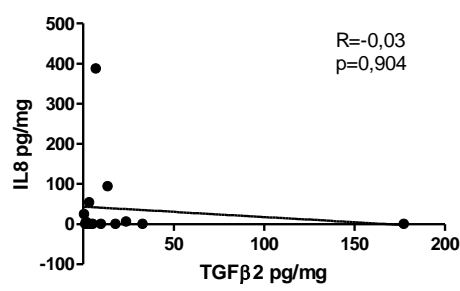

$\mathbf{L}$

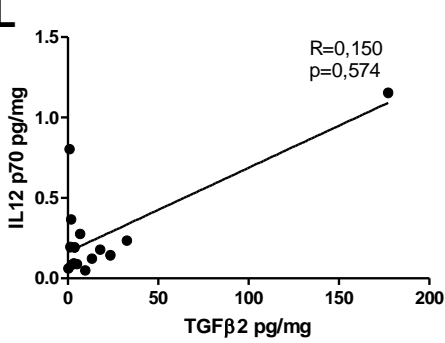

0

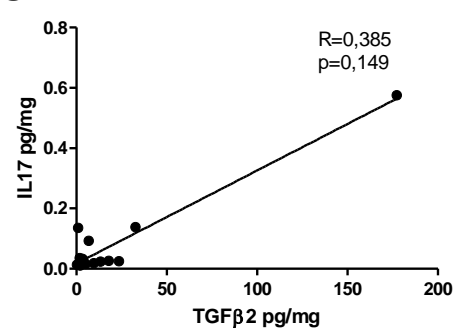

Figura 28 - Correlação entre TGF $\beta 2$ e Citocinas no Tecido Adiposo do grupo CC. A. TGFß2 vs TNFa. B. TGF $\beta 2$ vs IL6. C. TGF $\beta 2$ vs TNF $\beta$. D. TGF $\beta 2$ vs IL1 $\alpha$. E. TGF $\beta 2$ vs IL1 $\beta$. F. TGF $\beta 2$ vs IL2. G. TGF $\beta 2$ vs IL5. H. TGF $\beta 2$ vs IL7. I. TGF $\beta 2$ vs IL8. J. TGF $\beta 2$ vs IL10. K. TGF $\beta 2$ vs IL12 p40 L. TGF 32 vs IL12 p70. M. TGFß2 vs IL13. N. TGFß2 vs IL15. O. TGFß2 vs IL17. Valores do coeficiente da Correlação de Spearman (R) e nível de significância ( $p)$. ${ }^{*} p<0,05$. 
Figura 29 - Correlação entre TGFß3 e Citocinas no Tecido Adiposo do grupo CC.
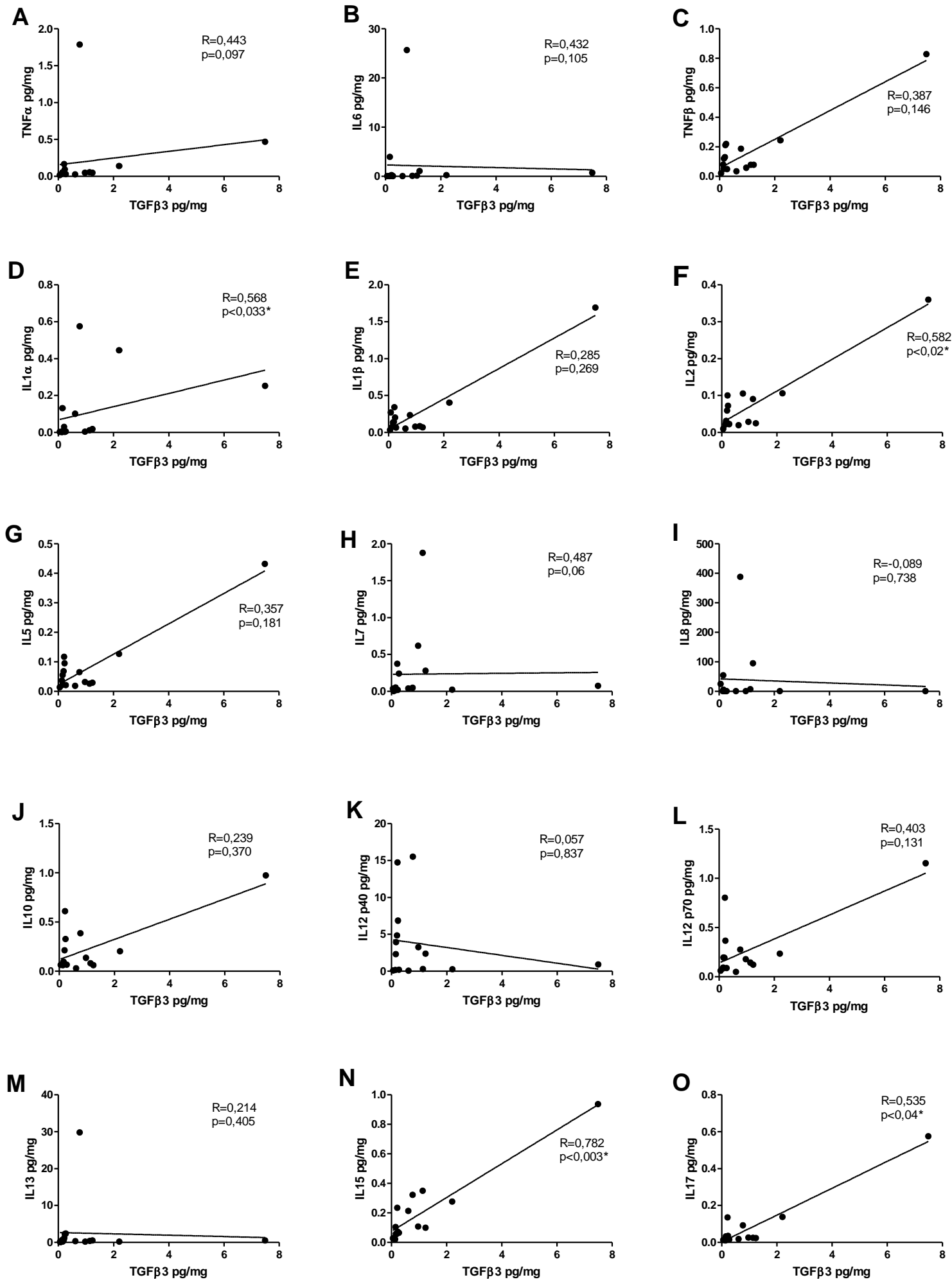

Figura 29 - Correlação entre TGF $\beta 3$ e Citocinas no Tecido Adiposo do grupo CC. A. TGF $\beta 3$ vs TNFa. B. TGF $\beta 3$ vs IL6. C. TGF $\beta 3$ vs TNF $\beta$. D. TGF $\beta 3$ vs IL1 $\alpha$. E. TGF $\beta 3$ vs IL1 $\beta$. F. TGF 33 vs IL2. G. TGF 33 vs IL5. H. TGF 33 vs IL7. I. TGF 33 vs IL8. J. TGF 33 vs IL10. K. TGF 33 vs IL12 p40 L. TGF 33 vs IL12 p70. M. TGFß3 vs IL13. N. TGF33 vs IL15. O.TGFß3 vs IL17. Valores do coeficiente da Correlação de Spearman $(R)$ e nível de significância $\quad(p) . \quad{ }^{*} p<0,05$. 


\section{DISCUSSÃo}

A caquexia associada ao câncer é uma síndrome debilitante e irreversível, caracterizada principalmente pela redução progressiva do peso corporal, resultante da perda de músculo esquelético e de tecido adiposo (Evans et al., 2008; Argilés et al., 2010). Aproximadamente nove milhões de indivíduos no mundo sofrem com a síndrome, cerca de $80 \%$ dos pacientes com câncer avançado, sendo que nesses, a caquexia é responsável diretamente por $20-40 \%$ dos óbitos (Evans et al., 2008; Tisdale, 2010; Lok, 2015).

O consenso internacional de 2011, no entanto, coloca que a perda de massa gorda durante a vigência da caquexia não está sempre presente (Fearon et al., 2011). Contudo, apesar de grande parte da literatura abordar principalmente a perda de massa muscular, a perda de tecido adiposo é atualmente, considerada um ponto importante, pois, está associada ao pior prognóstico, além de anteceder àquela de massa magra, podendo ser utilizada como marcador para síndrome (Bing et al., 2006; Bing e Trayhurn, 2009; Bing, 2011; Argilés et al., 2014).

O tecido adiposo é drasticamente afetado pela síndrome sofrendo alterações moleculares e celulares, tanto em modelos experimentais como em pacientes com câncer, as quais por outro lado, podem contribuir para o agravamento da síndrome (Bertevello e Seelaender, 2001; Machado et al., 2004; Batista, Neves, et al., 2012; Batista et al., 2013; Camargo et al., 2015; Batista et al., 2016).

O objetivo do presente estudo foi investigar a expressão de genes e proteínas relacionadas à via de sinalização do TGF $\beta$ no remodelamento do tecido adiposo subcutâneo na caquexia em pacientes com câncer gastrointestinal. Nesse contexto, nossos principais achados demonstram que o remodelamento da MEC no tecido adiposo subcutâneo é exclusivo à síndrome, e não a todos pacientes de câncer existindo a contribuição proveniente da via de sinalização do TGF $\beta$, em associação com o recrutamento dos miofibroblastos, para o cenário fibrótico.

A caquexia associada ao câncer é orquestrada, em parte, pela presença de inflamação sistêmica resultante do aumento de fatores inflamatórios sintetizados, tanto pelo tumor, quanto por órgãos e tecidos do organismo, que conduzem à inflamação sustentada (Tsoli e Robertson, 2013). Os critérios de caracterização dessa síndrome, de acordo com (Evans et al., 2008), incluem primeiramente, a 
perda de peso superior à $5 \%$ do peso corporal total nos últimos 12 meses ou menos. Em concordância com esse primeiro critério, os pacientes caquéticos do estudo apresentaram perda média de $14 \%$ do peso corporal (Tabela 2), não havendo variação significativa para os grupos Controle e WSC. Adicionalmente, os pacientes do grupo CC mostraram o grau de caquexia entre o médio (10\% de perda de peso) e o severo ( $15 \%$ de perda de peso). Em relação ao IMC, o estudo de Evans et al., (2008), descreve que esse parâmetro deve ser $<20,0 \mathrm{~kg} / \mathrm{m}^{2}$ para o diagnóstico da caquexia, quando não é possível acessar o histórico de peso corporal do paciente. Todavia, apesar do grupo CC haver uma perda de peso consideravelmente alta, a média do IMC desse grupo foi maior do que está previsto nessa recomendação, o que sugere que a média do IMC na população brasileira pode ser maior que a indicada nos estudos internacionais. O estudo de Gómez Valiente Da Silva et al., (2014), realizado com pacientes com câncer e brasileiros, com idade média acima de 50 anos, relata que a frequência de sobrepeso ou obesidade em $60 \%$ no grupo de pacientes.

Adicionalmente a perda de peso, e ainda de acordo com Evans et al., (2008), os pacientes com diagnóstico de caquexia devem apresentar os seguintes parâmetros bioquímicos alterados: $\mathrm{PCR}>5 \mathrm{mg} / \mathrm{L}$, hemoglobina $<12 \mathrm{~g} / \mathrm{dL}$ e albumina $<3,2 \mathrm{~g} / \mathrm{dL}$. Nossos achados demonstram que grupo CC apresentou concentrações de PCR (figura 7) acima do esperado, com média de 10,65 mg/L, enquanto nos outros grupos, os níveis estavam abaixo do valor predito para o diagnóstico de caquexia. Os níveis de hemoglobina também estavam abaixo de 12 $\mathrm{g} / \mathrm{dL}$ no grupo CC, no entanto, as concentrações de albumina em nosso grupo de pacientes caquéticos foram acima das recomendadas pelo consenso $(3,6 \mathrm{~g} / \mathrm{dL})$. A revisão realizada por (Morley et al., 2006), indica 3,5 g/dL de concentrações dessa proteína para diagnóstico da caquexia. Nosso grupo adota a razão entre PCR e albumina, que se mostrou eficiente como uma ferramenta adicional para o diagnóstico da caquexia.

Os dados obtidos em relação à presença de anorexia e fadiga, através da aplicação dos questionários FACT/ESPEN e EORTC QLQC30 foram utilizados apenas para classificação dos pacientes. Já os dados referentes ao score do questionário QLQC30 (figura 8) referentes à qualidade de vida, indicaram a diminuição drástica desse parâmetro nos pacientes com caquexia. Cabe ressaltar, que em nosso estudo, a qualidade de vida dos pacientes foi acessada previamente à 
internação. Um estudo realizado com mais de 400 pacientes com câncer gastrointestinal, de esôfago, entre outros, relatou a maior presença de caquexia entre aqueles com tumores no trato gastrointestinal, e que a redução na qualidade de vida no período pós-operatório, esteve correlacionada a menor taxa de sobrevivência, entre os pacientes com baixa qualidade de vida (Aahlin et al., 2016).

Nesse contexto, foi relatado no presente estudo, que 30\% dos pacientes caquéticos foram a óbito, enquanto no grupo câncer com peso estável ocorreu o óbito em apenas $15 \%$ dos pacientes, em um intervalo médio de 35 dias, e máximo de 5 meses, para ambos os grupos. Contudo, no grupo WSC foram relatadas complicações pós-cirúrgicas. Podemos ainda, relacionar a taxa de sobrevivência dos pacientes caquéticos com o total de $14 \%$ de perda de peso nesses pacientes. Por outro lado, a perda de tecido adiposo é relacionada ao tempo da doença. Em um estudo de coorte incluindo 108 pacientes com câncer de cólon-reto e câncer de pulmão, utilizando tomografia computadorizada, relatou-se que a perda de tecido adiposo subcutâneo e visceral ocorre no mesmo intervalo de tempo, e de forma acelerada aproximadamente 7-6 meses antes do óbito (Murphy et al., 2010). Não pudemos, contudo acessar a perda da massa gorda.

A depleção do tecido adiposo na caquexia associada ao câncer é resultante da alteração na composição corporal, em conjunto com a diminuição na capacidade de captar ácidos graxos, e lipólise aumentada (Ebadi e Mazurak, 2015). O processo de lipólise aumentada reflete na diminuição do conteúdo de triacilglicerol estocado em forma de gotícula lipídica nos adipócitos, e na consequente diminuição das dimensões dos mesmos (Bing et al., 2006; Tsoli et al., 2014). Em modelos animais, há a prevenção no estoque de lípides com a diminuição de fatores adipogênicos (C/EBPb, C/EBPa,PPARg and SREBP-1c) e fatores lipogênicos (ACC, FAS, SCD-1, GPAT and Glut-4), levando à atrofia do tecido adiposo que apresenta deposição de fibras do tecido conjuntivo (Bing et al., 2006). Nesse modelo, o animal recebe o implante com células de adenocarcinoma de cólon MAC16, e o efeito do tumor permite que o animal sobreviva por 18 dias (Bing et al., 2006). Porém, em modelos animais com adenocarcinoma de cólon C26, os quais sobrevivem somente 14 dias após a inoculação das células tumorais, é apenas observada a diminuição da área e perímetro dos adipócitos, bem como, o conteúdo total do tecido adiposo (Tsoli et al., 2014). Já nos modelos animais utilizados por nosso grupo de pesquisa, com injeção de células do carcinoma de Walker 256 no flanco direito do animal, com sobrevida 
de apenas 14 dias, foi observada a diminuição apenas do tecido adiposo epididimal em comparação aos outros depósitos estudados; retroperitoneal e mesentérico, assim também, foi relatada a diminuição na área, diâmetro e perímetro dos adipócitos nesse depósito em relação aos animais controle (Bertevello e Seelaender, 2001). Além disso, em outro estudo foi demonstrado que ocorre marcada infiltração de macrófagos entre os adipócitos no 14ํํa dia após inoculação do tumor (Machado et al., 2004).

Um elegante estudo conduzido por Dahlman (2010) realizado com pacientes de câncer gastrointestinal, caquéticos ou não, a perda de tecido adiposo subcutâneo foi relatada ocorrendo preferencialmente à perda de massa muscular, e de forma secundária à perda do volume celular dos adipócitos, sendo que as células não foram afetadas em termos de quantidade. As análises de array demonstram que mais de 400 genes são regulados pela caquexia, sendo 365 regulados para baixo, enquanto 61 são altamente expressos, e quando relacionados a processos celulares, genes ligados à adesão celular, MEC, citoesqueleto de actina foram pobremente regulados, no entanto, o fator de transcrição nuclear hepático HFN4, o que tem o papel na regulação da transcrição de maior parte desses genes mostrou exacerbado aumento de expressão (Dahlman et al., 2010).

Nesse contexto, e diante da relevância do papel da MEC em providenciar suporte mecânico para as células, bem como, do dinamismo de seus processos na regulação do microambiente tecidual, foi intuito da nossa dissertação de mestrado estudar uma pequena parte de seus componentes na vigência da caquexia associada ao câncer (Alves, 2011). Relatamos sobre alterações morfológicas e morfométricas no tecido adiposo com modificação de deposição de fibras do tecido conjuntivo, especialmente colágenos no grupo de pacientes com caquexia em comparação ao grupo controle (Alves, 2011). Mais recentemente, publicamos no Journal of Cachexia, Sarcopenia and Muscle, parte dos resultados, acerca do rearranjo sobre o qual o tecido adiposo subcutâneo é acometido, e aumento na deposição de colágeno com a utilização da coloração picro Sirius Red (luz polarizada). A análise de birrefrigência mostrou maior quantidade de colágeno do tipo I em relação ao tipo III, e em associação o aumento de células infiltrantes,identificadas por imunohistoquímica como sendo macrófagos e linfócitos (Batista et al., 2016). 
No presente estudo, no qual abordamos alterações vigentes em três grupos, de pacientes, sendo um controle, e os outros dois grupos com pacientes de câncer gastrointestinal, divididos em peso estável e com caquexia, pudemos demonstrar que as alterações morfológicas e morfométricas do tecido adiposo subcutâneo são dependentes da presença da caquexia. Não notamos diferenças entre a morfologia do grupo controle do grupo câncer de peso estável. A análise morfométrica detectou ainda, a diferença entre o tamanho dos adipócitos (área, diâmetro e perímetro) do grupo CC em comparação com o grupo WSC; contudo não foi encontrada diferença significativa entre o grupo CC e Controle.

Em acordo com estudos anteriores, acerca do tecido adiposo frente à caquexia, tanto em modelos experimentais, como em humanos (Bing et al., 2006; Alves, 2011; Batista et al., 2016), em nosso estudo, demonstramos o acúmulo de fibras colágenas (figura 10A); porém as análises quantitativas não detectaram diferença estatística. Houve claro remodelamento de fibras colágenas associadas à glicoproteínas e proteoglicanos. Nossos achados demonstram sob diferentes colorações (figura 12), que detectam estágios de acúmulo de elastina no tecido, de oxitalânicas, elaunínicas e fibras elásticas maduras, houve o acúmulo das fibras do sistema elástico no tecido adiposo dos pacientes caquéticos em relação aos outros grupos. Em modelos experimentais de obesidade induzida, por dieta hiperlipídica os níveis de RNAm de elastina aumentam em associação com os de colágeno 3A1 e 6A1, no tecido adiposo, nos animais obesos (Li et al., 2016).

Em conjunto, nossos achados demonstram que há remodelamento no tecido adiposo diante as modificações impostas durante a caquexia associada ao câncer, e que este é exclusivo à síndrome. O acúmulo de fibras do tecido conjuntivo, e deposição específica de colágenos, e fibronectina são resultantes no desenvolvimento da fibrose tecidual (Wynn e Ramalingam, 2012).

A obesidade é abertamente associada à presença de fibrose no tecido adiposo, pois devido ao aumento no tamanho dos adipócitos, há o remodelamento do tecido, e consequente fibrose. O trabalho de Khan et al. (2009) demonstra elegantemente que em modelos experimentais para a síndrome, utilizando animais geneticamente modificados ob/ob, e em animais com dieta hiperlipídica, a expressão gênica do colágeno VI, cadeias COL6A1 e COL6A3 é abundantemente aumentada no tecido adiposo. No mesmo estudo, quando os autores utilizaram animal nocaute para colágeno VI relataram que ocorre uma expansão desenfreada 
dos adipócitos (Khan et al., 2009). Já em humanos obesos, também foi relatado o aumento da expressão gênica, e proteica do colágeno VI no tecido adiposo subcutâneo, sendo este positivamente correlacionado com a presença de fibrose no tecido (Spencer et al., 2010).

A fibronectina é secretada por fibroblastos, de forma co-localizada com fibrilas de colágeno, e sua ausência leva à não agregação de colágenos, demonstrando que a secreção de um torna-se essencial ao outro (Singh et al., 2010). Em nosso estudo, caracterizamos a presença de fibrose no tecido adiposo dos pacientes com câncer gastrointestinal e caquexia, a expressão aumentada dos colágenos tipo: I, III, VI, e da fibronectina através da imunohistoquímica para os mesmos. As marcações positivas dessas proteínas foram notoriamente observadas no grupo $\mathrm{CC}$, em relação aos demais, especialmente nas áreas com maior deposição de MEC. Além disso, nossos resultados ilustram que não há diferença na intensidade de marcação dos colágenos do tipo I e III, em contraste do demonstrado nas análises de birrefrigência (Batista et al., 2016). Interessantemente, em um estudo com doenças inflamatórias do globo ocular, as análises patológicas de biópsias da gordura orbital, evidenciaram a presença de fibrose no tecido adiposo em associação com análises de expressão gênica, por array, relatando o aumento de fibronectina e colágenos tipo la2 e VIlla2 (Rosenbaum et al., 2015). Diante dessas evidências, a expressão dos colágenos tipo I, III e VI, e da fibronectina são importantes marcadores de fibrose no tecido adiposo em diferentes patologias.

A caquexia associada ao câncer é considerada uma condição de inflamação sistêmica, e os consensos internacionais recomendam que a concentração de IL6 deva ser utilizada para o diagnóstico da caquexia (Evans et al., 2008; Fearon et al., 2011). Além disso, altos níveis de TNFa, IL6, IL10 são frequentemente correlacionados com a caquexia (Tsoli e Robertson, 2013). Nossos resultados demonstram o aumento da concentração plasmática das citocinas inflamatórias do grupo CC: TNFa, IL6, IL5, IL7, IL8, IL10 e IL15 em relação aos pacientes controle e câncer de peso estável (Tabela 4). Corroborando com nossos achados, um estudo que aferiu os níveis plasmáticos de IL8 em pacientes com câncer avançado de pulmão (estadiamento IV), relatou que as altas concentrações dessa citocina estão correlacionadas com a caquexia (Gioulbasanis et al., 2012). Por outro lado, os níveis circulantes aumentados de IL8 também são relatados como marcadores em pacientes com fibrose pulmonar (Ziora et al., 2015). 
Podemos notar alta expressão de IL8 no tecido adiposo do grupo caquético, bem como, nos adipócitos isolados, apesar dos resultados apresentarem diferença estatística. No entanto, as concentrações de citocinas não estavam alteradas no tecido adiposo dos pacientes caquéticos, em contraste do que é relatado na literatura, havendo apenas a diminuição de TNF $\beta$ e IL1 $\beta$ no grupo câncer de peso estável em comparação ao controle (Batista, Peres, et al., 2012; Batista et al., 2013; Seelaender e Batista, 2014; Seelaender et al., 2015). Já nos adipócitos isolados, do tecido adiposo subcutâneo, houve a diminuição das citocinas IL2 no grupo WSC, e da IL17 no grupo CC, ambos em relação ao controle. A interleucina IL17 é relatada como contribuinte para produção de IL8 (Isailovic et al., 2015), e como os níveis circulantes de IL8 estavam aumentados, e da IL17 diminuída no tecido, podemos especular sobre o papel do tecido adiposo, e os adipócitos na tentativa de regular negativamente a IL8, ou ainda, na falha do tecido e suas células em produzir citocinas para amenizar efeitos circulantes da inflamação no mesmo.

Durante o processo de remodelamento, a expressão de a-SMA tem um papel crítico na motilidade celular, e na contractilidade da ferida para cicatrização, mas também está associada à entrada no estado fibrótico (Rockey et al., 2013). Estudos para investigação da fibrose pulmonar, utilizando linhagem de células epiteliais de pulmão imortalizadas, a indução à transição epitelial-mesenquimal (EMT) por Wnt3a, um efetor da via da $\beta$-catenina, leva ao aumento de a-SMA, FSP1 e vimentina (Van Der Velden et al., 2012). Ainda, a alta expressão a-SMA é relacionada com a ativação de fibroblastos à miofibroblastos (Wynn e Ramalingam, 2012). Relatamos no presente estudo, a intensa marcação para a-SMA, o aumento na expressão do gene FSP1, no tecido adiposo do grupo CC, associados à marcada expressão de vimentina nos fibroblastos do tecido adiposo desse grupo. Ainda, foi encontrado o marcador de proliferação (ki67) por imunohistoquímica alterado no tecido, bem como, a maior tendência à proliferação dos fibroblastos no ensaio de viabilidade. Corroborando nossos achados, um trabalho utilizando um modelo de fibrose induzida, em sistema 3D possuindo células mesenquimais provenientes do tecido adiposo, demonstrou que o microambiente fibrótico é associado ao aumento de $\alpha$ SMA, colágeno tipo I e TGF $\beta$ (Rajangam et al., 2016).

Nesse contexto, o TGF $\beta$ como citocina pró-inflamatória, ou pró-fibrótica pode atuar no tecido adiposo na vigência da caquexia, por promover a sustentada ativação de miofibroblastos, contínua deposição de MEC, aumentada síntese de 
colágeno, e conseqüente fibrose. Nossos resultados demonstram que não há modulação dessa citocina, no tecido adiposo subcutâneo, devido à presença do câncer gastrointestinal. Contudo, no tecido adiposo do grupo câncer e caquexia encontramos o aumento significativo da isoforma TGF $\beta 3$, enquanto, nos adipócitos estavam aumentadas as isoformas TGFß1 e TGFß3. A análise por imunohistoquímica mostrou a forte marcação do TGF $\beta 1$ no tecido adiposo do paciente caquético em relação aos outros grupos, em concordância com os resultados por Western blotting, demonstrando que há o aumento do TGF $\beta$ no tecido adiposo.

Entre as diferentes isoformas do TGF $\beta$, a $\beta 1$ parece ser mais relevante biologicamente, por ser prevalente em relação às outras na fase adulta; enquanto, a isoforma $\beta 3$ está relacionada à fases de desenvolvimento, e estágios iniciais no processo de cicatrização de feridas (Lichtman et al., 2016).Em células-tronco mesenquimais induzidas ao estado fibrótico, o uso de estratégias para diminuição da fibrose ocorre por diminuir a razão TGF $\beta 1 / T G F \beta 3$ (Lichtman et al., 2016). Por outro lado, há relatos que apontam para o papel anti-fibrótico, ou na reversão da fibrose pelo TGFß3 (Karamichos et al., 2014). De fato, seria necessário verificar o papel de ambas isoformas nos adipócitos, em um microambiente fibrótico, para afirmarmos 0 papel específico de cada isoforma na fibrose do tecido adiposo. Adicionalmente, na obesidade, a expressão de TGF $\beta 1$ tem sido correlacionada com a inflamação e fibrose do tecido adiposo (Tsurutani et al., 2011).

Na via de sinalização do TGF $\beta$, as SMADs desempenham papel fundamental. Após ativação dos receptores, a formação dos complexos de R-SMAD com a SMAD4 faz com que ocorra a rápida translocação do complexo para o núcleo, e a regulação em fatores de transcrição (Leask e Abraham, 2004). Não houve modulação da expressão gênica das SMADs 2 e 3, no entanto, o gene da SMAD4 estava significantemente mais expresso no tecido adiposo dos grupos CC e WSC em comparação ao controle. Contudo, a imunomarcação evidenciou expressão proteica mais intensa das SMADs 3 e 4, no grupo CC, em relação aos demais grupos. Podemos notar que as marcações foram mais pontuais, em relação aos demais marcadores utilizados no presente estudo, apesar de serem mais evidentes no grupo caquético.

Em acordo com nossos achados, a sinalização do TGF $\beta 1$ através da ativação da SMAD3 é relatada por Verrecchia et al., (2001) regulando a região promotora 
para transcrição de colágenos, e aumentando a expressão dos genes para os colágenos tipo COL1A1, COL1A2, COL3A1, COL5A2, COL6A1 e COL6A3 (Verrecchia et al., 2001). Apesar do contexto diferente da caquexia, no tecido adiposo subcutâneo, as altas concentrações de SMAD3 e SMAD3 fosforilada são observadas em animais com diabetes do tipo 2 (Beaudoin et al., 2014). Modelos experimentais com obesidade induzida por dieta hiperlipídica e nocaute de SMAD3, a deleção da SMAD3 resulta na falha desses animais em desenvolver resistência à insulina e diabetes do tipo 2 (Tan et al., 2012). Já a ablação genética da SMAD3, em modelos experimentais para fibrose, demonstra a redução na resposta fibrótica (Flanders, 2004).

Adicionalmente, a via de sinalização do TGFß/SMAD3 é relatada como potente indutora do aparecimento de áreas com características de tecido adiposo marrom (browning), entremeadas no tecido adiposo branco em reposta à mudanças ambientais, exposição ao frio, estimulação hormonal e obesidade (Yadav e Rane, 2012). Contudo, nossos estudos não demonstram evidências acerca do browning no tecido adiposo subcutâneo dos pacientes caquéticos.

Cabe ainda, retratarmos as limitações do nosso estudo, as expressões das SMADs não foram detectadas por Western blotting, bem como, as formas fosforiladas das mesmas.

Os efeitos do TGF $\beta$ nas células alvo dependem muito do contexto fisiológico, e do tipo celular. No ciclo celular, o TGF $\beta$ atua como potente inibidor regulando a transcrição de fatores regulatórios do ciclo celular. A célula comprometida a se replicar, continua a duplicar seu DNA, se divide, e em seguida entra na fase G1 do ciclo, o TGF $\beta$, por sua vez, pode regular o atraso na divisão por suprimir a expressão de c-Myc, ciclinas, e quinases dependentes de ciclina (CDKs). A SMAD4 atua nesse contexto promovendo a expressão de fatores, como por exemplo; p15INK4B (Kubiczkova et al., 2012; Lichtman et al., 2016). O c-Myc é um fator de transcrição que promove a transcrição de mais de $15 \%$ de todos os genes em humanos, e entre suas funções, a mais relevante é promover a progressão no ciclo celular na fase G1 através do aumento na expressão de ciclinas $A, D 1, D 3, E$, CDK2, CDK4. No entanto, altos níveis de expressão são correlacionados com muitos tipos de câncer (Nevzorova et al., 2013). A expressão proteica por imunoflurorescência de c-Myc no presente estudo foi mais evidente no grupo câncer e caquexia em relação ao WSC e Controle, no entanto a expressão gênica estava 
aumentada em ambos, em relação ao Controle. Podemos especular sobre a regulação do c-Myc no tecido adiposo em vigência da caquexia, contudo associada ao aumento de proliferação, em acordo, a CCND1 foi encontrada aumentada somente no caquético.

A Sirt1 é uma histona deacetilase, da família das proteínas sirtuin, e atua regulando a transcrição de diversos genes, bem como em processos celulares, tais como; proliferação e diferenciação. Recentemente, foi observado que a Sirt1 pode deacetilar a SMAD3 e promover sua ubiquitinação, e consequente degradação. Em pacientes com esclerose sistêmica, a expressão de Sirt1 é reduzida, de uma forma dependente do TGF $\beta$, e em fibroblastos com nocaute de Sirt1 exibem a diminuição na síntese de colágeno promovida pela redução da via TGFß/SMAD, portanto, a Sirt1 atua como reguladora dessa via (Zerr et al., 2016). No entanto, foi demonstrado em nossos grupos que a expressão gênica desse fator não foi modulada no tecido adiposo subcutâneo, em todos os grupos.

Por último, foi investigado as correlações entre TGF $\beta 1$, TGFß2 e TGF $\beta$ e as citocinas no tecido adiposo. As IL2 e IL17 parecem ter um importante papel no ambiente fibrótico do tecido adiposo em vigência da caquexia por apresentar correlação com TGF $\beta 1$ e TGFß3. Em células Natural killer, o TGF $\beta$ é encontrado reprimindo a alta expressão de c-Myc quando estimulada por IL2 (Lee et al., 2014). Por outro lado, no microambiente tumoral, o TGF $\beta$ estimula a IL17 em células T regulatórias. Na fibrose tecidual, a IL17 promove a infiltração de neutrófilos no sítio fibrótico, e a manutenção dos fatores produzidos por essas células podem aumentar ainda mais o dano tecidual (Wynn e Ramalingam, 2012). Podemos especular, que a IL2 pode atuar como antagonista ao TGF $\beta$, e a IL17 potencializando os efeitos do TGF $\beta$. Contudo, novamente a expressão do c-Myc foi relatada diminuindo a expressão de colágeno I, III, VI (todos cadeia alfa1) (Dang et al., 1999). Diante dessas informações, podemos especular que ocorre a regulação desse fator, por um mecanismo desconhecido para amenizar os efeitos fibróticos do TGF $\beta$ no tecido adiposo.

Considerando os nossos achados, a caquexia associada ao câncer induz o remodelamento tecidual, por modular os diferentes tipos de fibras do tecido conjuntivo no tecido adiposo. A fibrose no tecido adiposo é caracterizada, portanto, pelo aumento nos conteúdos dos colágenos (tipo I, III e VI), glicoproteínas adesivas (fibronectina), glicosaminoglicanos associados aos colágenos, e fibras elásticas, 
associada à maior deposição de MEC existe ainda, a ativação de fibroblastos para miofibroblastos e maior proliferação. $\mathrm{O}$ cenário fibrótico do tecido adiposo durante a caquexia é exclusivo ao mesmo, e não devido à presença do tumor. Entre as diferentes isoformas do TGF, a isoforma $\beta 1$ e a $\beta 3$ possuem o papel mais relevante na promoção da fibrose no contexto. A via de sinalização doTGF $\beta / S M A D s$ atua efetivamente como contribuinte para deposição de MEC, remodelamento e consequente fibrose do tecido adiposo na caquexia associada ao câncer. No entanto, maiores estudos são necessários para determinar o momento do surgimento da fibrose no tecido adiposo, e sua relação com os estágios clinicamente propostos o diagnóstico da caquexia, mas podemos sugerir a evolução de análises histopatológicas, quando possível, como parâmetro adicional no diagnóstico da síndrome. 


\section{CONCLUSÃO}

O tecido adiposo subcutâneo de pacientes com caquexia associada ao câncer gastrointestinal é acometido pelo remodelamento tecidual, e este é exclusivo à caquexia. A via de sinalização do TGF $\beta$ atua como contribuinte no desenvolvimento da fibrose nesse contexto. 


\section{REFERÊNCIAS*}

AAHLIN, E. K. et al. Health-Related Quality of Life, Cachexia and Overall Survival After Major Upper Abdominal Surgery: A Prospective Cohort Study. Scand J Surg, Apr 2016. ISSN 1799-7267. Disponível em: < http://www.ncbi.nlm.nih.gov/pubmed/27114108 >.

ALVES, M. J. Effects of cancer cachexia on the components of adipose tissue extracellular matrix. 2011. 72 (Master Thesis). Cell and Tissue Biology, University of Sao Paulo, Institute of Biomedical Sciences.

ARGILÉS, J. M.; BUSQUETS, S.; LÓPEZ-SORIANO, F. J. Cytokines in the pathogenesis of cancer cachexia. Curr Opin Clin Nutr Metab Care, v. 6, n. 4, p. 401-6, Jul 2003. ISSN 1363-1950. Disponível em: < http://www.ncbi.nlm.nih.gov/pubmed/12806213 >.

ARGILÉS, J. M. et al. Cancer cachexia: understanding the molecular basis. Nat Rev Cancer, v. 14, n. 11, p. 754-62, Nov 2014. ISSN 1474-1768. Disponível em: < http://www.ncbi.nlm.nih.gov/pubmed/25291291 >.

. The role of cytokines in cancer cachexia. Curr Opin Support Palliat Care, v. 3, n. 4, p. 263-8, Dec 2009. ISSN 1751-4266. Disponível em: < http://www.ncbi.nlm.nih.gov/pubmed/19713854 >.

ARGILÉS, J. M.; LÓPEZ-SORIANO, F. J. The role of cytokines in cancer cachexia. Med Res Rev, v. 19, n. 3, p. 223-48, May 1999. ISSN 0198-6325. Disponível em: < http://www.ncbi.nlm.nih.gov/pubmed/10232651 >.

ARGILÉS, J. M. et al. Cross-talk between skeletal muscle and adipose tissue: a link with obesity? Med Res Rev, v. 25, n. 1, p. 49-65, Jan 2005. ISSN 0198-6325. Disponível em: < http://www.ncbi.nlm.nih.gov/pubmed/15389734 >.

Optimal management of cancer anorexia-cachexia syndrome. Cancer Manag Res, v. 2, p. 27-38, 2010. ISSN 1179-1322. Disponível em: < http://www.ncbi.nlm.nih.gov/pubmed/21188094 >.

BATISTA, M. L. et al. Cachexia-associated adipose tissue morphological rearrangement in gastrointestinal cancer patients. J Cachexia Sarcopenia Muscle, v. 7, n. 1, p. 37-47, Mar 2016. ISSN 2190-5991. Disponível em: < http://www.ncbi.nlm.nih.gov/pubmed/27066317 >.

*De acordo com: ASSOCIAÇÃO BRASILEIRA DE NORMAS TÉCNICAS. NBR 6023: informação e documentação: referências: elaboração. Rio de Janeiro, 2002. 
Heterogeneous time-dependent response of adipose tissue during the development of cancer cachexia. J Endocrinol, v. 215, n. 3, p. 363-73, Dec 2012. ISSN 1479-6805. Disponível em: < http://www.ncbi.nlm.nih.gov/pubmed/23033362 >.

Adipose tissue-derived factors as potential biomarkers in cachectic cancer patients. Cytokine, v. 61, n. 2, p. 532-9, Feb 2013. ISSN 1096-0023. Disponível em: $<$ http://www.ncbi.nlm.nih.gov/pubmed/23200412 >.

Adipose tissue inflammation and cancer cachexia: possible role of nuclear transcription factors. Cytokine, v. 57, n. 1, p. 9-16, Jan 2012. ISSN 1096-0023. Disponível em: < http://www.ncbi.nlm.nih.gov/pubmed/22099872 >.

BEAUDOIN, M. S. et al. Novel effects of rosiglitazone on SMAD2 and SMAD3 signaling in white adipose tissue of diabetic rats. Obesity (Silver Spring), v. 22, n. 7, p. 1632-42, Jul 2014. ISSN 1930-739X. Disponível em: < http://www.ncbi.nlm.nih.gov/pubmed/24500776 >.

BENNANI-BAITI, N.; WALSH, D. What is cancer anorexia-cachexia syndrome? A historical perspective. J R Coll Physicians Edinb, v. 39, n. 3, p. 257-62, Sep 2009. ISSN 1478-2715. Disponível em: < http://www.ncbi.nlm.nih.gov/pubmed/20608345 >.

BERTEVELLO, P. S.; SEELAENDER, M. C. Heterogeneous response of adipose tissue to cancer cachexia. Braz J Med Biol Res, v. 34, n. 9, p. 1161-7, Sep 2001. ISSN 0100-879X. Disponível em: < http://www.ncbi.nlm.nih.gov/pubmed/11514840 >.

BING, C. Lipid mobilization in cachexia: mechanisms and mediators. Curr Opin Support Palliat Care, v. 5, n. 4, p. 356-60, Dec 2011. ISSN 1751-4266. Disponível em: < http://www.ncbi.nlm.nih.gov/pubmed/21934502 >.

BING, C. et al. Adipose atrophy in cancer cachexia: morphologic and molecular analysis of adipose tissue in tumour-bearing mice. Br $\mathbf{J}$ Cancer, v. 95, n. 8, p. 102837, Oct 2006. ISSN 0007-0920. Disponível em: < http://www.ncbi.nlm.nih.gov/pubmed/17047651 >.

BING, C.; TRAYHURN, P. New insights into adipose tissue atrophy in cancer cachexia. Proc Nutr Soc, v. 68, n. 4, p. 385-92, Nov 2009. ISSN 1475-2719. Disponível em: < http://www.ncbi.nlm.nih.gov/pubmed/19719894 >.

BONNANS, C.; CHOU, J.; WERB, Z. Remodelling the extracellular matrix in development and disease. Nat Rev Mol Cell Biol, v. 15, n. 12, p. 786-801, Dec 2014. ISSN 1471-0080. Disponível em: < http://www.ncbi.nlm.nih.gov/pubmed/25415508 >. 
BRUERA, E.; SWEENEY, C. Cachexia and asthenia in cancer patients. Lancet Oncol, v. 1, p. 138-47, Nov 2000. ISSN 1470-2045. Disponível em: < http://www.ncbi.nlm.nih.gov/pubmed/11905651 >.

CAMARGO, R. G. et al. NF-kBp65 and Expression of Its Pro-Inflammatory Target Genes Are Upregulated in the Subcutaneous Adipose Tissue of Cachectic Cancer Patients. Nutrients, v. 7, n. 6, p. 4465-79, Jun 2015. ISSN 2072-6643. Disponível em: < http://www.ncbi.nlm.nih.gov/pubmed/26053616 >.

CHEN, J. L. et al. Elevated expression of activins promotes muscle wasting and cachexia. FASEB J, v. 28, n. 4, p. 1711-23, Apr 2014. ISSN 1530-6860. Disponível em: < http://www.ncbi.nlm.nih.gov/pubmed/24378873 >.

DAHLMAN, I. et al. Adipose tissue pathways involved in weight loss of cancer cachexia. Br J Cancer, v. 102, n. 10, p. 1541-8, May 2010. ISSN 1532-1827. Disponível em: < http://www.ncbi.nlm.nih.gov/pubmed/20407445 >.

DANG, C. V. et al. Function of the c-Myc oncogenic transcription factor. Exp Cell Res, v. 253, n. 1, p. 63-77, Nov 1999. ISSN 0014-4827. Disponível em: < http://www.ncbi.nlm.nih.gov/pubmed/10579912 >.

DEWYS, W. D. et al. Prognostic effect of weight loss prior to chemotherapy in cancer patients. Eastern Cooperative Oncology Group. Am J Med, v. 69, n. 4, p. 491-7, Oct 1980. ISSN 0002-9343. Disponível em: < http://www.ncbi.nlm.nih.gov/pubmed/7424938 >.

DIVOUX, A.; CLÉMENT, K. Architecture and the extracellular matrix: the still unappreciated components of the adipose tissue. Obes Rev, v. 12, n. 5, p. e494503, May 2011. ISSN 1467-789X. Disponível em: < http://www.ncbi.nlm.nih.gov/pubmed/21366833 >.

EBADI, M.; MAZURAK, V. C. Potential Biomarkers of Fat Loss as a Feature of Cancer Cachexia. Mediators Inflamm, v. 2015, p. 820934, 2015. ISSN 1466-1861. Disponível em: < http://www.ncbi.nlm.nih.gov/pubmed/26508820 >.

EVANS, W. J. et al. Cachexia: a new definition. Clin Nutr, v. 27, n. 6, p. 793-9, Dec 2008. ISSN 1532-1983. Disponível em: < http://www.ncbi.nlm.nih.gov/pubmed/18718696 >.

FAIN, J. N.; TICHANSKY, D. S.; MADAN, A. K. Transforming growth factor beta1 release by human adipose tissue is enhanced in obesity. Metabolism, v. 54, n. 11, p. 1546-51, Nov 2005. ISSN 0026-0495. Disponível em: < http://www.ncbi.nlm.nih.gov/pubmed/16253647 >. 
FEARON, K. et al. Definition and classification of cancer cachexia: an international consensus. Lancet Oncol, v. 12, n. 5, p. 489-95, May 2011. ISSN 1474-5488. Disponível em: < http://www.ncbi.nlm.nih.gov/pubmed/21296615 >.

FEARON, K. C.; GLASS, D. J.; GUTTRIDGE, D. C. Cancer cachexia: mediators, signaling, and metabolic pathways. Cell Metab, v. 16, n. 2, p. 153-66, Aug 2012. ISSN 1932-7420. Disponível em: < http://www.ncbi.nlm.nih.gov/pubmed/22795476 >.

FLANDERS, K. C. Smad3 as a mediator of the fibrotic response. Int J Exp Pathol, v. 85, n. 2, p. 47-64, Apr 2004. ISSN 0959-9673. Disponível em: < http://www.ncbi.nlm.nih.gov/pubmed/15154911 >.

FRÜHBECK, G. et al. Regulation of adipocyte lipolysis. Nutr Res Rev, v. 27, n. 1, p. 63-93, Jun 2014. ISSN 1475-2700. Disponível em: < http://www.ncbi.nlm.nih.gov/pubmed/24872083 > .

GIOULBASANIS, I. et al. Baseline plasma levels of interleukin-8 in stage IV nonsmall-cell lung cancer patients: relationship with nutritional status and prognosis. Nutr Cancer, v. 64, n. 1, p. 41-7, 2012. ISSN 1532-7914. Disponível em: < http://www.ncbi.nlm.nih.gov/pubmed/22098075 >.

GLASS, D. J. Signaling pathways perturbing muscle mass. Curr Opin Clin Nutr Metab Care, v. 13, n. 3, p. 225-9, May 2010. ISSN 1473-6519. Disponível em: < http://www.ncbi.nlm.nih.gov/pubmed/20397318 >.

GULLETT, N. et al. Cancer-induced cachexia: a guide for the oncologist. J Soc Integr Oncol, v. 7, n. 4, p. 155-69, 2009. ISSN 1715-894X. Disponível em: < http://www.ncbi.nlm.nih.gov/pubmed/19883531 >.

GURTNER, G. C. et al. Wound repair and regeneration. Nature, v. 453, n. 7193, p. 314-21, May 2008. ISSN 1476-4687. Disponível em: < http://www.ncbi.nlm.nih.gov/pubmed/18480812 >.

GÓMEZ VALIENTE DA SILVA, H.; FONSECA DE ANDRADE, C.; BELLO MOREIRA, A. S. Dietary intake and nutritional status in cancer patients; comparing adults and older adults. Nutr Hosp, v. 29, n. 4, p. 907-12, 2014. ISSN 1699-5198. Disponível em: < http://www.ncbi.nlm.nih.gov/pubmed/24679035 >.

HARRIS, W. T. et al. Myofibroblast differentiation and enhanced TGF-B signaling in cystic fibrosis lung disease. PLoS One, v. 8, n. 8, p. e70196, 2013. ISSN 19326203. Disponível em: < http://www.ncbi.nlm.nih.gov/pubmed/23950911 >. 
HINZ, B. The extracellular matrix and transforming growth factor- $\beta 1$ : Tale of a strained relationship. Matrix Biol, v. 47, p. 54-65, Sep 2015. ISSN 1569-1802. Disponível em: < http://www.ncbi.nlm.nih.gov/pubmed/25960420 >

HORBELT, D.; DENKIS, A.; KNAUS, P. A portrait of Transforming Growth Factor $\beta$ superfamily signalling: Background matters. Int $\mathbf{J}$ Biochem Cell Biol, v. 44, n. 3, p. 469-74, Mar 2012. ISSN 1878-5875. Disponível em: < http://www.ncbi.nlm.nih.gov/pubmed/22226817 >.

HUMINIECKI, L. et al. Emergence, development and diversification of the TGF-beta signalling pathway within the animal kingdom. BMC Evol Biol, v. 9, p. 28, 2009. ISSN 1471-2148. Disponível em: < http://www.ncbi.nlm.nih.gov/pubmed/19192293 >.

ISAILOVIC, N. et al. Interleukin-17 and innate immunity in infections and chronic inflammation. J Autoimmun, v. 60, p. 1-11, Jun 2015. ISSN 1095-9157. Disponível em: $<$ http://www.ncbi.nlm.nih.gov/pubmed/25998834 >.

KARAMICHOS, D.; HUTCHEON, A. E.; ZIESKE, J. D. Reversal of fibrosis by TGF$\beta 3$ in a 3D in vitro model. Exp Eye Res, v. 124, p. 31-6, Jul 2014. ISSN 1096-0007. Disponível em: < http://www.ncbi.nlm.nih.gov/pubmed/24800655 >.

KHALIL, N. TGF-beta: from latent to active. Microbes Infect, v. 1, n. 15, p. 1255-63, Dec 1999. ISSN 1286-4579. Disponível em: < https://www.ncbi.nlm.nih.gov/pubmed/10611753 >.

KHAN, T. et al. Metabolic dysregulation and adipose tissue fibrosis: role of collagen VI. Mol Cell Biol, v. 29, n. 6, p. 1575-91, Mar 2009. ISSN 1098-5549. Disponível em: $<$ http://www.ncbi.nlm.nih.gov/pubmed/19114551 >.

KUBICZKOVA, L. et al. TGF- $\beta$ - an excellent servant but a bad master. J TransI Med, v. 10, p. 183, 2012. ISSN 1479-5876. Disponível em: < http://www.ncbi.nlm.nih.gov/pubmed/22943793 >.

KWOK, K. H.; LAM, K. S.; XU, A. Heterogeneity of white adipose tissue: molecular basis and clinical implications. Exp Mol Med, v. 48, p. e215, 2016. ISSN 2092-6413. Disponível em: < http://www.ncbi.nlm.nih.gov/pubmed/26964831 >.

LAVIANO, A. et al. Therapy insight: Cancer anorexia-cachexia syndrome--when all you can eat is yourself. Nat Clin Pract Oncol, v. 2, n. 3, p. 158-65, Mar 2005. ISSN 1743-4254. Disponível em: < http://www.ncbi.nlm.nih.gov/pubmed/16264909 >. 
LEASK, A.; ABRAHAM, D. J. TGF-beta signaling and the fibrotic response. FASEB J, v. 18, n. 7, p. 816-27, May 2004. ISSN 1530-6860. Disponível em: < http://www.ncbi.nlm.nih.gov/pubmed/15117886 >.

LEE, H. M.; KIM, K. S.; KIM, J. A comparative study of the effects of inhibitory cytokines on human natural killer cells and the mechanistic features of transforming growth factor-beta. Cell Immunol, v. 290, n. 1, p. 52-61, Jul 2014. ISSN 1090-2163. Disponível em: < http://www.ncbi.nlm.nih.gov/pubmed/24879062 >.

$\mathrm{LI}, \mathrm{X}$. et al. The role of metformin and resveratrol in the prevention of hypoxiainducible factor $1 \alpha$ accumulation and fibrosis in hypoxic adipose tissue. $\mathbf{B r} \mathbf{J}$ Pharmacol, v. 173, n. 12, p. 2001-15, Jun 2016. ISSN 1476-5381. Disponível em: < http://www.ncbi.nlm.nih.gov/pubmed/27059094 >.

LICHTMAN, M. K.; OTERO-VINAS, M.; FALANGA, V. Transforming growth factor beta (TGF- $\beta$ ) isoforms in wound healing and fibrosis. Wound Repair Regen, v. 24, n. 2, p. 215-22, Mar 2016. ISSN 1524-475X. Disponível em: < http://www.ncbi.nlm.nih.gov/pubmed/26704519 >.

LIRA, F. S. et al. Effect of endurance training upon lipid metabolism in the liver of cachectic tumour-bearing rats. Cell Biochem Funct, v. 26, n. 6, p. 701-8, Aug 2008. ISSN 1099-0844. Disponível em: < http://www.ncbi.nlm.nih.gov/pubmed/18636434 >.

LOK, C. Cachexia: The last illness. Nature, v. 528, n. 7581, p. 182-3, Dec 2015. ISSN 1476-4687. Disponível em: < http://www.ncbi.nlm.nih.gov/pubmed/26659165 >.

MACHADO, A. P.; COSTA ROSA, L. F.; SEELAENDER, M. C. Adipose tissue in Walker 256 tumour-induced cachexia: possible association between decreased leptin concentration and mononuclear cell infiltration. Cell Tissue Res, v. 318, n. 3, p. 50314, Dec 2004. ISSN 0302-766X. Disponível em: < http://www.ncbi.nlm.nih.gov/pubmed/15490241 >.

MACIAS, M. J.; MARTIN-MALPARTIDA, P.; MASSAGUÉ, J. Structural determinants of Smad function in TGF- $\beta$ signaling. Trends Biochem Sci, v. 40, n. 6, p. 296-308, Jun 2015. ISSN 0968-0004. Disponível em: < http://www.ncbi.nlm.nih.gov/pubmed/25935112 >.

MARIMAN, E. C.; WANG, P. Adipocyte extracellular matrix composition, dynamics and role in obesity. Cell Mol Life Sci, v. 67, n. 8, p. 1277-92, Apr 2010. ISSN 14209071. Disponível em: < http://www.ncbi.nlm.nih.gov/pubmed/20107860 >. 
MARKMANN, A. et al. Influence of decorin expression on transforming growth factorbeta-mediated collagen gel retraction and biglycan induction. Matrix Biol, v. 19, n. 7, p. 631-6, Dec 2000. ISSN 0945-053X. Disponível em: < https://www.ncbi.nlm.nih.gov/pubmed/11102752 >.

MASSAGUÉ, J. How cells read TGF-beta signals. Nat Rev Mol Cell Biol, v. 1, n. 3, p. 169-78, Dec 2000. ISSN 1471-0072. Disponível em: < http://www.ncbi.nlm.nih.gov/pubmed/11252892 >.

. TGF $\beta$ signalling in context. Nat Rev Mol Cell Biol, v. 13, n. 10, p. 616-30, Oct 2012. ISSN 1471-0080. Disponível em: < http://www.ncbi.nlm.nih.gov/pubmed/22992590 >.

MASSAGUÉ, J.; CHEN, Y. G. Controlling TGF-beta signaling. Genes Dev, v. 14, n. 6 , p. 627-44, Mar 2000. ISSN 0890-9369. Disponível em: < http://www.ncbi.nlm.nih.gov/pubmed/10733523 >.

MATHEW, S. J. InACTIVatINg cancer cachexia. Dis Model Mech, v. 4, n. 3, p. 2835, May 2011. ISSN 1754-8411. Disponível em: < http://www.ncbi.nlm.nih.gov/pubmed/21372048 >.

MORLEY, J. E.; THOMAS, D. R.; WILSON, M. M. Cachexia: pathophysiology and clinical relevance. Am J Clin Nutr, v. 83, n. 4, p. 735-43, Apr 2006. ISSN 0002-9165. Disponível em: < http://www.ncbi.nlm.nih.gov/pubmed/16600922 >.

MURPHY, R. A. et al. Loss of adipose tissue and plasma phospholipids: relationship to survival in advanced cancer patients. Clin Nutr, v. 29, n. 4, p. 482-7, Aug 2010. ISSN 1532-1983. Disponível em: < http://www.ncbi.nlm.nih.gov/pubmed/19959263 >.

MUSCARITOLI, M. et al. The "parallel pathway": a novel nutritional and metabolic approach to cancer patients. Intern Emerg Med, v. 6, n. 2, p. 105-12, Apr 2011. ISSN 1970-9366. Disponível em: < http://www.ncbi.nlm.nih.gov/pubmed/20596799 >.

NEVZOROVA, Y. A. et al. Overexpression of c-myc in hepatocytes promotes activation of hepatic stellate cells and facilitates the onset of liver fibrosis. Biochim Biophys Acta, v. 1832, n. 10, p. 1765-75, Oct 2013. ISSN 0006-3002. Disponível em: < http://www.ncbi.nlm.nih.gov/pubmed/23770341 >.

OUCHI, N. et al. Adipokines in inflammation and metabolic disease. Nat Rev Immunol, v. 11, n. 2, p. 85-97, Feb 2011. ISSN 1474-1741. Disponível em: < http://www.ncbi.nlm.nih.gov/pubmed/21252989 >. 
RAJANGAM, T.; PARK, M. H.; KIM, S. H. 3D human adipose-derived stem cell clusters as a model for in vitro fibrosis. Tissue Eng Part C Methods, May 2016. ISSN 1937-3392. Disponível em: < http://www.ncbi.nlm.nih.gov/pubmed/27216608 >.

ROCKEY, D. C.; WEYMOUTH, N.; SHI, Z. Smooth muscle a actin (Acta2) and myofibroblast function during hepatic wound healing. PLoS One, v. 8, n. 10, p. e77166, 2013. ISSN 1932-6203. Disponível em: < http://www.ncbi.nlm.nih.gov/pubmed/24204762 >.

RODBELL, M. METABOLISM OF ISOLATED FAT CELLS. I. EFFECTS OF HORMONES ON GLUCOSE METABOLISM AND LIPOLYSIS. J Biol Chem, v. 239, p. 375-80, Feb 1964. ISSN 0021-9258. Disponível em: < http://www.ncbi.nlm.nih.gov/pubmed/14169133 >.

RODRÍGUEZ, A. et al. Revisiting the adipocyte: a model for integration of cytokine signaling in the regulation of energy metabolism. Am J Physiol Endocrinol Metab, v. 309, n. 8, p. E691-714, Oct 2015. ISSN 1522-1555. Disponível em: < http://www.ncbi.nlm.nih.gov/pubmed/26330344 >.

ROSENBAUM, J. T. et al. Fibrosis, gene expression and orbital inflammatory disease. Br J Ophthalmol, v. 99, n. 10, p. 1424-9, Oct 2015. ISSN 1468-2079. Disponível em: < http://www.ncbi.nlm.nih.gov/pubmed/26038391 >.

ROUBENOFF, R. et al. Standardization of nomenclature of body composition in weight loss. Am J Clin Nutr, v. 66, n. 1, p. 192-6, Jul 1997. ISSN 0002-9165. Disponível em: < http://www.ncbi.nlm.nih.gov/pubmed/9209192 >.

SCHMIERER, B.; HILL, C. S. TGFbeta-SMAD signal transduction: molecular specificity and functional flexibility. Nat Rev Mol Cell Biol, v. 8, n. 12, p. 970-82, Dec 2007. ISSN 1471-0080. Disponível em: < http://www.ncbi.nlm.nih.gov/pubmed/18000526 >.

SEELAENDER, M. et al. Inflammation in Cachexia. Mediators Inflamm, v. 2015, p. 536954, 2015. ISSN 1466-1861. Disponível em: < http://www.ncbi.nlm.nih.gov/pubmed/26523095 >.

SEELAENDER, M. C.; BATISTA, M. L. Adipose tissue inflammation and cancer cachexia: the role of steroid hormones. Horm Mol Biol Clin Investig, v. 17, n. 1, p. 5-12, Jan 2014. ISSN 1868-1891. Disponível em: < http://www.ncbi.nlm.nih.gov/pubmed/25372726 >. 
SHI, M. et al. Latent TGF- $\beta$ structure and activation. Nature, v. 474, n. 7351, p. 3439, Jun 2011. ISSN 1476-4687. Disponível em: < http://www.ncbi.nlm.nih.gov/pubmed/21677751 >.

SHI, Y.; MASSAGUÉ, J. Mechanisms of TGF-beta signaling from cell membrane to the nucleus. Cell, v. 113, n. 6, p. 685-700, Jun 2003. ISSN 0092-8674. Disponível em: < http://www.ncbi.nlm.nih.gov/pubmed/12809600 >.

SINGH, P.; CARRAHER, C.; SCHWARZBAUER, J. E. Assembly of fibronectin extracellular matrix. Annu Rev Cell Dev Biol, v. 26, p. 397-419, 2010. ISSN 15308995. Disponível em: < http://www.ncbi.nlm.nih.gov/pubmed/20690820 >.

SPENCER, M. et al. Adipose tissue macrophages in insulin-resistant subjects are associated with collagen $\mathrm{VI}$ and fibrosis and demonstrate alternative activation. Am $\mathbf{J}$ Physiol Endocrinol Metab, v. 299, n. 6, p. E1016-27, Dec 2010. ISSN 1522-1555. Disponível em: < http://www.ncbi.nlm.nih.gov/pubmed/20841504 >.

TAN, C. K. et al. Getting 'Smad' about obesity and diabetes. Nutr Diabetes, v. 2, p. e29, 2012. ISSN 2044-4052. Disponível em: < http://www.ncbi.nlm.nih.gov/pubmed/23449528 >.

THEOCHARIS, A. D. et al. Extracellular matrix structure. Adv Drug Deliv Rev, v. 97, p. 4-27, Feb 2016. ISSN 1872-8294. Disponível em: < https://www.ncbi.nlm.nih.gov/pubmed/26562801 >.

TISDALE, M. J. Cancer cachexia: metabolic alterations and clinical manifestations. Nutrition, v. 13, n. 1, p. 1-7, Jan 1997. ISSN 0899-9007. Disponível em: < http://www.ncbi.nlm.nih.gov/pubmed/9058439 >.

\begin{tabular}{ccccc} 
& Cachexia in cancer patients. Nat Rev Cancer, v. 2, n. 11, p. 862-71, Nov \\
\hline 2002. & ISSN & $1474-175 X$. & Disponível & em:
\end{tabular} http://www.ncbi.nlm.nih.gov/pubmed/12415256 >.

$\begin{array}{ccccc}\text {. } & \begin{array}{c}\text { Cancer cachexia. Curr Opin Gastroenterol, v. 26, n. 2, p. 146-51, Mar } \\ \text { 2010. }\end{array} \text { ISSN }_{1531-7056 .}^{\text {Disponível }} & \text { em: }\end{array}$ http://www.ncbi.nlm.nih.gov/pubmed/19918173 >.

TSOLI, M.; ROBERTSON, G. Cancer cachexia: malignant inflammation, tumorkines, and metabolic mayhem. Trends Endocrinol Metab, v. 24, n. 4, p. 174-83, Apr 2013. ISSN 1879-3061. Disponível em: < http://www.ncbi.nlm.nih.gov/pubmed/23201432 >.

TSOLI, M. et al. Depletion of white adipose tissue in cancer cachexia syndrome is associated with inflammatory signaling and disrupted circadian regulation. PLoS 
One, v. 9, n. 3, p. e92966, 2014. ISSN 1932-6203. Disponível em: < http://www.ncbi.nlm.nih.gov/pubmed/24667661 >.

TSURUTANI, $Y$. et al. The roles of transforming growth factor- $\beta$ and Smad3 signaling in adipocyte differentiation and obesity. Biochem Biophys Res Commun, v. 407, n. 1, p. 68-73, Apr 2011. ISSN 1090-2104. Disponível em: < http://www.ncbi.nlm.nih.gov/pubmed/21356196 >.

UEHA, S.; SHAND, F. H.; MATSUSHIMA, K. Cellular and molecular mechanisms of chronic inflammation-associated organ fibrosis. Front Immunol, v. 3, p. 71, 2012. ISSN 1664-3224. Disponível em: < http://www.ncbi.nlm.nih.gov/pubmed/22566952 >.

VAN DER VELDEN, J. L. et al. Induction of a mesenchymal expression program in lung epithelial cells by wingless protein $(\mathrm{Wnt}) / \beta$-catenin requires the presence of $\mathrm{c}$ Jun N-terminal kinase-1 (JNK1). Am J Respir Cell Mol Biol, v. 47, n. 3, p. 306-14, Sep 2012. ISSN 1535-4989. Disponível em: < http://www.ncbi.nlm.nih.gov/pubmed/22461429 >.

VERRECCHIA, F.; CHU, M. L.; MAUVIEL, A. Identification of novel TGF-beta /Smad gene targets in dermal fibroblasts using a combined cDNA microarray/promoter transactivation approach. J Biol Chem, v. 276, n. 20, p. 17058-62, May 2001. ISSN 0021-9258. Disponível em: < http://www.ncbi.nlm.nih.gov/pubmed/11279127 >.

WANG, B.; TRAYHURN, P. Acute and prolonged effects of TNF-alpha on the expression and secretion of inflammation-related adipokines by human adipocytes differentiated in culture. Pflugers Arch, v. 452, n. 4, p. 418-27, Jul 2006. ISSN 0031 6768. Disponível em: < http://www.ncbi.nlm.nih.gov/pubmed/16586095 >.

WYNN, T. A. Common and unique mechanisms regulate fibrosis in various fibroproliferative diseases. J Clin Invest, v. 117, n. 3, p. 524-9, Mar 2007. ISSN 0021-9738. Disponível em: < http://www.ncbi.nlm.nih.gov/pubmed/17332879 >.

\begin{tabular}{l}
. Cellular and molecular mechanisms of fibrosis. J Pathol, v. 214, n. 2, p. \\
\hline Ja9-210, Jan 2008. ISSN 0022-3417. Disponível em:
\end{tabular} http://www.ncbi.nlm.nih.gov/pubmed/18161745 >.

WYNN, T. A.; RAMALINGAM, T. R. Mechanisms of fibrosis: therapeutic translation for fibrotic disease. Nat Med, v. 18, n. 7, p. 1028-40, Jul 2012. ISSN 1546-170X. Disponível em: < http://www.ncbi.nlm.nih.gov/pubmed/22772564 >.

YADAV, H.; RANE, S. G. TGF- $\beta /$ Smad3 Signaling Regulates Brown Adipocyte Induction in White Adipose Tissue. Front Endocrinol (Lausanne), v. 3, p. 35, 2012. ISSN 1664-2392. Disponível em: < http://www.ncbi.nlm.nih.gov/pubmed/22654861 >. 
ZERR, P. et al. Sirt1 regulates canonical TGF- $\beta$ signalling to control fibroblast activation and tissue fibrosis. Ann Rheum Dis, v. 75, n. 1, p. 226-33, Jan 2016. ISSN 1468-2060. Disponível em: < http://www.ncbi.nlm.nih.gov/pubmed/25180292 >.

ZHOU, X. et al. Reversal of cancer cachexia and muscle wasting by ActRIIB antagonism leads to prolonged survival. Cell, v. 142, n. 4, p. 531-43, Aug 2010. ISSN 1097-4172. Disponível em: < http://www.ncbi.nlm.nih.gov/pubmed/20723755 >.

ZIORA, D. et al. Circulating concentration of markers of angiogenic activity in patients with sarcoidosis and idiopathic pulmonary fibrosis. BMC Pulm Med, v. 15, p. 113, 2015. ISSN 1471-2466. Disponível em: < http://www.ncbi.nlm.nih.gov/pubmed/26438257 >. 
ANEXO A

TCLE Versão Final 11.04.2014

\section{TERMO DE CONSENTIMENTO LIVRE E ESCLARECIDO}

\section{ESTUDO: CAQUEXIA ASSOCIADA AO CÂNCER: A VIA DE SINALIZAÇÃO DO TGF-ß E SUA CONTRIBUIÇÃO NO REMODELAMENTO DO TECIDO ADIPOSO.}

Você está sendo convidado (a) a participar do Projeto de Pesquisa acima citado. O documento abaixo contém todas as informações necessárias sobre a pesquisa que estamos fazendo. Sua colaboração neste estudo será de muita importância para nós, e caso queira desistir a qualquer momento, isso não causará nenhum prejuízo a você.

Eu, (inserir o nome, sexo, profissão, residente e domiciliado na, telefone) portador da Cédula de identidade, RG , e inscrito no

$\mathrm{CPF} / \mathrm{MF}$ nascido (a) em $/$ , abaixo assinado (a), concordo de livre e espontânea vontade em participar como voluntário (a) do estudo

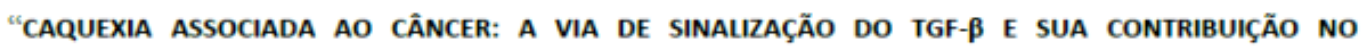
REMODELAMENTO DO TECIDO ADIPOSO". Declaro que obtive todas as informações necessárias, bem como todos os eventuais esclarecimentos quanto às dúvidas por mim apresentadas e que irei receber uma via idêntica deste Termo de Consentimento Live e Esclarecido (TCLE).

\section{Estou ciente que:}

I) O estudo se faz necessário para que possamos investigar as possíveis causas da caquexia, caracterizada pela grande perda de peso, atrofia muscular, fadiga, fraqueza e diminuição do apetite; temos como objetivo verificar como a caquexia afeta o remodelamento do tecido adiposo subcutâneo como um todo e como isso pode estar relacionado com a inflamação do tecido;

II) Caso o paciente aceite participar desta pesquisa e dependendo de cada procedimento cirúrgico efetuado, poderá ser retirados fragmentos de aproximadamente um grama por tecido adiposo subcutâneo, com tempo total de coleta de aproximadamente 5 minutos. Esse procedimento possui grau de risco mínimo e não interfere nos procedimentos padrões da cirurgia. Mas se houver intercorrência com o (a) participante da pesquisa, decorrente da pesquisa, este será atendido no HU/USP, segundo o critério do mesmo (Hospital de atendimento secundário). Esse material coletado será importante para o entendimento da etiologia do processo da caquexia;

III) Concordo que serão realizadas coletas de $20 \mathrm{~mL}$ de sangue em pacientes com câncer (exceto hepático), mas sem caquexia e pacientes com câncer (exceto hepático) e caquexia, para que os parâmetros plasmáticos e séricos possam ser aferidos. A coleta será realizada por um profissional da saúde devidamente habilitado previamente à cirurgia, sem interferir no procedimento cirúrgico;
( ) $\operatorname{Sim}$
ou
( ) Não 
IV) Essas coletas (sangue e tecido) serão realizadas apenas para este estudo e ou em outros projetos (pesquisas futuras) desde que autorizada pela Comissão de Ética deste Instituto, em nada influenciará o tratamento e não modificará o procedimento anestésico e cirúrgico;

V) Não vai me curar, não vai me causar nenhum problema, não haverá nenhum incômodo de dor no momento da coleta;

VI) A participação neste projeto não tem objetivo de me submeter a um tratamento, bem como não me acarretará qualquer despesa financeira com relação aos procedimentos médicos, clinicos e terapêuticos efetuados com o estudo;

VII) Tenho a liberdade de desistir ou de interromper a colaboração neste estudo no momento em que desejar, sem necessidade de qualquer explicação;

VIII) A desistência não causará nenhum prejuízo à minha saúde ou bem estar físico. Não virá a interferir no atendimento ou tratamento médico;

IX) Os resultados obtidos durante este estudo serão mantidos em sigilo, mas concordo que sejam divulgados em publicações cientificas, desde que meus dados pessoais não sejam mencionados;

X) Concordo que o material e os dados coletados, por mim autorizados, e os resultados de análises obtidos pelos pesquisadores poderão ser utilizados em outros projetos (pesquisas futuras);
( ) $\operatorname{Sim}$
ou
( ) Não

XI) Concordo que após os materiais serem coletados e armazenados em soluções especificas para cada técnica, serão acondicionados em freezer $-80^{\circ}$ para manter a integridade do tecido, e posteriormente serem utilizados;
( ) $\operatorname{Sim}$
ou
( ) Não

XII) Concordo que após os materiais serem utilizados para fins de pesquisa e os objetivos serem alcançados, o restante será incinerado em local para descarte de material biológico humano, conforme preconizado nas resoluçães do Conselho Nacional de Saúde (CNS);
( ) Sim
ou
( ) Não

XIII) Caso eu desejar, poderei pessoalmente tomar conhecimento dos resultados ao final desta pesquisa que terá uma duração prevista de 24 a 48 meses;

( ) Desejo conhecer os resultados desta pesquisa

( ) Não desejo conhecer os resultados desta pesquisa.

"DECLARO QUE, APÓS CONVENIENTEMENTE ESCLARECIDO PELO PESQUISADOR E TER ENTENDIDO O QUE ME FOI EXPLICADO, CONSINTO EM PARTICIPAR DA PRESENTE PESQUISA".

São Paulo, de de 20

( ) Paciente / ( ) Responsável 
Testemunha 1:

Nome / RG / Telefone:

Testemunha 2:

Nome / RG / Telefone:

Responsável pelo Projeto:

m

Prof ${ }^{2}$ Dra. Marilia Cerqueira Leite Seelaender

Instituto de Ciências Biomédicas I

Telefone para contato: $3091-7225$

Identificação do CEP-HU: $\quad$ Endereço: Av. Prof. Lineu Preste, 2565 - Cidade Universitária CEP: 05508-000 - São Paulo - SP

Telefones: 3091-9457 - Fax: 3091-9479 - E-mail: cep@hu.usp.br

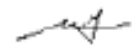

Rubrica do sujeito da pesquisa ou responsável

Rubrica do pesquisador 


\section{ANEXO B}

\section{EORTC QLQ-C30 (version3)}

Gostaríamos de conhecer alguns pormenores sobre si e sua saúde. Responda você mesmo/a, por favor, a todas as perguntas fazendo um círculo à volta do número que melhor se aplica ao seu caso. Não há respostas certas ou erradas. A informação fornecida é estritamente confidencial.

Escreva as iniciais do seu nome:

A data de nascimento (dia/mês/ano):

A data de hoje (dia/mês/ano):

Não Um

12

3

4 carregar um saco de compras pesado ou uma mala?

2. Custa-Ihe percorrer uma grande distância a pé?

3. Custa-Ihe dar um pequeno passeio a pé, fora de casa?

12

12

12

1

2

Não

Um
pouco

1

2

3

4 de suas atividades diárias?

7. Sentiu-se limitado/a na ocupação habitual dos seus tempos livres ou noutras atividades de lazer

8. Teve falta de ar?

12

12

3

4

9. Teve dores?

12

3

4

11. Teve dificuldade em dormir?

12

3

4

12. Sentiu-se fraco?
12

3 
13. Teve falta de apetite?

14. Teve enjoos?

15. Vomitou?

Durante a última semana:

16. Teve prisão de ventre?

17. Teve diarréia?

18. Sentiu-se cansado?

19. As dores perturbaram suas atividades diárias?

20. Teve dificuldade em concentrar-se, por exemplo, para ler o jornal ou ver televisão?

21. Sentiu-se tenso(a)?

22. Teve preocupações?

23. Sentiu-se irritável?

24. Sentiu-se deprimido?

25. Teve dificuldade em lembrar-se das coisas?

26. O seu estado físico ou tratamento médico interferiram na sua vida familiar?

27. O seu estado físico ou tratamento médico interferiram na sua atividade social?

28. O seu estado físico ou tratamento médico causaram-lhe problemas de ordem finaceira?

$\begin{array}{llll}1 & 2 & 3 & 4 \\ 1 & 2 & 3 & 4 \\ 1 & 2 & 3 & 4\end{array}$

Não Um Bastante Muito pouco

$\begin{array}{llll}1 & 2 & 3 & 4\end{array}$

$\begin{array}{llll}1 & 2 & 3 & 4\end{array}$

$\begin{array}{llll}1 & 2 & 3 & 4\end{array}$

$\begin{array}{llll}1 & 2 & 3 & 4\end{array}$

$\begin{array}{llll}1 & 2 & 3 & 4\end{array}$

$12 \quad 2 \quad 3 \quad 4$

$\begin{array}{llll}1 & 2 & 3 & 4\end{array}$

$\begin{array}{llll}1 & 2 & 3 & 4\end{array}$

$\begin{array}{llll}1 & 2 & 3 & 4\end{array}$

$\begin{array}{llll}1 & 2 & 3 & 4\end{array}$

$\begin{array}{llll}1 & 2 & 3 & 4\end{array}$

$\begin{array}{llll}1 & 2 & 3 & 4\end{array}$

12

3

4

Nas perguntas que se seguem faça um círculo à volta do número, entre 1 e 7, que melhor se aplica ao seu caso

29. Como classificaria a sua saúde em geral durante a última semana?
1
3
4
5
6
7
péssima
ótima

30. Como classificaria a sua qualidade de vida global durante a última semana?

$\begin{array}{lllllll}1 & 2 & 3 & 4 & 5 & 6 & 7 \\ \text { péssima } & & & & & & \end{array}$




\section{ANEXO C}

\section{PROJETO MEDICINA BASEADA EM EVIDÊNCIAS}

\section{AVALIAÇÃO MÉDICA}

DADOS DE IDENTIFICAÇÃO DO PACIENTE:

Nome:

Telefone:

Idade:

Sexo:(F) (M)

Profissão:

Altura:

Peso:

IMC:

CASO:
Coleta de sangue às: Jeium de (horas):

CLASSIFICAÇÃO: (CA COM CAQUEXIA)(CA SEM CAQUEXIA) (CAQUEXIA SEM TUMOR) (CONTROLE) PERDA> 10\% NOS ÚLTIMOS 6 MESES: (SIM) (NÃO)

RELAÇÃO CINTURA QUADRIL:

EXAMES (data):

\begin{tabular}{|c|c|c|c|c|c|}
\hline $\begin{array}{c}\text { Aval. } \\
\text { laboratorial }\end{array}$ & $\begin{array}{c}\text { Resultado } \\
\text { exames }\end{array}$ & $\begin{array}{c}\text { Aval. } \\
\text { laboratorial }\end{array}$ & $\begin{array}{c}\text { Resultado } \\
\text { exames }\end{array}$ & $\begin{array}{c}\text { Aval. } \\
\text { laboratorial }\end{array}$ & $\begin{array}{c}\text { Resultado } \\
\text { exames }\end{array}$ \\
\hline HG & & Glicose & & Creatinina & \\
\hline PCR & & Colesterol & & Uréia & \\
\hline Albumina & & Triglicérides & & & \\
\hline
\end{tabular}

\section{FÁRMACOS EM USO:}

Medicamento

Frequência e dose
Há quanto
tempo

Motivo 


\section{FACCT-ESPEN}

Nome e sobrenome:

Sexo: Data de nascimento:

Tipo de neoplasia:

Estadiamento: Terapia precedente:

Comorbidade:

Primeira visita:

Perda de peso(S/N): Tamanho da perda de peso (\% nos últimos 3 meses):

Peso (na hospitalização):

Altura:

IMC:

Como está seu apetite no último mês? Aumentado Normal Diminuído

Quantidade ingerida no almoço do dia anterior? $\quad \begin{array}{lllll}100 \% & 75 \% & 50 \% & 25 \% & 0 \%\end{array}$

Pontuação anoréxica

\begin{tabular}{|l|c|c|c|c|c|}
\hline & Nada & $\begin{array}{l}\text { Um } \\
\text { pouco }\end{array}$ & Moderadamente & Bastante & Muito \\
\hline Meu apetite é bom? & 0 & 1 & 2 & 3 & 4 \\
\hline A quantidade que eu como me satisfaz? & 0 & 1 & 2 & 3 & 4 \\
\hline Me preocupo com meu peso? & 0 & 1 & 2 & 3 & 4 \\
\hline Os alimentos têm gosto ruim? & 4 & 3 & 2 & 1 & 0 \\
\hline Estou preocupado por parecer magro? & 4 & 3 & 2 & 1 & 0 \\
\hline Meu apetite acaba no início das refeições? & 4 & 3 & 2 & 1 & 0 \\
\hline $\begin{array}{l}\text { Há dificuldade de comer alimentos pesados ou } \\
\text { elaborados? }\end{array}$ & 4 & 3 & 2 & 1 & 0 \\
\hline Minha família me induz a comer? & 4 & 3 & 2 & 1 & 0 \\
\hline Vômitos? & 4 & 3 & 2 & 1 & 0 \\
\hline Me sinto satisfeito após algumas mordidas? & 4 & 3 & 2 & 1 & 0 \\
\hline Dores no estômago? & 4 & 3 & 2 & 1 & 0 \\
\hline Minha saúde está melhorando? & 0 & 1 & 2 & 3 & 4 \\
\hline
\end{tabular}

Questionário anorexia

Saciedade precoce? Carnofobia? Alterações de gosto/odor? Náusea/vômito?

Escala analógica visual

$\begin{array}{lllllllllll}0 & 1 & 2 & 3 & 4 & 5 & 6 & 7 & 8 & 9 & 10\end{array}$

Faminto Saciado

$\mathrm{Cm}$ :

Visita de controle (3 meses): $\quad$ Peso: $\quad$ IMC:

Terapia realizada (cirurgia/ radio/ quimio): Complicações: 